\title{
Kernos
}

Revue internationale et pluridisciplinaire de religion grecque antique

$14 \mid 2001$

Varia

\section{Chronique archéologique de la religion grecque}

Athéna Tsingarida, Alain Duplouy, François Quantin, Polyxeni Bouyia, Kalliopi Chatzinikolaou, Emmanuel Voutiras, Patrick Constancio, Alexis D'Hautcourt, Natacha Massar, Didier Viviers, Isabelle Tassignon, Massimo Osanna et Nicola Cucuzza

\section{OpenEdition \\ Journals}

Édition électronique

URL : http://journals.openedition.org/kernos/780

DOI : $10.4000 /$ kernos.780

ISSN : 2034-7871

Éditeur

Centre international d'étude de la religion grecque antique

Édition imprimée

Date de publication : 1 janvier 2001

Pagination : 233-299

ISSN : 0776-3824

Référence électronique

Athéna Tsingarida, Alain Duplouy, François Quantin, Polyxeni Bouyia, Kalliopi Chatzinikolaou,

Emmanuel Voutiras, Patrick Constancio, Alexis D'Hautcourt, Natacha Massar, Didier Viviers, Isabelle Tassignon, Massimo Osanna et Nicola Cucuzza, "Chronique archéologique de la religion grecque », Kernos [En ligne], 14 | 2001, mis en ligne le 14 avril 2011, consulté le 15 septembre 2020. URL : http:// journals.openedition.org/kernos/780 


\section{Chronique archéologique de la religion grecque (ChronARG)}

\section{Introduction}

Comme nous l'expliquions dans le volume 13 (2000) de Kernos (p. 239-240), l'importance et le renouvellement des matériaux archéologiques dans le domaine de la religion grecque nous ont semblé justifier la reprise et l'amplification de cette chronique qui avait, durant quelques années, rendu compte de fouilles récentes dont les résultats touchaient à cette matière. Toutefois, concevoir une véritable chronique archéologique de la religion grecque pose de nombreux problèmes, tant de définition que de nature plus largement épistémologique. On sait notamment la difficulté constante qui naît de l'identification des structures archéologiques avec une fonction cultuelle. Des études très récentes n'ont pas manqué de soulever un certain nombre de questions touchant à la définition et à la portée de l'« archéologie religieuse ${ }^{1}$. Les difficultés de l'entreprise ne nous échappent donc pas, mais notre objectif est avant tout pragmatique et relève du souci de fournir un outil de travail que nous espérons aussi utile, dans le domaine de l'archéologie, que le Bulletin épigraphique publié dans ces pages par Angelos Chaniotis et ses collaborateurs.

Il n'est pas impossible que, chemin faisant, les prochaines livraisons en viennent à modifier peu à peu le champ de cette « chronique archéologique ». Il nous apparaît cependant utile de préciser le cadre général qui la sous-tend. Il s'agit avant tout d'une " archéologie des cultes » qui s'appuie essentiellement sur les travaux de fouilles ou travaux récents en matière d'archéologie de terrain. Les apports de l'iconographie ne sont donc intégrés que dans la mesure où ils éclai rent une identification ou une interprétation cultuelle. L'archéologie funéraire n'est pas non plus prise en compte comme telle, sauf si un culte des morts semble attesté, au-delà du simple contenu des tombes ou de l'organisation d'une nécropole. On renonce également à faire état des études proprement architecturales, même lorsqu'elles ont trait à des édifices cultuels, si elles n'interviennent pas directement dans notre connaissance du culte. Dans ces limites, nous tente-

1 A.H. Borbein, T. Hölscher (éds), Klassische Archäologie, Eine Einführung, Berlin, Reimer, 2000 : l'article de R. HÄGG, "Archäologie der Heiligtümer", p. 280-290, et celui de J. DE LA GENiÈre, "Archäologie und Religion am Beispiel der griechischen Welt in archaischer und klassischer Zeit", p. 291-312; ainsi que l'intervention d'A. Schnapp, "Peuton parler d'une archéologie de la religion grecque?", in R.F. Docter, E.M. MoormanN (éds), Proceedings of the XVth intern. Congress of Classical Archaeology, Amsterdam, july 12-17, 1998. Classical Arcbaeology towards the Third Millenium: Reflections and Perspectives, Amsterdam, Allard Pierson Stichting, Publication Dept., 1999, p. 34-39. 
rons, autant que possible, de souligner la fragilité des interprétations proposées, sans pour autant être toujours en mesure de produire une critique de première main.

Le champ chronologique de cette rubrique couvre l'histoire de la cité grecque (sans négliger les "communautés » grecques de l'Ouest) et s'étend par conséquent du $\mathrm{IX}^{\mathrm{e}}$ siècle av. J.-C. environ jusqu'à l'Antiquité païenne tardive. La distribution de la matière suit un ordre géographique, au départ de l'Attique et selon la répartition suivante :

Athènes, Attique, Mégaride

Péloponnèse

Béotie, Eubée

Phocide, Locride, Étolie

Acarnanie, Épire, Illyrie méridionale, îles ioniennes

Phthiotide, Thessalie

Macédoine

Thrace

Îles de l'Égée

Crète

Chypre

Asie mineure

Grande Grèce

Sicile

À l'intérieur de chaque «région», nous avons souhaité maintenir un parcours géographique qui tienne compte du sens de la périégèse générale, en privilégiant le sens horaire ainsi que les regroupements civiques avec, autant que possible, un centre comme point de départ. Ainsi, on s'acheminera de l'Acarnanie vers l'Illyrie méridionale, selon un parcours Sud-Nord, et l'on rebroussera chemin, du Nord vers le Sud, en égrainant les îles ioniennes, pour reprendre la description à partir de l'Achaïe Phthiotide. De même, après une description de la Macédoine et de la Thrace, selon une succession Ouest-Est, on détaillera les îles de l'Égée selon une progression du Nord vers le Sud, jusqu'en Crète où nous irons d'Ouest en Est, avant de rejoindre l'île de Chypre, etc. Le sens adopté à l'intérieur de chaque région dépend ainsi de la région qui la précède et de celle qui la suit dans la description générale. Sans nier qu'une telle organisation de la matière pourrait parfois générer quelques incohérences géographiques, nous tentons d'offrir ainsi une description qui tienne majoritairement compte de la géographie historique. Les inconvénients éventuellement liés à cette présentation seront facilement palliés par le recours aux index.

L'orthographe des lemmes toponymiques nous a également contraints à des choix. En règle générale, nous avons opté pour les caractères italiques dans la graphie des noms de cités antiques, même s'ils ont survécu jusqu'à nous (ainsi, par exemple, Athènes). Pour tous les autres toponymes (îles, montagnes, etc.), tant modernes qu'antiques, nous avons maintenu les caractères droits, y compris lorsque le nom antique désignait également une cité (dans le cas de certaines îles par exemple). Dans le cas des toponymes modernes, on mentionne, si nécessaire, le lieu-dit entre parenthèses. Enfin, on identifie autant que possible les respon- 
sables de la recherche, et la référence complète de la source d'information apparaît systématiquement à la fin de chaque notice.

La "chronique archéologique » de cette année s'appuie, d'une part, sur les publications parues en 1999, même si les ouvrages portent parfois un millésime antérieur, et, d'autre part, sur des rapports internes de fouilles ou d'activités, des articles de presse ou des communications personnelles qui rendent compte des toutes dernières découvertes de l'année 2000. Toutefois, les informations de l'année 2000 sont encore fort incomplètes et leur mention ne sera pas systématique d'une région à l'autre.

Pour la transcription des toponymes en grec moderne, nous avons opté pour un système intermédiaire entre le respect de l'orthographe et celui de la prononciation $^{2}$, mais en maintenant la graphie francisée quand l'usage le demande (par ex. Athènes, Éleusis, Héraklion, Claros, etc.). Le grec ancien translittéré apparaît en italiques sans accents (hormis ô pour $\omega$ ), à l'exception des épiclèses divines en caractère romains (avec $\eta=$ è en fin de mot, $\omega=\hat{o}$ ) et des termes dont l'usage courant en français impose l'accent (par ex. : Achéron, Parthénon, Asclépieion, Ménélaion, etc.).

Nous tenons à remercier très vivement tous les collaborateurs qui ont accepté de se lancer dans l'aventure.

Vinciane PirenNe-DeLforge \& Didier Viviers

\section{Athènes, Attique, [Mégaride] (Athéna Tsingarida)}

\subsection{0 - Gênêralitês}

- E. Vikela passe en revue l'ensemble des reliefs votifs connus et découverts en Attique afin de préciser les fonctions diverses que peuvent avoir les divinités vénérées dans cette région. L'A. se fonde également sur les pièces qui offrent un contexte de découverte précis pour démontrer la présence de nouvelles divinités dans des sanctuaires connus mais aussi pour localiser d'autres cultes dans certaines régions de l'Attique.

E. Vikela, "Attische Weihreliefs und die Kult-Topographie Attikas", MDAI(A) 112 (1997), p. 167-246.

01.01 - Athènes, Acropole - Ire Éphorie des antiquités prébistoriques et classiques - En 2000, lors des nettoyages effectués autour du Parthénon, on aurait localisé les propylées du temenos de Dionysos. La notice ne renseigne cependant pas l'emplacement précis.

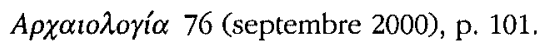

01.02 - Athènes, Agora - École américaine d'Athènes - De nouveaux sondages ouverts au $S$ de la rue Adrianou ont mis au jour les plus anciens niveaux connus de la voie des Panathénées, datés de l'époque archaïque tardive. À l'angle NE de l'Agora, ces fouilles ont également révélé les traces des poteaux qui étaient destinés à soutenir les sièges des spectateurs de la procession.

J.M. CAMP, $A D 49$ (1994) [1999], B'1, p. 26.

2 Les signes d'aspiration seront supprimés (par ex. : Agia et non Hagbia), le $\zeta$ est transcrit par « $z$ », le $\eta$ par « $i$ », le $\theta$ par « th», le к par «k», le v par «y», le $\varphi$ par «ph», le $\chi$ par «ch», le $\omega$ par « $\hat{o} »$, les diphtongues $\alpha v$ par «av» ou «af », $\varepsilon v$ par « ev» ou " ef », $\alpha 1$ par « ai », eı par « ei », le double $\gamma \gamma$ devient « ng ». 
- Bien que l'on s'accorde à voir dans le Metrôon hellénistique un bâtiment destiné à abriter les archives de la ville, on n'avait pas encore déterminé les fonctions précises des quatre espaces qui le constituent. Dans une communication, P. Valavanis reprend cette question et, parmi les pièces considérées, propose d'identifier la deuxième salle, en allant du S vers le $\mathrm{N}$, au temple de la Mère des dieux, dont on avait trouvé la base de la statue de culte dans le bâtiment et qui fut vénérée du $3^{\mathrm{e}}$ quart du $\mathrm{II}^{\mathrm{e}} \mathrm{s}$. av. J.-C. jusqu'à la destruction par les Hérules en 267 ap. J.-C.

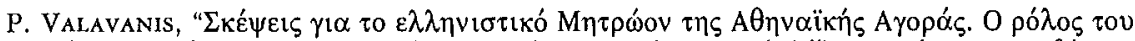

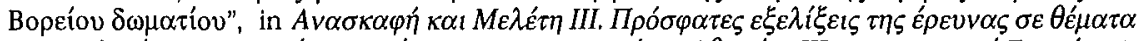

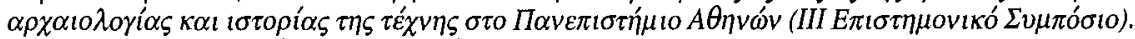

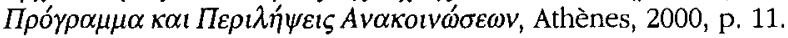

01.03 - Athènes, Plaka (rue Dloskourou) - $I^{r e}$ Éphorie des antiquités prébistoriques et classiques - On rapporte la découverte d'un relief ayant conservé la partie supérieure du torse d'une prêtresse d'Isis. Dans la même rue, aux $n^{\circ} 5$ et 6 , on mentionne la mise au jour de fragments architecturaux et sculpturaux, comprenant une Cybèle assise.

A. Spetsieri-Choremi, $A D 49$ (1994) [1999], B'1, p. $20-22$.

$01.04-A t h e ̀ n e s$, Zappeion (avenue Amalias $\mathbf{n}^{\circ} 2$ ) - IIr $r^{e}$ Ephorie des antiquités prébistoriques et classiques - Les fouilles ont découvert deux structures rectangulaires : la première, conservée sur quatre assises et ouverte vers le $S$, est datée, d'après le matériel trouvé dans les fondations, de l'époque classique tardive; la seconde, beaucoup plus petite, située au $\mathrm{N}$, a conservé deux assises. Pour le fouilleur, la forme irrégulière et peu commune de la première construction indiquerait que nous sommes face à une section du péribole d'un sanctuaire hypèthre, la deuxième structure, identifiée à un bothros ou à un autel, aurait appartenu à ce même sanctuaire.

O. Zachariadou, $A D$ 49-50 (1994) [1999], B'1, p. 32-33.

01.05 - Athènes, Mets - III Éphorie des antiquités prébistoriques et classiques - Le temple d'Artémis Agrotera, situé sous les rues Arditou, Koutoula, Képhalou et Thomopoulou, est connu depuis le $\mathrm{xvIII}^{\mathrm{e}}$ s. Il est resté intact jusqu'en 1778 , date à laquelle il fut démantelé par le voîvoïde d'Athènes pour la construction des murs de la ville autour de l'Acropole. Le plan du temple, composé d'un pronaos et d'une cella, fut reconstitué par A. Skias en 1897, puis précisé en partie par Travlos en 1965. Les fouilles menées par E. Likouri-Tolia en 1994 ont permis de retrouver l'emplacement exact du temple sous les habitations et les rues actuelles et de préciser l'état de conservation des restes du bâtiment. Un premier sondage, réalisé devant les $\mathrm{n}^{\circ} 18$ et 20 de la rue Arditou, confirme que seul l'angle NE de la fondation du pronaos est conservé et que de nombreuses entailles ont été faites par l'installation de conduits d'eau et d'électricité sur le reste des fondations. Un deuxième sondage, sous le $\mathrm{n}^{\circ} 22$ de la rue Arditou, a révélé une section de l'analemma.

E. Ligouri-Tolia, $A D 49$ (1994) [1999], B'1, p. 36-40.

01.06-Eleusis - K. Kokkou-Viridi publie le matériel découvert dans les foyers qui se trouvaient en dehors de la cour du Telesterion d'Éleusis et qui furent fouillés par D. Philios en 1883 et en 1885 ainsi que par E. Kourouniotis en 1931. Malgré la difficulté de l'entreprise, due à l'absence d'inventaires pour ces fouilles anciennes, l'A. étudie le matériel et tente d'identifier la provenance exacte des différents objets. Elle met en évidence le caractère cultuel de ces trois foyers, situés à l'intérieur du sanctuaire. Ils devaient être utilisés lors de pratiques rituelles liées aux Thesmophories ou encore aux Mystères, qui avaient lieu à l'intérieur du temple. L'analyse du matériel a également permis de déterminer la periode de fonctionnement de ces trois foyers, qui débute au viI $s$. et se poursuit jusqu'au $1^{\text {er }}$ quart du $v^{e} s$. av. J.-C. L'ouvrage comprend, par ailleurs, un 
catalogue détaillé, qui fournit une bonne description du matériel et sa provenance probable.

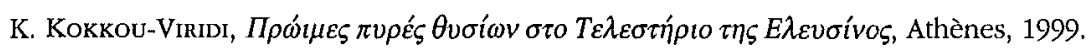

01.07 - Phylè (Spilies) - II Éphorie des antiquités prébistoriques et classiques - Au SO de Kalistirion, des fouilles entreprises en 1919 avaient révélé un petit bâtiment taillé dans le rocher, composé de deux pièces, que le fouilleur identifiait à un tombeau [pour l'emplacement précis, voir H. KauperT, Karten von Attika II (1881-1900), p. 44 et 49]. M. Platonos-Giota a repris ces fouilles en 1994 et propose de reconnaitre dans cette construction un berôon. La présence d'une niche sur le mur $\mathrm{E}$ de la chambre orientale, sans doute destinée à recevoir une sculpture votive, ainsi que la découverte d'une structure cylindrique dans la chambre occidentale, identifiée à un autel, confirmeraient cette thèse. Le fouilleur mentionne par ailleurs l'existence d'une base de statue votive, aujourd'hui disparue, mais dont il ne mentionne pas l'emplacement exact. Il relève la trace de nombreux autres bâtiments au $S$ et à l'O du petit sanctuaire, qui reflètent un peuplement dense et confirmeraient l'identification du site avec l'ancien dème d'Oè.

M. Platonos-Grota, $A D 49$ (1994) [1999], B'1, p. 73-74.

01.08 - Skala Oropou - Société archéologique d'Atbènes - A. Mazarakis-Ainian a repris la fouille, commencée par A. Dragona en 1985 et 1986, d'un site d'époque géométrique et archaïque situé sur le terrain de l'Organisme des Bâtiments Scolaires (O.L.K). En attendant que l'étude du matériel soit achevée, la publication porte sur les découvertes achitecturales et la chronologie des structures. Dans la partie occidentale du site (secteur E), on a découvert un bâtiment de plan absidal, daté du Géométrique Récent. La fonction de ce bâtiment pose problème. D'une part, le plan et la taille importante $(30 \mathrm{~m}$ de long) de cette construction pourraient témoigner de son caractère cultuel alors que, d'autre part, l'occupation de sa partie $S$ par une habitation, dès le vir ${ }^{\mathrm{e}}$ s., semblerait exclure cette interprétation. Dans le même secteur, le fouilleur mentionne une habitation de plan orthogonal, composée de trois pièces articulées autour d'un pastas dont la date de construction remonterait au début du viI ${ }^{\mathrm{e}}$ s. av. J.-C. Dans l'état actuel de l'étude, la fonction précise de ce bâtiment n'est pas établie, il faut cependant noter la découverte dans la pièce $G$ d'un matériel comportant, entre autres, des statuettes votives d'époque archä́que, qui trahissent vraisemblablement la fonction cultuelle de cette pièce. L'A. note également, à l'O de ce secteur, la présence d'un mur de péribole, de taille importante.

Dans la partie orientale du site (sous les bâtiments scolaires I et IV), la fouille a mis au jour un vaste complexe d'établissements destinés à des activités métallurgiques et datés du milieu du vin à la fin du $v^{\mathrm{e}}{ }^{\mathrm{e}}$ s. J.-C. Deux des édifices découverts sous le bâtiment scolaire I pourraient avoir rempli des fonctions cultuelles. Le matériel venant du premier (ST) montrerait un emploi double, à la fois en tant qu'atelier métallurgique et espace cultuel. Par son plan particulier (au départ ellipsoïdal, puis absidal, comprenant un espace rectangulaire qui met en évidence l'entrée), le deuxième bâtiment (Q), occupé depuis la fin du virr ${ }^{\mathrm{e}}$ jusqu'à la fin du viI ${ }^{\mathrm{e}}$ s. J.-C, pourrait être également un temple ou l'habitation d'un personnage important. Le fouilleur souligne la nature particulière de la céramique, comprenant, entre autres, des lécythes, des kotyles, des skyphoi et des cratères miniatures, ainsi que la présence de petits objets en bronze qui appuieraient l'interprétation cultuelle de ce deuxième bâtiment.

Près de ces zones habitées, on a également trouvé un ensemble de fosses et de tombes. Parmi celles-ci, l'A. mentionne une construction rectangulaire (XXXIV), fouillée en partie en 1996, qui prenait appui sur l'abside d'un bâtiment antérieur (IA). Sur les plaques inférieures qui formaient cette structure, on a trouvé un bloc orthogonal, taillé, qui pourrait avoir servi de stèle. Pour le fouilleur, cet indice, combiné au plan et à la présence de restes organiques calcinés et de nombreux fragments céramiques, indiquerait que ce petit 
bâtiment, daté du viI ${ }^{\mathrm{e}} \mathrm{s}$, av. J.-C., était un cénotaphe où l'on pratiquait des sacrifices et assistait aux repas cultuels. Par ailleurs, la découverte de nombreux ossements animaux calcinés et de céramique cassée dans le comblement des tombes, attesterait des pratiques sacrificielles et des repas cultuels lors de la mise au tombeau.

Dans les conclusions de cette étude préliminaire, l'A. confirme le caractère cultuel des deux bâtiments ST et $Q$, contemporains du péribole qui les entoure, qui pourrait témoigner de l'association, fréquente pour les époques géométrique et archaïque, entre un lieu de culte (vraisemblablement chthonien) et des établissements d'artisanat métallurgique. Il estime cependant que le caractère domestique d'une partie du matériel découvert dans ces constructions et le peu d'objets qui revêtent clairement une fonction votive demandent des recherches plus approfondies afin de préciser la nature exacte de ces installations. Il en va de même en ce qui concerne les pratiques rituelles liées à un culte des morts observées dans le secteur de la nécropole, qui doivent également être précisées davantage.

A. Mazarakis-Ainian, PAAH (1996) [1999], p. 21-124.

01.09-Rhamnonte - Société archéologique d'Atbènes - Dans la cour du «synedrion", V. Petrakos mentionne la découverte de deux fragments d'une plaque votive dédiée par le stratège Thoukritos fils d'Alkimachos du dème de Myrrhinonte à une divinité inconnue. Une partie de cette plaque dont on avait perdu la trace était connue depuis les fouilles de 1958 qui la mentionnaient remployée comme couverture tombale. Les deux nouveaux fragments livrent le nom du dédicant. Leur emplacement originel dans la cour constitue, par ailleurs, un élément supplémentaire pour l'identification du bâtiment au synedrion, construit par Thoukritos en $252 / 51$ av. J.-C. Dans les couches inférieures du comblement de cette cour, le fouilleur rapporte la présence de nombreux fragments de sculptures et d'autels en pierre ou en marbre. Au-dessus du dallage de la cour, on a également mis au jour trois flambeaux en bronze portant des inscriptions dédicatoires à Zeus Sôter et Athéna Sôteira pour commémorer des victoires à la course aux flambeaux. Devant une des pièces de la cour du synedrion, les fouilles ont révélé la base d'un hermès reprenant les noms des éphèbes de la tribu Léontis de l'année 333/332 av. J.-C. Au croisement des routes menant à la porte $S$ et à la porte $\mathrm{E}$, on a découvert une plaque non travaillée, en marbre local, qui porte une inscription mentionnant la dédicace d'une statue, œuvre du dédicant, à Hermès.

V. Petrakos, PAAH (1996) [1999], p. 1-19.

- À l'O du théâtre, V. Petrakos a fouillé un bâtiment dont les murs $\mathrm{E}$ et $\mathrm{O}$ étaient déjà connus par Staïs. L'orientation de cette construction, ouverte à l'E, et la présence d'un pressoir transformé en autel attestent de la fonction cultuelle de l'édifice, en activité jusqu'au $\mathrm{Iv}^{\mathrm{e}} \mathrm{s}$. ap. J.-C. Cette interprétation pourrait se voir renforcée par la nature du matériel, découvert dans la plus grande pièce et constitué d'inscriptions dédicatoires à diverses divinités (Cybèle, Isis...) et de sculptures votives (dont une pourrait avoir été consacrée à Déméter et à Korè). Le fouilleur estime cependant que seule une fouille des alentours pourra déterminer la provenance exacte de ces pièces et, partant, l'identité du culte qui était pratiqué dans ce bâtiment.

V. Petrakos, Ergon 46 (1999), p. 18-20.

01.10 - Gerakas (Stavros) - II Éphorie des antiquités prébistoriques et classiques - Des fouilles de sauvetage dans les rues Androutsou et Zallogou (terrain ThomopoulouPhlorou) ont révélé les restes d'un temple d'époque classique, identifié par le fouilleur au temple d'Athéna Pallènè, généralement situé dans cette région. Les fouilles ont mis au jour les fondations en poros d'un grand temple dorique, orienté SO/NE, dont l'élévation devait être en marbre, comme l'indiquent les quelques fragments qui nous en sont parvenus. On a dégagé jusqu’à présent le pronaos et une partie de la cella, qui comportait 
une double colonnade en hauteur. Le fouilleur mentionne également la découverte, dans les remblais des fondations, de nombreux fragments de statuettes d'oiseaux en $T$, datées des $\mathrm{vIII}^{\mathrm{e}}-\mathrm{vII}{ }^{\mathrm{e}}$ s. av. J.-C., qui attesteraient l'existence d'un lieu de culte dès l'époque archaïque. Les fouilles continuent autour du bâtiment et sur les flancs de la colline.

Ce temple a fait l'objet d'une étude récente de M. Korrès ("A A yoox́", Horos 10-12 [1992-1998], p. 83-104). On savait depuis longtemps (W.B. Dinsmoor, Hesperia 9 [1940], p. 1-52) que le temple d'Arès sur l'Agora d'Athènes avait été reconstruit sur des fondations datant de l'époque romaine; son origine était fréquemment située à Acharnes. Par une analyse attentive des fondations du bâtiment de Stavros, l'A. montre que c'est ce temple qui fut démonté puis remonté sur l'Agora d'Athènes, en raison de la correspondance presque parfaite entre les fondations du temple de Pallènè et ce qui reste de l'élévation du temple d'Arès. Cette identification soulève cependant, comme le reconnaît l'A. lui-même, quelques problèmes, liés notamment au changement de divinité. Si l'identification du temple originel à celui d'Athéna Pallènè est exacte, il reste en effet à comprendre pourquoi l'édifice, une fois déplacé, fut consacré au culte d'Arès.

M. Platonos-Grota, $A D 49$ (1994) [1999], B'1, p. 71-73.

01.11 - Anavyssos - II Éphorie des antiquités prébistoriques et classiques - Au lieu-dit "Tripia Kouphi » ou "Souvlero », le sol d'une grotte, connue sous le nom de " grotte de Daveli ", a livré une grande quantité de matériel composé de nombreux lécythes cassés, de fragments de coupes, de figurines et de plaques en terre cuite à décor mouluré. La présence d'une niche sur la paroi $\mathrm{NE}$ et la nature du matériel indiquent que l'usage originel de cette grotte était cultuel. La première phase d'activité débute à la fin du vin ${ }^{\mathrm{e}} \mathrm{s}$. et s'étend jusqu'à la $1^{\text {re }}$ moitié du $v^{e} s$. av. J.-C. C'est surtout durant cette dernière période que la grotte est le plus fréquentée. Le fouilleur identifie l'endroit au sanctuaire de Pan, du dème d'Anaphlystos, mentionné par Strabon (IX, 398). Il aurait été consacré aux Nymphes à l'époque géométrique puis à Pan, suivant une pratique courante en Attique qui associe ces deux cultes. Cette découverte est importante, car elle constitue un des rares exemples de culte dans une grotte connus en Attique, remontant à l'époque géométrique [l'autre exemple connu est également situé à Anavyssos, sur le versant $\mathrm{N}$ de "Kastela i spilia » (voir H. Lohmann, Atene I, Cologne, 1993, p. 230)]. Si l'identification au sanctuaire de Pan est démontrée, cette grotte serait également le plus ancien témoignage de ce culte en Attique puisqu'il n'est généralement attesté qu'à partir du ve $\mathrm{s}$. (R. PARKer, Athenian Religion: a History, Oxford, 1996, p. 164-165).

M. OІкоnомakou, $A D 49$ (1994) [1999], B'1, p. 67-68.

01.12 - Thorikos (Agios Georgios) - II Éphorie des antiquités prébistoriques et classiques - Sur le terrain Chr. Roma, situé au $51^{\mathrm{e}} \mathrm{km}$ de la route Athènes-Laurion, $200 \mathrm{~m}$ à l'O de l'église Saint-Georges, on a continué les fouilles d'un grand bâtiment composé de deux ailes. La première campagne [voir $A D 45$ (1990), B'1, p. 76-77] avait été consacrée à la fouille de l'aile orientale, composée d'un couloir central bordé de quatre pièces qui comportaient des structures tantôt en pierre tantôt taillées dans le rocher, sans doute destinées à soutenir des tables ou des banquettes. Ces mêmes pièces ont livré une grande quantité de céramique, datée de la $2^{\mathrm{e}}$ moitié du $\mathrm{v}^{\mathrm{e}}$ et du $\mathrm{rv}^{\mathrm{e}} \mathrm{s}$. av. J.-C. Notons également la découverte d'une petite statue d'enfant nu, assis sur une jambe repliée, en dehors de la pièce B. Cette fouille avait dégagé, par ailleurs, deux pièces à l'angle NE du bâtiment (E et Ea). La première présentait deux supports en pierre et la deuxième un banc, ainsi qu'un égout installé dans le pavement mosaïque. Les fouilles de 1994 ont achevé le dégagement de l'aile orientale et se sont surtout concentrées sur l'aile occidentale. Elles ont permis de préciser la fonction de certaines pièces appartenant à l'aile orientale (bestiatorion et chambre à coucher ?) et de reconstituer le plan de l'aile occidentale, qui comportait également des installations pour l'évacuation des eaux. Le matériel, composé notamment 
de pinakes, de phiales, de kalatboi miniatures et d'un kernos (découvert dans la pièce E) ainsi que de petits objets en bronze, trahirait la nature cultuelle du bâtiment, dont la principale phase d'activité remonterait au $\mathrm{IV}^{\mathrm{e}} \mathrm{s}$. av. J.-C. Le fouilleur identifie la construction à un temple consacré à Déméter dont le culte était fort répandu à Thorikos.

M. Sallora-Orkonomakou, $A D 49$ (1994) [1999], B'1, p. 64-67.

\section{Péloponnèse (Alain Duptouy)}

\section{Corinthie}

02.01 - Corintbe - École américaine d'Athènes - En 1994, deux sondages furent menés à l'intérieur du sanctuaire de Déméter et Korè; l'objectif était de déterminer la nature de la flore et de la faune composant les repas rituels. Plusieurs salles de banquet furent méticuleusement fouillées, venant ainsi s'ajouter aux nombreuses pièces déjà dégagées lors des campagnes précédentes (le sanctuaire en comptait au moins 36 vers 400 av. J.-C.). Le lavage et le tamisage des terres permirent de récolter un échantillon représentatif d'ossements et de restes végétaux carbonisés. Blé, orge, lentilles, olives, raisins et figues constituaient l'essentiel des aliments consommés lors des repas rituels; par leur composition, ceux-ci ne se distinguaient donc guère de l'alimentation quotidienne, à cela près que la fouille ne permet pas de mettre en évidence le mode de préparation, peut-être particulier, de ces aliments lors des fêtes. Du côté animal, le porc devance de loin le mouton et la chèvre, ce qui n'étonnera guère. La présence majoritaire du porc dans les sactifices en l'honneur de Déméter est bien attestée en d'autres endroits. On notera enfin, de manière plus exceptionnelle, les restes de quelques poissons et oursins.

N. Bookidis, J. Hansen, L. SNyder, P. Goldberg, "Dining in the Sanctuary of Demeter and Kore at Korinth", Hesperia 68 (1999), p. 1-54.

- Chr. Pfaff présente la céramique des $\mathrm{XI}^{\mathrm{e}}$-viII ${ }^{\mathrm{e}} \mathrm{s}$. découverte entre 1961 et 1994 lors des fouilles du sanctuaire de Déméter et Korè sur le versant $\mathrm{N}$ de l'Acrocorinthe. Du point de vue cultuel, la publication de ce matériel revêt une réelle importance. De zone d'habitat à la fin de l'Âge du Bronze, le site apparaît en effet' sous un aspect clairement cultuel dans la $2^{\mathrm{e}}$ moitié du $\mathrm{vII}^{\mathrm{e}}$ s., mais il était jusqu'à présent difficile de préciser quand s'était effectuée la réaffectation religieuse de l'endroit. Si la continuité des céramiques entre le $\mathrm{XI}^{\mathrm{e}}$ et le $\mathrm{vII}^{\mathrm{e}}$ s. apporte aujourd'hui la preuve qu'il n'y a eu aucune interruption dans l'occupation du site, il n'est pas possible de déterminer sa fonction exacte durant cette période. La plupart des objets publiés se rencontrent en effet tant dans des contextes domestiques que religieux. Mais l'absence de cratère en céramique commune, d'ordinaire fréquent en zone d'habitat au viII ${ }^{\mathbf{e}} \mathrm{s}$, et la présence de trois vases miniatures de la fin du viII ${ }^{e} s$. laissent penser que le site fut utilisé comme sanctuaire au moins dès le viII $s$.

Chr. A. PFAfF, "The Early Iron Age Pottery from the Sanctuary of Demeter and Kore at Corinth", Hesperia 68 (1999), p. 55-134.

02.02 - Isthmia - École américaine d'Athènes, Université de Cbicago - La campagne de 1994 visait essentiellement à la préparation de la publication du matériel du sanctuaire de Poséidon. L'étude de la céramique et des monnaies a permis de suggérer un terminus post quem de $c, 470-450$ av. J.-C. pour l'incendie du temple archaïque.

E.R. Gebhard, $A D 49$ (1994) [1999], B'1, p. 167-168.

- En 1998, D. Reese et E. Gebhard ont étudié les restes d'animaux provenant de l'autel de Poséidon, du puits consacré à Melikertes-Palaimon et du réservoir d'eau du sanctuaire archaïque. Il apparaît que les membres antérieurs des ovins et des bovidés étaient les morceaux préférés pour les sacrifices; de plus, les animaux sacrifiés à Poséidon étaient 
généralement retirés du feu avant que le squelette ne soit brûlé. Un article est en préparation.

E.R. Gebhard, AR 1998-1999 (1999), p. 23.

- La publication du matériel des fouilles conduites par l'Université de Chicago au sanctuaire de Poséidon se poursuit avec la parution du tome VIII, consacré aux vestiges de la fin de l'Âge du Bronze et aux premiers temps du sanctuaire. Le volume, dû à C. Morgan, dresse le catalogue de tous les objets (céramique, métaux, armes et figurines en terre cuite) datant des $\mathbf{x v I}^{\mathrm{e}}-\mathrm{vIII}^{\mathrm{e}} \mathrm{s}$. Le site est occupé depuis les confins de l'HM et de l'HR et durant toute la phase finale de l'Âge du Bronze. Si pour cette époque aucun bâtiment n'a été préservé, la nature de la céramique découverte indique clairement l'existence d'un habitat. Après un bref hiatus durant le Submycénien, l'occupation du site reprend avec le PG Ancien sous un aspect dès lors exclusivement cultuel. Les environs immédiats du sanctuaire ne paraissent toutefois pas habités avant l'époque archaïque et il semble que celui-ci attirait une clientèle d'une zone assez vaste, probablement de toute la Corinthie (dont Isthmia était alors, semble-t-il, le seul lieu de culte). Jusque dans la $2^{\text {e }}$ moitié du virr ${ }^{\mathrm{e}}$ s., aucune structure construite n'apparaît sur un site qui demeure essentiellement le lieu de sacrifices et de repas rituels, auxquels viennent s'ajouter quelques offrandes. À partir du virre s., de nouvelles formes de dédicaces (trépieds et armes en bronze) apparaissent et témoignent d'un investissement aristocratique accru sur le site, mais aussi d'une spécialisation progressive des offrandes par rapport aux nouveaux établissements cultuels que sont Perachora et Solygeia.

C. Morgan, Isthmia. Excavations by the University of Chicago under the Auspices of the American School of Classical Studies at Athens. Volume VIII. The Late Bronze Age Settlement and Iron Age Sanctuary, Princeton, 1999.

02.03 - Némée - École américaine d'Athènes - En 1998, les travaux se sont poursuivis au sanctuaire du héros Opheltès. Un sondage $\mathrm{N}$-S à travers le centre de l'aire sacrée a montré que l'enclos construit vers 300 av. J.-C. remplaçait un tumulus érigé vers le milieu du $\mathrm{vI}^{\mathrm{e}}$ s.; les remblais du tumulus contenaient de nombreuses offrandes, en particulier de la vaisselle de banquet.

S.G. MiLler, AR 1998-1999 (1999), p. 25-26.

\section{Argolide}

02.04 - Argos (terrain Rembélou) - IVe Éphorie des antiquités prébistoriques et classiques - On signale la découverte en 1998 d'un dépôt appartenant au sanctuaire d'une divinité féminine, non encore identifiée, fréquenté aux époques archaïque et classique.

ЕҮППО 2 (1998), p. 78.

02.05 - Trachia (Kastraki) - IVe Épborie des antiquités prébistoriques et classiques - En

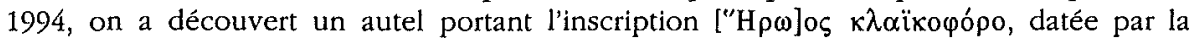
paléographie du $\mathrm{Iv}^{\mathrm{e}}-\mathrm{III}^{\mathrm{e}}$ s. av. J.-C., ainsi que plusieurs fragments de perirrbanteria, dont l'un avec l'inscription Ev่ $\alpha \rho \chi^{\prime} \delta \alpha_{\zeta}$ 'A $A \eta v \alpha_{i}^{\prime} \alpha_{\mathbf{l}}$ (III ${ }^{\mathrm{e}} \mathrm{s}$, av. J.-C.), suggérant ainsi l'existence d'un

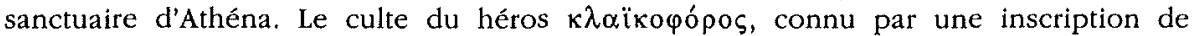
l'Asclépieion d'Épidaure $\left(I G \mathrm{IV}^{2}, 297\right)$, se trouve dès lors localisé avec vraisemblance.

Chr. Piteros, $A D 49$ (1994) [1999], B'1, p. 165.

02.06 - Épidaure - Société archéologique d'Athènes - En 1996 et en 1998, outre les travaux d'anastylose de l'autel classique d'Apollon, V. Lambridounakis a poursuivi le dégagement des vestiges préhistoriques sur le sommet de la colline du sanctuaire d'Apollon Maleatas, révélant deux bâtiments à abside de l'HA III et du début de l'HM. 
V. Lambrinoudakis, PAAH 151 (1996), p. 125-128; V. Petrakos, Ergon 45 (1998), p. 6870; Engon 46 (1999), p. 56-58.

\section{Laconie}

02.07 - Sparte - University College, Institute of Classical Studies - Dans le cadre des activités menées à Sparte depuis 1989 sous la direction de J. Wilkes et de G. Waywell, ce dernier présente l'apport des fouilles récentes à la compréhension de la topographie spartiate. Outre un réexamen complet du théâtre, on relèvera surtout, du point de vue cultuel, la réinterprétation du "Round Building ». Associé depuis sa découverte en 18921893 avec l'oikodomema peripheres de Pausanias, le « Round Building 》 apparaît plutôt comme une imposante structure semi-circulaire $(43,30 \mathrm{~m}$ de diamètre) formant une base à trois degrés, dont l'architecture rappelle celle du Ménélaion. L'A. fait l'hypothèse d'une identification au cénotaphe du général Brasidas, mentionné par Pausanias (III, 14, 1). Pour plus de détails, on renverra cependant au premier rapport de fouille ( $A B S A 89$ [1994], p. 414-419).

G. WAYwELL, "Sparta and its Topography", BICS 43 (1999), p. 1-26.

02.08 - Sparte - $V^{e}$ Éphorie des antiquités prébistoriques et classiques - Rue des Thermopyles, les archéologues ont découvert en 1994, dans un quartier de maisons hellénistiques, des fragments de cratère avec scène dionysiaque, ainsi que deux figurines semblables à celles provenant du sanctuaire d'Artémis Orthia, du Ménélaion et du sanctuaire de Zeus Messapeus.

$$
\text { E.P. ZABBOU, } A D 49 \text { (1994) [1999], B'1, p. 171-173. }
$$

- À l'occasion d'un colloque tenu à Londres en 1995, St. Raftopoulou fait état des activités conduites par le Service des fouilles grec entre 1991 et 1995. Du point de vue cultuel, si aucun reste architectural ne fut mis au jour, on retiendra la découverte de plusieurs dépôts votifs. Le premier, sur le flanc S de l'acropole (terrain Polychronakos), contenait des lekanai et des canthares miniatures. Un second dépôt, localisé à $200 \mathrm{~m}$ au NO du sanctuaire d'Artémis Orthia (rue Stauffert), a révélé un nombre important de figurines et de plaquettes en terre cuite. Enfin, un espace cultuel a été fouillé au $S$ de Toumbano, sur le versant $\mathrm{N}$ de la colline (terrain Zaimis); celui-ci doit sans doute être mis en relation avec un petit cimetière archaïque et classique et pourrait indiquer l'existence d'un culte funéraire.

S. Raftopoulou, "New finds from Sparta", in W.G. Cavanagh, S.E.C. Walker (éds), Sparta in Laconia. Proceedings of the $19^{\text {th }}$ British Museum Classical Colloquium, Londres, 1999, p. 125-140.

02.09 - Amyclées - Ve Éphorie des antiquités prébistoriques et classiques - On signale la fouille, en 1998, d'un dépôt votif dans le sanctuaire d'Agamemnon et KassandraAlexandra, qui avait déjà livré en 1960-1961 des vestiges semblables (céramique, figurines et plaquettes en terre cuite).

$$
\text { ЕYППО } 2 \text { (1998), p. } 82 .
$$

- Après deux articles parus dans l'ABSA (80 [1985], p. 29-84 et 83 [1988], p. 21-24), W.D. Coulson complète son étude de la céramique géométrique des sanctuaires spartiates conservée dans la Collection de l'École américaine par l'examen des vases du Géométrique Récent. La plupart des fragments étudiés proviennent de l'Amyklaion; deux seulement sont issus du Ménélaion, où ils constituent les plus anciens témoins du culte.

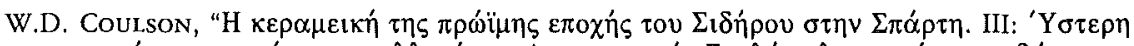

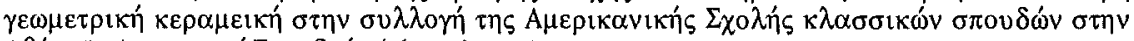
A 
02.10 - Geraki - Institut néerlandais d'Athènes - La quatrième campagne menée sur l'acropole de Geraki (ancienne Geronthrai), essentiellement consacrée à l'étude du matériel recueilli les années précédentes, a néanmoins révélé en 1998 un dépôt votif comprenant, entre autres choses, de la céramique miniature, suggérant ainsi l'existence d'un sanctuaire archaïque.

J. Crouwel, M. Prent, AR 1998-1999 (1999), p. 30-31; J. Crouwer et al., "Geraki. An Acropolis Site in Lakonia. Preliminary Report on the Fourth Season (1998)", Pharos 6 (1998), p. 93-118.

\section{Messénie}

02.11 - Messène - Société archéologique d'Atbènes - En 1996, les sondages menés à l'intérieur du sanctuaire d'Asclépios par P. Themelis, entre la stoa et le temple, ont révélé, dans le comblement d'une fosse, des canthares et des skyphoi miniatures ainsi que des statuettes archaïques et classiques identiques à celles découvertes précédemment. Dans le gymnase, c'est une statue d'Hermès qui fut mise au jour. En 1998 et 1999, outre la découverte de plusieurs statues divines (deux statues d'Aphrodite en 1998, une statue de Satyre et une d'Hermès en 1999), on retiendra surtout la découverte d'un dépôt votif contenant nombre d'offrandes (statuettes féminines, protomés, brûle-parfums et pinakes), vestiges, selon le fouilleur, d'un berôon qui pourrait être celui du Messénien Aristomenès (Pausanias, IV, 32, 6).

P. Themelis, PAAH 151 (1996), p. 139-171; V. Petrakos, Ergon 45 (1998), p. 39-50; Ergon 46 (1999), p. 45-56.

\section{Élide}

02.12 - Elis - Br. Eder et V. Mitsopoulou consacrent un article à l'histoire de la cité d'Élis (et de ses sanctuaires) antérieure au synocisme de 471 av. J.-C.; en l'absence presque complète de textes, c'est surtout l'occasion de dresser un bilan détaillé des fouilles menées jusqu'à présent dans la cité. En particulier, on signalera l'existence de plusieurs objets isolés en bronze - dont une attache de chaudron en forme de protomé de lion -, qui pourraient appartenir au matériel d'un sanctuaire. De plus, trois fragments de sima, datés vers 500 av. J.-C., sont vraisemblablement à rapporter au bâtiment $\mathrm{C}$ de l'agora, qui a l'aspect d'un petit temple. En somme, l'archéologie montre clairement qu'à l'époque du synœcisme, le site de la nouvelle Élis était occupé depuis plusieurs siècles par des édifices publics et cultuels.

Br. Eder, V. Mrtsopoulou-Leon, "Zur Geschichte der Stadt Elis vor dem Synoikismos von 471 v. Chr.: Die Zeugnisse der geometrischen und archaischen Zeit", JÖAI 68 (1999) Beiblatt, p. 1-40.

02.13 - Olympie - Institut archéologique allemand - Depuis sa publication en 1961 par

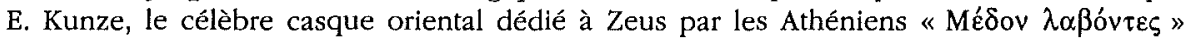
passe parfois pour un unicum. Il fait en réalité partie d'un ensemble d'objets orientaux mineurs, qui n'avaient pas encore été appréciés à leur juste valeur. H. Baitinger dresse le catalogue d'une série de pointes de flèche en bronze à trois ailerons selon un type répandu dans tout le Proche-Orient jusqu'en Égypte, de plusieurs carquois en bronze perses, etc. L'A. avance l'hypothèse selon laquelle tous ces objets appartiendraient à une même offrande faite par les Athéniens au lendemain de leur victoire de Marathon.

H. Baitinger, "Waffen und Bewaffnung aus der Perserbeute in Olympia", $A A$ (1999), p. 125-139.

- E. Völling publie deux sceaux orientaux découverts à Olympie. Le premier est un cachet de chalcédoine de style achéménide $\mathrm{du}_{\mathrm{vI}}{ }^{\mathrm{e}}$ s., relativement rare en contexte grec. Peut- 
être, postule l'A., ce sceau faisait-il partie du même butin prélevé sur les Perses et dédié par les Athéniens à la suite de la bataille de Marathon. Le second objet est un cylindresceau assyrien en malachite du règne de Sargon II (722-705), que l'A. tient pour l'un de ces objets orientaux parvenus dans les sanctuaires grecs au titre de curiosité exotique.

E. VölLıNG, "Zwei altorientalische Siegel aus Olympia", $A A$ (1999), p. 277-289.

\section{Arcadie}

02.14-Tégée - Lors du $100^{\mathrm{e}}$ Congrès de l'Archaeological Institute of America, L. Hammond (University of Missouri, Columbia) a présenté une communication sur la vaisselle miniature découverte dans les fouilles norvégiennes menées entre 1990 et 1994 dans l'enceinte du sanctuaire d'Athéna Alea à Tégée. L'A. constate des variations dans la distribution des vases offerts à la divinité selon l'endroit de découverte dans le sanctuaire et l'époque de consécration, variations qu'elle met en relation avec les différentes activités de culte.

L. HAMmOND, "The Miniature Votive Vessels from the Norwegian Excavations at Tegea", AJA 103 (1999), p. 309-310.

02.15 - Tégée (Agios Sostis) - L'étude de deux reliefs votifs découverts naguère dans la région de Tégée et dont l'iconographie est associée au culte de Perséphone et d'Hécate, permet à A. Leventi de revenir sur le sanctuaire d'Agios Sostis, qui présente toutes les caractéristiques d'un Thesmophorion. À la bibliographie citée par l'A., on ajoutera M. Jost, Sanctuaires et cultes d'Arcadie, Paris, 1985, p. 154-156.

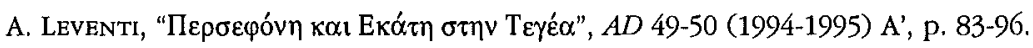

02.16 - Asea (Agios Elias) - Institut suédois d'Atbènes - En 1997, une équipe scandinave dirigée par J. Forsén conduisit une campagne de fouilles sur le site du plus grand temple archaïque d'Arcadie entièrement construit en pierre. Déjà étudié par le Suédois Holmberg dans les années 1930, le temple du mont Saint-Élie de Kandréva date vraisemblablement du début du ve s. (500-490). Les fouilles de 1997 ont montré que celui-ci avait été précédé par un premier édifice; un terminus post quem à sa construction pourrait être fourni par une épingle en bronze du milieu $\mathrm{vII}^{\mathrm{e}}-\operatorname{milieu}_{\mathrm{vl}^{\mathrm{e}}} \mathrm{s}$. De la céramique et des offrandes (en or, bronze, fer, plomb et ivoire) attestent toutefois une activité cultuelle sur le site dès le virI ${ }^{\mathrm{e}}$ s., avant la construction de toute structure. En relation avec ce matériel archaïque, un autel de cendres a livré environ 5000 ossements appartenant à près de 80 ovidés. Quelques tessons mycéniens et protogéométriques furent également mis au jour, malheureusement hors stratigraphie, indiquant néanmoins, selon les fouilleurs, une activité cultuelle dès le $\mathrm{x}^{\mathrm{e}} \mathrm{s}$. L'importance des offrandes et la taille du temple tardoarchaïque laissent croire, selon les fouilleurs, qu'il s'agissait du sanctuaire régional de Ménalie méridionale.

J. ForsÉn, B. ForsÉn, E. Østry, "The Sanctuary of Agios Elias. Its Significance, and Its Relations to Surrounding Sanctuaries and Settlements", in Th. H. NiELSEN, J. Rox (éds), Defining Ancient Arkadia, Copenhagen, 1999, p. 169-191.

02.17 - Phigalie (Kourdoubouli) - Société archéologique d'Athènes - De 1996 à 1998, $X$. Arapogianni a entrepris la fouille d'un petit temple $(15,70 \times 7,70 \mathrm{~m})$ du Ive s. situé sur le sommet d'une colline à l'O du bourg actuel. Les murs sont conservés sur trois assises de blocs en appareil isodome. Au centre de la cella, on a retrouvé en place le socle de la statue de culte, devant lequel se trouvait la table d'offrandes composée de deux plaques verticales ornées de pattes de lion. La découverte d'une base de statue inscrite, offrande d'un certain Évagoras à Athéna et à Zeus Sôter, livre une précieuse indication sur l'identité des divinités honorées. Ni Athéna ni Zeus Sôter ne sont mentionnés dans le récit de Pausanias (VIII, 39-41) et nul doute que cette identification fasse progresser la connais- 
sance de la topographie et des cultes de l'antique Phigalie. Néanmoins, on notera qu'Athéna était déjà connue à Phigalie par une inscription du $\mathrm{r}^{\mathrm{er}} \mathrm{s}$. ap. J.-C., précisément découverte au lieu-dit Kourdoubouli ( $S E G$ XXIII, 237), et bien attestée par le monnayage impérial (cf. M. Jost, Sanctuaires et cultes d'Arcadie, Paris, 1985, p. 85-88). Découverte non loin de là (dans la chapelle de la Croix), une seconde inscription, très mutilée ( $I G \mathrm{~V}$ $2,421)$, laisse apparaître l'épiclèse Пlo $\lambda$ tó $[\delta 1]$, qui ne peut guère s'appliquer qu'à Athéna. Si M. Jost hésitait encore à attribuer les vestiges affleurant sur la colline de Kourdoubouli à un culte d'Athéna (attesté par les inscriptions) ou de Dionysos (connu par Pausanias), le doute n'est à présent plus permis. Il s'agit bien du sanctuaire d'Athéna et, qui plus est, de la divinité poliade. Au demeurant, l'importance de ce sanctuaire pour la cité de Phigalie se mesure aisément à la quantité d'inscriptions récupérées en 1996 - le fouilleur rapporte au moins quatre décrets de proxénie, sept listes de noms, une dédicace et un traité avec Lepreon, jadis confiés à la garde de la divinité. Parmi les offrandes, quantité d'objets en bronze, en fer et en plomb furent découverts : signalons entre autres une plaquette en bronze figurant Athéna avec lance et bouclier (comme sur les monnaies !) et une dédicace archaïque à Athéna. Les nombreuses petites barques en terre cuite doivent sans doute être mises en relation avec une remarque de Pausanias (VIII, 41, 3) sur la fréquentation de la rivière voisine Nedas. En 1997 et 1998, l'exploration archéologique s'est poursuivie par la fouille des vestiges (HM) dégagés précédemment au $\mathrm{N}$ et à l'intérieur du temple. À cette occasion, les fouilles ont révélé, à l'intérieur de la cella, un niveau de sol antérieur à l'époque classique (peut-être archaïque ?), ainsi que de la céramique d'époque classique.

V. Petrakos, Ergon 44 (1997), p. 43-49; Ergon 45 (1998), p. 51-53; X. Arapogianni, PAAH 151 (1996), p. 129-137.

02.18 - Kleitor (Agios Athanasios) - Dans une étude sur les réseaux routier et défensif du territoire de Kleitor, Y. Pikoulas propose de localiser le sanctuaire d'Athéna Koria, mentionné par Pausanias (VIII, 21, 4), sur le sommet du mont Saint-Athtanase.

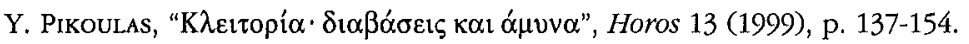

02.19-Lousoi - Institut autrichien d'Athènes - Les recherches se sont concentrées en 1998 sur le «bâtiment Est », qui s'élevait à l'E du temple d'Artémis. Il s'agit d'un édifice reçtangulaire orienté $\mathrm{E}-\mathrm{O}$, construit à l'époque archaïque et détruit avant la fin $\mathrm{du}_{\mathrm{rv}} \mathrm{e}^{\mathbf{s}} \mathbf{s}$ Les fouilleurs font remarquer que son mur $S$ se situait dans l'alignement exact de la colonnade $\mathrm{S}$ du futur temple du $\mathrm{II}^{\mathrm{e}} \mathrm{s}$. Ces nouveaux indices ont permis d'orienter l'interprétation du «bâtiment Est » vers une destination cultuelle, sans doute à mettre en relation avec un ancien temple d'Artémis.

V. Mitsopoulou-Leon, $A R$ 1998-1999 (1999), p. 29-30; V. Mitsopoulou-Leon,

G. LADSTÄTteR, "Lousoi", ÖAI Jabresbericht 1998 (1999), p. 70-76.

02.20 - Pheneos - Institut autrichien d'Athènes - Depuis 1993, le territoire des cités nord-arcadiennes de Lousoi et de Pheneos ont fait l'objet d'une prospection intensive, dont K. Tausend présente aujourd'hui les résultats. Aucun sanctuaire n'est attesté dans la chôra de Lousoi, que ce soit par la tradition littéraire, par l'épigraphie ou par l'archéologie. En revanche, le sanctuaire urbain d'Artémis Hemera, son unique sanctuaire, dépasse de loin en importance tous ceux de la région; à l'époque romaine, les concours qui y étaient organisés, les Hemerasia, attiraient des concurrents non seulement de tout le Péloponnèse, mais aussi d'Asie Mineure. Par ailleurs, jusqu'il y a peu, aucun des sanctuaires de la chôra de Pheneos attestés par les textes n'avait été repéré. Plusieurs propositions de localisation plus ou moins assurées sont à présent faites pour les sanctuaires d'Apollon Pythios, d'Artémis Pyrônia, de Déméter Thesmia et d'Hermès sur le mont Cyllène (Ziria). Le matériel relativement pauvre qui y a été découvert tendrait à confirmer le caractère essentiellement local de ces lieux de culte. 
K. Tausend (éd.), Pheneos und Lousoi. Untersucbungen zu Geschichte und Topographie Nordostarkadiens, Francfort, 1999.

02.21 - Stymphale - University of British Columbia, Institut canadien d'Atbènes Fouillée entre 1924 et 1930 par Orlandos, la cité de Stymphale est, depuis 1982, l'objet d'un nouveau programme de recherches mené par les archéologues canadiens. Depuis 1994, leur activité a notamment porté sur l'acropole et sur son temple, qu'une inscription découverte en 1925 permet d'associer à Athéna Polias. La découverte de sculptures en marbre à l'intérieur du temple (et nulle part ailleurs dans la cité), la variété des offrandes et la preuve d'une destruction violente vers le milieu du $I^{\mathrm{e}}$ s. av. J.-C. indiquent qu'il s'agissait d'un sanctuaire majeur de la cité. La campagne de 1997 avait pour objectif de préciser la date de construction de l'édifice; l'étude de la céramique est en cours, mais on peut d'ores et déjà évoquer le $\mathrm{Iv}^{\mathrm{e}}$ s. av. J.-C. Bien que certains objets solent antérieurs (un kouros et une korè de la fin de l'archaïsme, des figurines du $v^{e} s$.), aucune structure n'a toutefois pu être mise en relation avec ces activités anciennes.

H. Williams et al., "Excavations at Ancient Stymphalos, 1997", EMC 42 (1998), p. 261319.

- Lors du $100^{e}$ Congrès de l'Archaeological Institute of America, K.D. Sherwood (Montreal Society) a présenté une communication sur les terres cuites corinthiennes mises au jour par l'équipe canadienne dans le temple d'Athéna Polias. La présence, du v $\mathrm{v}^{\mathbf{e}}$ $\mathrm{au}_{1}{ }^{\text {er }}$ s. av. J.-C., de plaquettes votives et de figurines en terre cuite corinthiennes atteste ainsi la diffusion des productions de Corinthe en Arcadie.

K.D. SHerwood, "Corinthian Products at Arcadian Stymphalos: A Preliminary Report on the Votive Terracottas from the Acropolis Temple", AJA 103 (1999), p. 310.

02.22 - Lafka (Tria Goupata) - IVe Éphorie des antiquités prébistoriques et classiques En 1994, on a procédé à une première exploration d'une grotte située sur le mont Messiano, contenant de la céramique corinthienne archaique, des lécythes du $v^{e} s .$, des fragments de statuettes du type de la femme assise ( $\left.v_{I}{ }^{e} v^{e} s.\right)$, des figurines de chevaux, des boucliers en bronze miniatures et des os d'animaux. Le fouilleur évoque la possibilité d'un culte chthonien.

Chr. Piteros, $A D 49$ (1994) [1999], B'1, p. 161.

\section{[03. Béotie, Eubée]}

\section{[04. Phocide, Locride, Étolie]}

\section{Acarnanie, Épire, Illyrie méridionale, îles ioniennes (François QUANTIN)}

\subsection{0 - Généralités}

- Dans l'ouvrage collectif de P. Berktold, J. Schmid, Ch. WACKer, Acarnanien. Eine Landschaft im antiken Griechenland, Würzburg, 1996, plusieurs articles concernent les cultes et les sanctuaires acarnaniens : R. Hilpert-Greger, Der Acheloos-Mythos, p. 71; Ch. WACKer, Astakos (cf. en particulier le temple de Zeus), p. 99; H.P. IsLER, Der akarnaniscbe Flußgott Acbeloos in der Bildkunst, p. 169; M. Osanna, Artemis in Patras: Wandel einer Polis im Spiegel ibrer Kulte, p. 183. 
- Courte synthèse sur les cultes épirotes insistant sur le fait qu'ils ne sont réductibles ni à un modèle dodonéen, ni à l'influence des panthéons des colonies littorales. L'étude de quelques aspects de la vie religieuse montre que l'hellénisme épirote est ancien, et que ses singularités sont intimement liées aux particularités sociales et politiques de l'Épire. Ces traits illustrent de plus larges spécificités, car ils intéressent notre connaissance du sentiment religieux des populations montagnardes dans l'Antiquité. Brefs développements sur les offrandes de fouets à Dodone, interprétées comme les indices d'une fréquentation pastorale du sanctuaire, sur la morphologie des lieux de culte en Épire et sur les actes du culte.

F. QuANTIN, "Aspects épirotes de la vie religieuse antique", REG 112 (1999), p. 61-98.

- É. Fouache et F. Quantin reprennent le dossier de l'édifice de Mésopotamos, critiquent, à la suite, entre autres, de D. BAATz ("Teile hellenistischer Geschütze aus Griechenland", $A A 94$ [1979], p. 68-75 et "Hellenistische Katapulte aus Ephyra (Epirus)", MDAI(A) 97 [1982], p. 211-233), son interprétation cultuelle comme sanctuaire nécromantique, et insistent sur la fonction militaire et économique de l'édifice en évoquant des parallèles d'illyrie méridionale. Afin de situer le Nekyomanteion mentionné par Hérodote et Pausanias, les A. proposent la région de Glyki, à la sortie des gorges de l'Achéron, grâce à des arguments typologiques, archéologiques et géomorphologiques. Le sanctuaire serait avant tout un lieu naturel, une entrée des enfers, dont l'origine pourrait être liée à la présence éléenne dans la région.

É. Founche, F. Quantin, "Représentations et réalité géographique de l'entrée des enfers de Thesprôtie", in Ch. Cusset (éd.), La nature et ses représentations dans l'Antiquité, Actes du colloque de l'É.N.S. Fontenay-Saint-Cloud (24-25 octobre 1996), Paris, 1999, p. 29-61.

\section{Acarnanie}

05.01 - Oiniadai - VI Éphorie des antiquités préhistoriques et classiques - Au $\mathrm{N}$ des hangars à bateaux du port antique de la ville, une concentration de céramique fine d'époque hellénistique, de lampes et de figurines féminines en terre cuite, pourrait confirmer l'existence d'un sanctuaire dans les environs.

L. Kolonas, $A D 47$ (1992) [1997], B'1, p. 148; G. Touchais, $B C H 122$ (1998), Chron. p. 812.

05.02 - Drymonas - VIe Éphorie des antiquités prébistoriques et classiques - Découverte, à $5 \mathrm{~km}$ à l'E de Mytikas, d'un sanctuaire d'Artémis perturbé par des fouilles clandestines; mention de bases de statue - certaines sont épigraphes -, de figurines en terre cuite, de statuettes en marbre et en pierre, de monnaies de bronze et de tessons de céramique. Le matériel date des périodes classique et hellénistique. Le site est abandonné au $\mathrm{II}^{\mathrm{e}}$ ou au $\mathrm{III}^{\mathrm{e}}$ s, ap. J.-C.

L. Kolonas, $A D 48$ (1993) [1998], B'1, p. 140; D. Blackman, $A R$ 1998-1999 (1999), p. 42.

05.03 - Lepenou (Spathari) - VIe Éphorie des antiquités prébistoriques et classiques - $\AA$ $6 \mathrm{~km}$ à l'O de Stratos, lors d'une fouille d'urgence, on a découvert les fondations d'un temple archaïque à pronaos et opisthodome $(8 \times 12 \mathrm{~m})$. L'assise de réglage, la krepis et les éléments conservés des murs sont en calcaire local. Des fragments de décoration de la toiture sont de style corinthien; d'autres, d'époque hellénistique, sont l'indice d'une restauration. Des éléments architecturaux, dont des chéneaux à têtes de lion, suggèrent une riche décoration de l'élévation ( $c f$. L. Kolonas, $A D 48$ (1993) [1998], B'1, p. 141).

L. Kolonas, $A D 49$ (1994) [1999], B'1, p. 242. 
05.04 - Gionia - VIe Éphorie des antiquités prébistoriques et classiques, Institut archéologique allemand d'Athènes, Universités de Freiburg, Münster et Heidelberg - Au cours du survey de la région de Stratos, une concentration de figurines en terre cuite des époques archaïque et classique repérée à Gionia, à l'O de Stratos, est interprétée comme le dépôt votif d'un sanctuaire rural.

L. Kolonas, $A D 48$ (1993) [1998], B'1, p. 140-141; D. BlaCkMan, AR 1998-1999 (1999), p. 43 .

\section{Épire}

05.05 - Ambracie - XII Éphorie des antiquités prébistoriques et classiques - Rappelons que la colonie d'Ambracie (actuelle Arta), comme Corcyre, Anactorion et Leucade, fut fondée au $\mathrm{vII}^{\mathrm{e}} \mathrm{s}$. par des colons corinthiens (Thuc. II, 83, 3) et que le site était précédem-

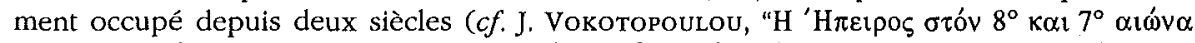

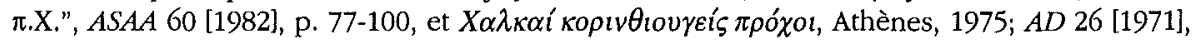
B'1, p. 331-332, pour la découverte de tessons datés autour de 800-750 av. J.-C.). La ville moderne et contemporaine est superposée à l'occupation antique et médiévale; la construction de nouveaux bâtiments et l'amélioration du réseau des égouts de la ville sont donc à l'origine de nombreuses opérations de fouille d'urgence. Nous rendons compte des recherches de 1994, publiées en 1999.

- Rue Arkadiou (terrain Kôstadima et Naskari, site $n^{\circ} 203$ ), A. Douzougli signale la découverte dans un contexte manifestement domestique datant de l'époque hellénistique de nombreux fragments de statuettes et de petits reliefs en terre cuite.

A. Douzougli, $A D 49$ (1994) [1999], B'1, p. 370.

- Lors de l'exploration de l'édifice $S$ du sondage mené rue Agia Paraskevi (terrain Kontella, site $\mathrm{n}^{\circ} 200$ ), les fouilleurs ont découvert dans le niveau archaïque - sans doute de la $2^{\mathrm{e}}$ moitié du vi ${ }^{\mathrm{e}} \mathrm{s}$. - un fragment de statuette féminine en terre cuite coiffée du polos et de style "dédalique », qu'A. Douzougli rapproche d'un exemplaire corinthien (Corinth XII, p. 29 [81], pl. 5). Du même sondage proviennent des fragments de statuettes et de reliefs en terre cuite plus récents.

\section{A. Douzougl., $A D 49$ (1994) [1999], B'1, p. 372.}

- Au centre d'Arta, dans le secteur des rues Alexopoulou et Karä̈skaki, Th. Kontogianni signale la découverte de tronçons de rues antiques, d'édifices, et de deux bases de statue en particulier, qui pourraient indiquer que les fouilleurs ne sont pas loin du centre cultuel et administratif de la ville antique. Il faut aussi, dans ces réflexions topographiques, tenir compte de la position du temple de l'archaïsme tardif de la rue Pyrrou (pour un plan de la ville antique et une tentative de localisation de l'agora grâce aux édifices connus, dont le prytanée, $c f$. I. Andreou, "Ambracie, une ville ancienne se reconstitue peu à peu par les recherches", in P. CaBanes (éd.), L'Tllyrie méridionale et l'Épire dans l'Antiquité II. Actes du deuxième colloque international de Clermont-Ferrand (2527 octobre 1990), Paris, 1993, p. 99-100, fig. 9; Th. Kontogianni, ibid., p. 381, n. 77 donne la liste des comptes rendus des interventions sur le temple, qui n'a malheureusement pas encore fait l'objet d'une publication d'ensemble), et du petit thêatre de la rue Agios Konstantinou (Denys d'Halicarnasse I, 50, 4, mentionne à Ambracie un sanctuaire d'Aphrodite et un berôon d'Énée près du petit théâtre conservant un xoanon archaïque du héros troyen). Le petit théâtre d'Ambracie est fouillé et publié, mais aucun autre vestige ne fut découvert dans les environs, ce que la faible extension de la fouille ne

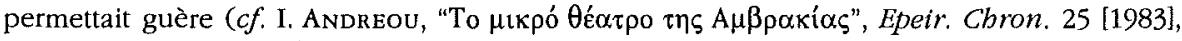
p. 9-23, qui situe l'édifice à la fin du $\mathrm{Iv}^{\mathrm{e}}$ s. ou au début du $\mathrm{In}^{\mathrm{e}} \mathrm{s}$. av. J.-C., datation trop haute pour J.-Ch. MoRETTI, Topoi 1 [1991], p. 22, $\mathrm{n}^{\circ} 73$ ). La fouille a mis au jour l'angle SE de la krepis du grand temple de la rue Pyrrou, qui est sans doute le sanctuaire principal 
des Ambraciotes. La divinité est probablement Apollon Sôter ( $c f$. P. CABANEs, J. ANDrÉou, "Le règlement frontalier entre les cités d'Ambracie et de Charadros", BCH 109 [1985], p. 499-544; compléments apportés p. 753-757 de la même livraison).

Th. Kontogianni, $A D 49$ (1994) [1999], B'1, p. 379.

05.06 - Phanari [plaine du] - Université de Boston, École américaine d'Athènes, XII Éphorie des antiquités prébistoriques et classiques, VIIre Éphorie des antiquités byzantines - Dans la basse vallée de l'Achéron, à la frontière de la Thesprôtie et de la Cassôpie, un programme gréco-américain de prospection et d'étude dans le sud de l'Épire s'est intéressé, entre autres, au Phanari, la plaine alluviale de l'Achéron. Les limites du lac Achérousia, l'emplacement des zones habitées et la chronologie de ces occupations ont été précisés.

J. Wiseman, K. Zachos, Ph. Kephallonitou, $A D 49$ (1994) [1999], B'1, p. 401-403.

05.07 - Paramythia [région de] - VIII É Éphorie des antiquités prébistoriques et classiques - En Thesprôtie, près de Sévastos et Kyra Panagia, la fouille d'un petit sanctuaire rural comportant un naïskos et un autel a été achevée; « on y a trouvé plusieurs milliers de figurines fragmentaires en terre cuite et autres offrandes " (G. Touchais, $B C H 122$ [1998], Cbron. p. 802; cf. aussi D. BlaCKMAN, $A R$ 1998-1999 [1999], p. 54) G. Riginos signale un berôon - probablement doté d'un autel - à Marmara, site connu par S.I. Dakaris ( $\Theta \varepsilon \sigma \pi \rho \omega \tau i ́ \alpha$, Athènes, $1972[A G C, 15]$, p. 139 et 176-177), et un péribole funéraire à Delvitsi - un autre berôon? -, près du Cocyte à moins d'1 km au so de Marmara, G. Riginos reprend la description de ces vestiges, et leur interprétation, avec de nombreuses photographies des structures et du matériel. Grâce aux travaux de l'A., la carte archéologique de cette région du sud de la Thesprôtie s'enrichit et livre d'intéressants vestiges cultuels qu'il faut maintenant confronter à l'iconographie numismatique régionale, en particulier à celle du monnayage d'Elea (Veliani).

G. Riginos, $A D 47$ (1992) [1997], B'1, p. 348-354 et 360-361; ID., "Ausgrabungen in antiker Eleatis und ihrer Umgebung", in P. CaBAnes (éd.), L'Illyrie méridionale et l'Épire dans l'Antiquité III, Actes du troisième colloque international de Chantilly (1619 octobre 1990), Paris, 1999, p. 173-174.

05.08 - Dodone - Société archéologique d'Athènes, Université de loannina - La mission, dirigée par le professeur Dakaris jusqu'à sa disparition en 1996, a mis au jour depuis plusieurs campagnes le prytanée (édifice O-O1), situé à l'intérieur de l'enceinte du sanctuaire, immédiatement au $\mathrm{S}$ du bouleuterion (édifice E2). S. I. Dakaris $t$, Ch. Tzouvara-Souli, A. Vlachopoulou-Oikonomou et K. Gravani-Katsiki livrent, avant la publication d'une monographie sur le prytanée, des éléments concernant la stratigraphie et l'architecture. La première phase du prytanée - datée, comme le bouleuterion voisin de la fin du IV ${ }^{e}$ ou du début du $\operatorname{III}^{\mathrm{e}} \mathrm{s}$. - associe une pièce carrée et couverte, au centre de laquelle une "exèdre " indique un foyer, à une cour à péristyle, où les fouilleurs ont découvert un autel dans la partie hypèthre. Avant le raid étolien de Dorimachos en 219 av. J.-C., l'édifice s'enrichit, au N, de plusieurs pièces ouvrant sur la cour à péristyle, et, à l'E, d'une colonnade ionique (aile O1), afin d'augmenter ses capacités d'accueil. Une couche de destruction est attribuée à l'expédition punitive de Paul-Émile en 167 ( $c f$. P. CABanes, L'Épire, de la mort de Pyrrbos à la conquête romaine (272-167), Paris, 1976, p. 297-308 et 335); l'aile O1 est alors réutilisée, mais elle n'est plus associée au prytanée qui est reconstruit, sans doute au $\mathrm{I}^{\mathrm{er}} \mathrm{s}$. av. J.-C., pour perdurer jusqu'au milieu du $\mathbf{I I}^{\mathrm{e}} \mathrm{s}$. ap. J.-C., époque à laquelle l'édifice s'intègre à la construction d'une maison privée.

S.I. Dakaris $\dagger, \mathrm{Ch}$, Tzouvara-Souli, A, Vlachopoulou-Oikonomou, K. GravaniKATSIKI, "The prytaneion of Dodona", in L'Illyrie méridionale et l'Épire dans l'Antiquité III (supra 05.07), p. 149-159; EID., PAAH (1996) [1998], p. 215-228; cf. 
G. Touchais, BCH 122 (1998), Cbron., p. 804; Ch. Souli, A. Vlachopoulou, K. Gravani, $P A A H$ (1997) [1999], p. 155-163.

- Ch. Tzouvara-Souli donne une riche étude des méthodes mantiques employées à Dodone d'après les sources littéraires, souvent contradictoires, et s'interroge sur ce que peuvent nous apprendre les lamelles oraculaires au sujet de la procédure de consultation

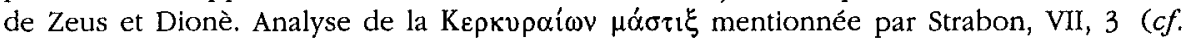
A.B. Cook, "The Gong at Dodona", JHS 22 [1902], p. 5-28).

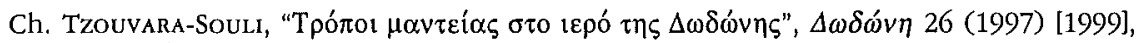
p. 29-70, 12 fig.

- Grâce à l'étude de M.-F. BAsLez, "Olympias, la royauté et le sacré : à propos des affaires de Dodone et d'Oropos", in L'Illyrie méridionale et l'Épire dans l'Antiquité III (supra 05.07), p. 389-393, de l'epikosmesis de la statue de Dionè à Dodone par les Athéniens, mentionnée par Hypéride (Pour Euxénippe, 24-25), on peut proposer l'hypothèse selon laquelle l'une des chapelles de Dodone qui environnent la maison sacrée est une offrande athénienne (cf. F. QUANTIN, REG 112 [1999], p. 72, et Bull. archi., RA [1998], p. 363).

05.09 - Kastritsa - XII Éphorie des antiquités prébistoriques et classiques A. Douzougli (p. 363, et fig. 1, p. 364) rappelle que S. 1. Dakaris proposait de reconnaître un temple parmi les édifices intra muros couronnant l'acropole de Kastritsa, au $\mathrm{S}$ du lac de Ioannina en Molossie, peut-être l'ancienne Tekmon (PAAH [1951], p. 174). La fouille des vestiges des édifices $\mathrm{A}$ et $\mathrm{B}$, qui ne sont vraisemblablement pas plus anciens que l'époque hellénistique, n'a pas pour l'instant permis de vérifier cette hypothèse.

A. Douzougli, $A D 49$ (1994) [1999], B'1, p. 363-367.

05.10 - Dourouti (cité universitaire de Ioannina) - I. Andreou et K. Gravani ont découvert un nouveau lieu de culte en Molossie, remarquable à plus d'un titre. Au NE de la colline de Dourouti, à la sortie des gorges de Megalo Langadi qui débouchent sur la plaine de Ioannina, des fouilles d'urgence (1976-1981), puis des interventions programmées (1995-1998) ont mis au jour la nécropole - de la fin de l'époque géométrique à la période hellénistique - et deux ensembles architecturaux d'un village, qualifié de $\pi$ ó $\lambda_{1} \sigma \mu \alpha$ et rapproché par I. Andreou de Vitsa dans l'histoire de l'urbanisme en Épire ("D'Ambracie à Nicopolis, les villes-jalons de l'urbanisme en Épire", in L'Tllyrie méridionale et l'Épire dans l'Antiquité III (supra 05.07), p. 343):

a) Le premier ensemble, au $\mathrm{N}$, est composé des fondations d'un édifice circulaire de 10,50 $\mathrm{m}$ de diamètre à deux anneaux concentriques, et de structures orthogonales et curvilignes. Les murs de l'édifice circulaire sont construits à l'aide de moellons dégrossis en calcaire local. L'élévation maximale conservée du cercle extérieur est de 1,30 m; le diamètre du cercle intérieur est de $5,70 \mathrm{~m}$. La construction de ce bâtiment, d'après le matériel, peut être située dans la $1^{\text {re }}$ moitié du $\mathrm{IV}^{\mathrm{e}} \mathrm{s}$. av. J.-C.

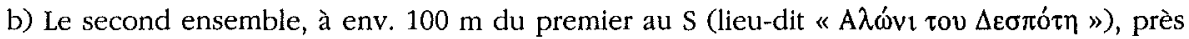
du monastère de Dourouti, associe aussi une structure circulaire dallée, peut-être liée à deux tombes archaïques voisines, à un édifice rectangulaire $(8 \times 7 \mathrm{~m})$ dont le plan est celui d'un petit temple.

Une partie du matériel récupéré en particulier lors de la fouille de l'édifice circulaire de la zone $\mathrm{N}$ pourrait présenter un caractère cultuel (on trouve aussi des pesons, des fragments de tuiles et de meules) : des fragments de figurines féminines en terre cuite, un sceau en pierre représentant une vache allaitante attelée à une charrue, une petite « lamelle » de bronze avec en relief une représentation de Déméter portant sceptre et flambeau. Notons aussi la découverte d'une lame de couteau en fer, de fragments de phiales et d'une monnaie en bronze d'Alexandre. Forme des édifices et matériel conduisent les A. à reconnaître à Dourouti un sanctuaire de Déméter, ou de Déméter et de Korè (p. 596), qui serait alors le premier en Épire, mais que l'on peut comparer à 
l'édifice circulaire du Thesmophorion de Pella. Les A. rapprochent ces vestiges d'une des rares attestations objectives en Épire d'un culte de Déméter : une question posée par un consultant à Dodone qui se demande s'il doit acheter l'étang situé près du sanctuaire de Déméter ( $c f$. D. Evangriddis, PAAH [1955], p. 172, b; J. et L. RoberT, Bull. épigr. [1961], 372; SEG XIX, 1963, 432; lamelle M 40). Un passage lacunaire de Pausanias (IX, 8, 1) est aussi évoqué : le périégète rapporte un rite qui se déroule dans le sanctuaire de Déméter et Korè à Potniai, à $3 \mathrm{~km}$ au SO de Thèbes : des porcelets réapparaissaient à Dodone à la saison suivante après un voyage, peut-être souterrain, qui heurte l'esprit critique de Pausanias.

I. Andreou et K. Gravani notent à juste titre que l'identification d'un sanctuaire de Déméter à Dourouti se heurte à une objection importante : l'absence de certaines catégories de matériel associées au culte de la déesse (p. 601) : kernoi, vases miniatures, ou figurines de porcs. Ajoutons que les deux structures circulaires gardent en partie leur caractère énigmatique (peut-être pourrait-on découvrir quelques pistes ou éléments de comparaison chez A. Mazarakis Ainian, From Rulers' Dwellings to Temples, Jonsered, 1997, chap. 5 , spéc. C. Circular Pavings, p. 122-123 et F. RÉCHIN, "Établissements pastoraux du piémont occidental des Pyrénées", in G. FABRE (éd.), Organisation des espaces antiques, Table ronde du GRA à l'Université de Pau (21-22 mars 1997), Biarritz, 2000, p. 13-50, qui étudie des aires de galets, parfois circulaires, dans un contexte pastoral), et que le texte de Pausanias et l'inscription sont peu contraignants (mention d'un limnion près d'un sanctuaire de Déméter : un étang de la plaine de Ioannina? D'où vient le consultant ?). Quoi qu'il en soit, l'hypothèse d'un culte rendu à une divinité féminine est justifiée; on peut aussi penser à une Artémis Phôsphoros (une figurine en terre cuite d'Artémis provenant d'Ambracie porte une torche, Musée d'Arta ${ }^{\circ}$ 523) ou Hegemonè, épiclèse connue à Passaron, ou Hécate. Cela pourrait permettre de poser autrement la question de l'antiquité du culte d'une parèdre de Zeus à Dodone, dont Dourouti est proche géographiquement ( $c f$. H. Petersmann, "Der homerische Demeterhymnus, Dodona und Südslawisches Brauchtum", WS 99 [1986], p. 69-85; ID., "Demeter in Dodona und Thrakien. Ein Nachtrag", WS 100 [1987], p. 5-12). La présence de Déméter n'est pas directement attestée à Dodone. Les A. annoncent d'autres recherches à Dourouti, qui devraient beaucoup enrichir notre connaissance des sanctuaires épirotes.

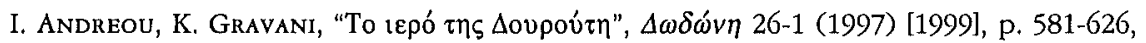
8 fig.

05.11 - Goumani (Gitanai) - VIII Épborie des antiquités prébistoriques et classiques - En Thesprôtie, dans la région de Philiates, au SE des collines de Vrysella, sur la rive droite du Kalamas, l'ancien Thyamis, près du confluent où s'ajoutent les eaux du Kalpakiotikos, une fouille a commencé en 1995 dont K. Preka-Alexandri donne les premiers résultats, en présentant exclusivement la stoa au $\mathrm{N}$ de l'agora, proche typologiquement des portiques de Grèce du Nord-Ouest et datée du milieu du $\mathrm{II}^{\mathrm{e}}{ }^{\mathrm{s}}$ s. av. J.-C. La stoa est allongée à l'O d'une structure contemporaine, divisée en deux parties. Dans la pièce occidentale, les fouilleurs découvrirent plus de 500 fragments, surtout de céramique - représentations d'Athéna, d'Éros, de satyres et de Pan -, qui ont probablement une fonction votive et font de cette pièce « a storage shed». À l'E, les découvertes les plus remarquables sont un acte d'affranchissement et une base, à droite de l'entrée, formée de deux blocs superposés : le premier est décoré d'une plate-bande périphérique, le second est un cylindre mouluré lui aussi. C. Preka-Alexandri propose de reconnaître une zone consacrée au culte d'Apollon Agyieus.

K. Preka-AleXANDri, "Recent excavations in ancient Gitani", in L'llyyrie méridionale et l'Épire dans l'Antiquité III (supra 05.07), p. 167-169. 
05.12 - Boutbrôtos en Chaonie - Fouilles albano-britanniques - Les fouilles dirigées par R. Hodges s'intègrent à un projet global d'étude et de mise en valeur des patrimoines archéologique et naturel de la région de Butrint (Butrint Fondation). N. Ceka publie dans ce cadre le premier guide archéologique du site, où sont décrits les vestiges du sanctuaire d'Asclépios et d'un temple in summa cavea que l'A. propose d'attribuer à Dionysos (p. 37-30), du «temple de Minerve » dont la première phase date du $\operatorname{mI}^{\mathrm{e}}$ s. av. J.-C. (p. 43), du nymphée construit au $\mathrm{II}^{\mathrm{e}} \mathrm{s}$. ap. J.-C. où l'on a découvert une statue d'Apollon et une autre de Dionysos (p. 49-50), et d'un puits gravé d'une inscription : 'Iovví $\alpha$ 'Povpeîv $\alpha$

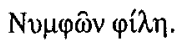

\section{N. Ceka, Butrint. A Guide to the City and its Monuments, Londres, 1999.}

- C. Tussi étudie le culte d'Esculape à Aquileia et dans les autres centres des régions nord-adriatiques et, en s'interrogeant sur «le problème des voies de diffusion du culte d'Esculape de Grèce vers l'aire nord-adriatique » (chap. 5, p. 107-118), l'A. aborde le dossier archéologique et épigraphique du culte d'Asclépios à Bouthrôtos (p. 108-109), en insistant notamment sur le rôle de ville épirote dans les navigations adriatiques, l'association topographique du temple du dieu médecin au théâtre, schéma bien connu dans le monde romain.

C. Tussi, Il culto di Esculapio nell'area nord-adriatica, Rome, 1999 (Quazar) (Collection Studi e ricercbe sulla Gallia Cisalpina).

05.13 - Liatovouni [colline de] - XII Éphorie des antiquités prébistoriques et classiques - Au centre de la plaine de Konitsa, A. Douzougli a exploré 101 tombes, datées entre les $\mathrm{XIII}^{\mathrm{e}} / \mathrm{XII}^{\mathrm{e}} \mathrm{s}$. et l'époque classique. Des indices pourraient éventuellement établir la réalité d'un culte funéraire: certaines tombes à fosse sont recouvertes d'un tas de pierres, interprété par l'archéologue comme un sema, à l'aide d'un vers d'Euripide (La folie d'Héraclès, 1332). Seule la tombe 66 offre des traces d'un dépôt de matière périssable.

A. Douzougli, $A D 49$ (1994) [1999], B'1, p. 367-370.

\section{Illyrie méridionale}

05.14-Apollonia-Mission épigrapbique et arcbéologique française en Albanie, Institut archéologique albanais - En 1999, les fouilles, commencées en 1993, au N du grand portique à niches découvert par L. Rey, se sont étendues à l'O, au $\mathrm{N}$ et à l'E, sous la direction de J.-L. Lamboley, B. Vrekaj et leurs collaborateurs, qui livrent les premiers résultats des travalix apolloniates dans une communication donnée lors du $\mathrm{III}^{\mathrm{e}}$ colloque sur L'Illyrie méridionale et l'Épire dans l'Antiquité. À l'E de la zone fouillée, en particulier dans l'éboulis de la rue E-O menant au plateau qui sépare. l'acropole de la " colline 104 ", de grands fragments d'architecture d'ordre corinthien ont été découverts - base de colonne, chapiteau, chéneau à tête de lion, etc. Ces éléments architecturaux n'appartiennent sûrement pas tous au même édifice, mais leur nombre augmente à chaque campagne, ce qui suggère l'existence d'un grand bâtiment au bord du plateau, qui pourrait être un temple. L'édifice serait alors l'indice d'un programme édilitaire datant de la pax augustea.

J.-L. Lamboley, B. VrekaJ, "Premiers résultats des fouilles franco-albanaises à Apollonia (1993-1996)", in L'Illyrie méridionale et l'Épire dans l'Antiquité III (supra 05.07), p. 189-203.

- Pour la nécropole tumulaire, à l'E et au SE de la ville, V. Dimo et $\mathrm{A}$. Fenet résument les interventions précédentes (tumulus I à V, par A. Mano; tumulus VI et VII par V. Dimo) et détaillent la fouille du tumulus VIII étudié par les A. en septembre 1996, dans l'espoir de la découverte d'une céramique proche de la date traditionnelle de la fondation de la cité des Apolloniates. V. Dimo et A. Fenet rappellent l'antiquité et la pérennité de la forme 
tumulaire des nécropoles dans ces régions, l'usage à la fois de l'incinération et de l'inhumation - plus courante, semble-t-il -, et le fait que la tombe la plus ancienne semble avoir été respectée. Coexistent aussi des sarcophages de calcaire de belle facture, des " constructions en briques et en tuiles », et de "simples fosses d'inhumation ". Les A. évoquent le probable caractère votif de certains dépôts de matériel non connectés à une tombe précise, mais restent prudents à propos d'un éventuel culte funéraire. Ces informations seront reprises bientôt dans le cadre d'une publication d'ensemble.

V. Dimo, A. Fenet, "Nouvelles recherches sur la nécropole tumulaire d'Apollonia", L'Illyrie méridionale et l'Épire dans l'Antiquité III (supra 05.07), p. 217-223.

- Sanctuaire péri-urbain de la colline de Shtyllas, dont est conservée la colonne en place d'un temple, à moins d'1 $\mathrm{km}$ au $\mathrm{S}$ de la porte méridionale d'Apollonia. F. Quantin résụme les mentions du temple par les voyageurs $d u x x^{e} s$. et les études des archéologues $\mathrm{du} \mathrm{xx}^{\mathrm{e}}$ s., donne une description des vestiges actuels et propose quelques pistes de recherche. La seule fouille fut celle de C. Praschniker, qui n'entreprend que des sondages limités. G. Pani, architecte de l'Institut des Monuments Culturels, donne en 1985 une restitution du temple, fondée sur une réflexion métrologique ("Tempulli në Shtyllas Përpjekje për formulimin arkitektonik", Monumentet [1985], 1, p. 79-85). Les dimensions de ce temple hexastyle sont précisées, ainsi que le nombre des assises de la krepis, grâce aux altitudes de quelques blocs en place et du soubassement de la colonne. Les tranchées de récupération des blocs du temple permettent de décrire le plan à pronaos. Parfaitement visible depuis le centre monumental d'Apollonia, le temple, que l'on peut situer à l'époque classique - voir le profil de l'échine et une palmette peinte -, appartenait sûrement à une divinité importante d'Apollonia, peut-être Artémis. L'hypothèse est fondée sur les témoignages de Cyriaque d'Ancône en 1436 et de F.-C.-H.-L. Pouqueville qui rapporte la découverte, en 1813, d'une «statue de Diane en marbre ».

F. Quantin, "Le sanctuaire de Shtyllas à Apoilonia d'Illyrie : bilan et perspectives de recherche", L'Illyrie méridionale et l'Épire dans l'Antiquité III (supra 05.07), p. 229237.

05.15 - Mallakastra (région d'Apollonia) - Institut archéologique albanais, Université de Cincinnati (Ohio) - J.L. Davis et M.M. Korkuti publient sur internet les rapports préliminaires des activités du « Mallakastra Regional Archaeological Project » en 1998, 1999 et 2000, dont l'objectif est d'établir une carte archéologique de l'occupation préhistorique et historique par une prospection intensive et une étude environnementale. Les différentes équipes ont découvert de nombreux sites ou zones de concentration, du Paléolithique à l'époque ottomane. La période hellénistique est bien représentée, en particulier par des fermes isolées. Aucun des trois rapports annuels ne signale un nouveau sanctuaire, ou ne formule une hypothèse dans ce sens. Des résultats intéressent néanmoins la topographie religieuse : le survey intensif mené dans le vallon de Kryegjata - nécropole au S et SE d'Apollonia - montre que la densité des vestiges est bien moindre en direction du temple de Shtyllas, et qu'il faut donc exclure l'hypothèse d'un habitat péri-urbain dans cette zone (Rapport 2000, p. 3); le temple ionique de Kryegjata vu par W.M. LEake (Travels in Nortbern Greece, Londres, 1835, vol. 1, p. 372-373) et étudié par C. Praschniker ("Muzakhia und Malakastra. Archäologische Untersuchungen in Mittelalbanien", JÖAI 21-22 [1922-1924], Beiblatt, col. 42-51) n'a pu être localisé (l.c., et p. 36); découverte d'un serpent en bronze bicéphale (SF 1892, Rupport 2000, p. 33, fig. 13) à Shën Marina dans la région d'Havaleas au N d'Apollonia; le temple de Shtyllas ne livre pas l'abondant matériel attendu, mais on remarque des concentrations aux environs.

J.L. Davis, M.M. Korkuti et al., Rapports 1998, 1999, 2000, "The Mallakastra Regional Archaeological Project: Internet Edition" : http://river.blg.uc.edu/MRAP. html. 


\section{Îles ioniennes}

05.16 - Corfou - VIII Éphorie des antiquités prébistoriques et classiques - Dans la zone méridionale de la ville antique de Corcyre (Phigareto), on a poursuivi la fouille d'un atelier céramique avec fours et dépotoirs, qui a permis la découverte de nombreuses statuettes féminines en terre cuite, dont certaines remontent à l'époque archaïque. Ces objets renforcent l'hypothèse d'un atelier de sanctuaire.

G. TouchaIs, BCH 122 (1998), Chron. p. 795-796.

- Au S de la presqu'île méridionale de la ville de Corcyre (Kanoni, terrain PourikiVellianiti-Artavani), près du monastère de la Panagia Kassopitras, K. Kanta-Kitsou a continué la fouille d'un grand édifice hellénistique, auquel est associé une canalisation, et signale la découverte près de l'entrée du bâtiment d'un fragment de "colonne " ou d'un «pilier» en calcaire appartenant peut-être à la seconde phase de construction. Le fragment est monolithe et son diamètre s'amenuise vers le haut (sans photographie). $\mathrm{K}$. Kanta-Kitsou estime que la colonne était primitivement dressée sur une base orthogonale découverte à côté d'un kouros archaïque, l'identifie comme le symbole du culte de l'Apollon Agyieus de Corcyre et évoque les parallèles d'Ambracie et d'Apollonia (sur l'agyieus en général, $c f$. V. Fenren'tz, "Der Antike Agyieus", JDAI 108 [1993], p. 123-19; sur

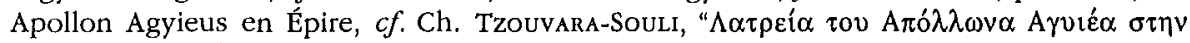
'H $\pi \varepsilon \imath \rho 0^{\prime}, \Delta \omega \delta \omega v \eta 13$ [1984], p. 427-442; pour l'exemplaire d'Apollonia, $c f$. H. MYRTo, "Konsiderata mbi obeliskun e Apolonisë", Monumentet 35 [1988-1], p. 81-86). Rappelons que le terrain Pouriki est situé à une centaine de mètres de l'église Agia Paraskevi où H. Lechat avait découvert en 1889 des milliers de figurines artémisiaques; le lieu est alors nommé le " petit sanctuaire d'Artémis » ( $c f . B C H 15$ [1891], p. 1-111, pl. X-VII, et K. KANTAKitsou, $A D 47$ (1992) [1997], B'1, p. 334-338). De ce terrain proviennent aussi le kouros archaïque mentionné ci-dessus ( $c f$. EAD., "Der Kuros von Kerkyra", MDAI(A) 111 [1996], p. 79-107), et une inscription en boustrophédon, très probablement incomplète : ПAN. Les lettres sont gravées sur le couvercle à double pente de la canalisation voisine; la forme des lettres est archaïque. $C f$. EAD., $A D 47$ (1992) [1997], B'1, p. 338, pl. $101 \delta$ pour une photographie de l'inscription in situ.

K. Kanta-Kitsou, $A D 49$ (1994) [1999], B'1, p. 421, fig. 4 pour le relevé des vestiges.

05.17 - Leucade, Phryni (grotte d'Asvotripa) - Ch. Tzouvara-Souli présente pour la première fois le matériel votif, composé essentiellement de figurines en terre cuite, découvert dans cette grotte de Leucade, connue depuis la fin des années cinquante. Parmi env. 225 statuettes et petits reliefs votifs datant de l'époque archaïque à la période hellénistique, on peut identifier des nymphes ( $c f$. Ch. Tzouvara-Souli, " $\Lambda \alpha \tau \rho \varepsilon i \alpha \tau \omega v$

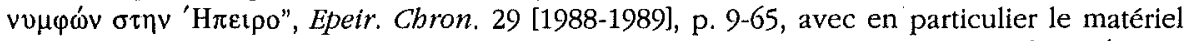
de la grotte de Koudounotripa dans la région d'Ambracie, et aussi EAD., $H \lambda \alpha \tau \tau \varepsilon i ́ \alpha \tau \omega \nu$

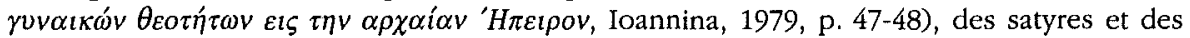
silènes ( $c f$. fig. 3 et 4 , p. 404, Musée de Leucade, inv. no 65 et 66), Hermès ( $c f$. deux Hermès criophores à la fig. 5, p. 405, Musée de Leucade, inv, $\mathrm{n}^{\circ} 146$ et 147) et Pan ( $c f$. fig. 6, p. 405, Musée de Leucade, inv, $\mathrm{n}^{\circ} 76$ ). L'A. étudie plus particulièrement un type, représenté par 84 figurines : les groupes en terre cuite façonnés à la main associant un chœur circulaire de femmes se tenant la main et un aulète au centre, en les comparant à des exemplaires de Corinthe, Corcyre, Céphalonie, Ithaque, Apollonia, etc. Ces figurines frustes sont organisées en un catalogue raisonné, décrites et datées par la recherche de parallèles. L'A. insiste sur le caractère corinthien de l'aire de diffusion régionale de ce culte aux Nymphes dans des grottes, et développe le thème de la danse de ces divinités rurales, bien attesté chez Homère lorsque les compagnons d'Ulysse se réveillent sur l'île du Soleil, avant de commettre leur crime irréparable (Od. XII, 318). 


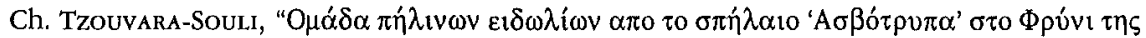
$\Lambda \varepsilon v \kappa \alpha ́ \delta \alpha \varsigma^{\prime}, \Delta \omega \delta \omega ́ v \eta$ 27-1 (1998) [1999], p. 371-436 (avec catalogue et 114 illustrations).

05.18 - Ithaque (grotte de Polis) - I. Malkin réexamine le lien entre Ulysse et Ithaque à partir des sources odysséennes et du matériel de la grotte de Polis, revenant sur les conclusions de C. Antonaccio (Ulysse n'est pas " cultuellement " présent à Polis avant l'époque hellénistique : An Archaeology of Ancestors, Lanham, 1995, p. 152-155), au profit de l'antiquité d'un lieu de culte à Ulysse, où les Grecs - Eubéens, Corinthiens et Achéens -, en route vers l'Occident, auraient reproduit la piété envers les Nymphes de leur héros en consacrant des trépieds en bronze dès le $\mathrm{Ix}^{\mathrm{e}} \mathrm{s}$. Ses arguments sont les suivants : a) la présence attestée d'Athéna Polias et d'Héra Teleia ne peut être alléguée pour reconstruire l'histoire du sanctuaire à haute époque - «visiting gods » conviendrait peut-être mieux que " additions" pour qualifier le statut des deux déesses (p. 101); b) rien ne nous contraint à situer à l'époque hellénistique l'association d'thaque et d'Ulysse, qui, comme le montre l'iconographie des monnaies insulaires (= de la cité d'Ithaque) du $\mathrm{IV}^{\mathrm{e}} \mathrm{s}$., est plus ancienne; c) le culte d'Ulysse à Ithaque est aussi bien attesté au $\mathrm{IV}^{\mathrm{e}} \mathrm{s}$. par Aristote, qui rapporte un aition qui suggère l'ancienneté de ce culte; d) l'inadéquation est flagrante entre la consécration de trépieds en bronze et le culte des Nymphes qui ne reçoivent pas ce type d'offrandes. Les Nymphes, en revanche, permettent d'expliquer la présence de nombreuses figurines féminines et de masques; cela suggère qu'existait une autre divinité à qui étaient destinés les trépieds, sans nier le caractère exceptionnel de ces offrandes, en particulier en contexte héroïque; e) il est par ailleurs improbable que les trépieds aient été offerts à une divinité olympienne, dont le lieu de culte est rarement une grotte, malgré les exemples crétois - monts Ida et Diktè, Amnissos - et arcadiens - grotte de Déméter Melaina; f) la quantité et la diversité typologique et chronologique des trépieds découverts n'engagent pas à considérer qu'ils furent déposés là lors du réaménagement du sanctuaire au $\mathrm{IV}^{\mathrm{e}} s_{\text {., }}$ que l'A. ne nie pas. En résumé, l'A. estime qu'Ulysse est dès l'origine honoré dans la grotte de Polis, qui est un sanctuaire local, de plus en plus fréquenté par les « traders / adventurers / explorers » en route vers l'Épire, Corcyre ou l'Italie.

I. Malkin, The Returns of Odysseus. Colonization and Ethnicity, Berkeley, 1998, en particulier chap. 3, "Ithaka and the Cult of Odysseus", p. 94-119 ( $c f$. le c.r. très complet de I. Papadopoulou-Belmehdi, Kernos 13 [2000], p. 289-294); ID., "Ithaka, Odysseus and the Euboeans in the eighth century", in M. BATs, B. D'Agostrno (éds), Euboica. L'Eubea e la presenza euboica in Calcidica e in Occidente, Atti del Convegno Internazionale di Napoli (13-16 novembre 1996), Naples, 1998 (CJB, 16. AION(ArCh), Quaderno 12), p. 1-10.

\section{Phthiotide, Thessalie (Polyxeni BouyIA)}

06.01 - Melitaia (Achaïe Phthiotide) - Une partie d'un bâtiment, daté du dernier quart du Iv ${ }^{\mathrm{e}}$ s. av. J.-C., comportant une stoa et des espaces implantés sur le rocher naturel a été associée au culte d'Asclépios grâce à la découverte d'une base inscrite $(\Theta \mathrm{E} \Omega \Delta \Omega \mathrm{PA}$

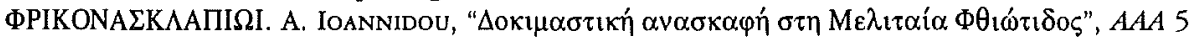
[1972], p. 47-57). D. Theocharis soupçonnait déjà l'existence d'un Asclépieion sur l'acropole de Thèbes de Phtiotide en raison de certaines trouvailles de surface ( $c f$.

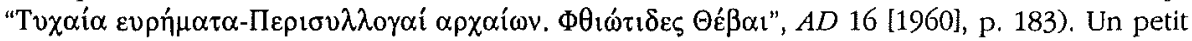
temple entouiré d'un péribole fut fouillé en 1991 et les objets qu'il a livrés (tête et torse appartenant à des statues d'Asclépios, statuette de la divinité, et stèles avec inscriptions) confirment l'identité de la divinité vénérée, alors que des monnaies en bronze attestent que ce sanctuaire était en activité du $\mathrm{Iv}^{\mathrm{e}}$ au ier $\mathrm{s}$. av. J.-C.

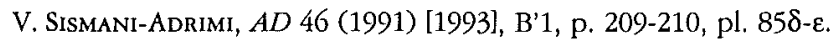


06.02 - Mitropoli - XIII ${ }^{e}$ Épborie des antiquités prébistoriques et classiques B. Intzesiloglou présente un premier rapport de fouille consacré au temple archaïque d'Apollon, situé à $2 \mathrm{~km}$ à l'O de l'agglomération de Mitropoli, dans la province de Karditsa, ainsi qu'à la découverte d'une statue de culte dans la cella de ce bâtiment. Cette fouille (1994-1997) ainsi qu'une description préliminaire du bâtiment et de la statue font l'objet de deux fascicules, l'un destiné aux instituteurs, et l'autre aux élèves d'école primaire. Ils ont été réalisés par le fouilleur et publiés à Volos dans le cadre du programme éducatif "Melina. Le monde de l'antiquité ». Le temple fut fondé un peu avant le milieu du $\mathrm{vI}^{\mathrm{e}} \mathrm{s}$. av. J.-C. Il fut en activité durant tout le $\mathrm{IV}^{\mathrm{e}} \mathrm{s}$, av. J.-C., - époque à laquelle Peithôla fille de Pharakidas a érigé un chien en bronze dans le naos - et fut détruit par un grand incendie au $\mathrm{II}^{\mathrm{e}} \mathrm{s}$. av. J.-C. Le bâtiment présente une largeur de $13,75 \mathrm{~m}$ et s'ouvre, sur son petit côté, vers l'E. D'après la longueur qui subsiste $(30,68 \mathrm{~m})$, il pourrait s'agir d'un temple bekatompedon. Il possédait cinq colonnes doriques (reconstituées) sur les petits côtés et onze sur les longs, d'une hauteur de $4,30 \mathrm{~m}$. Les cinq bases en pierre qui se trouvent à l'intérieur de la cella (sur sa longueur) attestent l'existence de piliers ou d'une colonnade, qui devaient soutenir le toit en double pente, comme en témoignent les tuiles faîtières. Bien que l'échine des chapiteaux qui ont subsisté présente les mêmes motifs ornementaux, une alternance de fleurs de lotus ouverts et fermés, la courbe et la composition de ces éléments varient d'un exemplaire à l'autre. Le fouilleur préfère voir dans cette variation le témoignage de la réalisation successive de ces chapiteaux, qui auraient remplacé au fur et à mesure les premiers éléments en bois, à l'instar d'une pratique observée au temple d'Héra à Olympie. L'A. considère également, et avec raison, que l'entablement devait être en bois car aucun élément en pierre n'en a été retrouvé. Les quelques fragments de sculptures en terre cuite indiqueraient l'existence d'acrotères. La sima et l'architrave étaient décorées. Dans la couche de destruction, on a découvert des tuiles estampillées, portant les noms de Philleos ou Kleomachos, et des tuiles d'époque archaïque, appartenant au premier toit, attestant ainsi les nombreuses réfections que ce temple avait dû subir. Ce toit était couvert de tuiles corinthiennes. Les murs sur la longueur du naos avaient été construits en poros jusqu'à la hauteur des orthostates. $\AA$ un moment, la partie arrière du naos fut isolée par un mur de séparation pour créer l'adyton du temple. C'est à cet endroit que l'on conservait les objets de culte et où avaient peutêtre lieu des pratiques cultuelles, comme en témoignent un larnax en terre cuite et une amphore pour libations. À l'intérieur de la cella, on a trouvé des fragments de stèles et de bases, de figurines en terre cuite, de la céramique et des objets liturgiques. Dans cet espace, on a placé deux bancs et on a étendu en largeur le podium de la statue de culte. Cette statue mesure $0,802 \mathrm{~m}$ et fut découverte, en pièces, sur et autour du podium. Elle est datée du milieu du $v^{e}{ }^{e}$ s. av. J.-C. et fut abattue au moment de la destruction du temple au $\mathrm{II}^{\mathrm{e}}$ s. av. J.-C. Elle représente Apollon, sous la forme d'un.hoplite, à la manière d'un kouros archaïque. Le dieu porte un casque, une armure, des jambières et des protections pour les bras. La main droite, levée, brandissait une lance, alors que la gauche, aujourd'hui disparue, devait tenir un arc.

Soulignons d'emblée l'importance du bâtiment et de la statue pour l'histoire de l'architecture, de la sculpture mais aussi de la religion. On peut appliquer ici ce que notait R. Felsch au sujet du plus petit temple dans le sanctuaire d'Artémis Elaphebolia à Kalapodi ("Kalapodi. Bericht 1978-1982", AA 102 [1987], p. 24) : "Zunächst vermehrt er unsere Kenntnis der frühen dorischen Tempel um einen weiteren Bau, der typologisch in der Lücke zwischen den Tempeln mit hölzerner Peristase, wohl aus dem ersten Viertel des 6. Jhs. und den voll entwickelten Steintempeln der Mitte des 6. Jhs. Zu stellen ist. Gegenüber allen anderen dorischen Tempeln dieser Zeit besitzt er den Vorteil, dass er durch stratigraphische Befunde recht genau, etwa in der Zeit $570-560 \mathrm{v}$. Chr. datiert ist. Er bietet demnach einen festen Anhaltspunkt für die Datierung auch anderer Tempel oder einzelner Bauglieder bzw. Dachterrakotten ». La petite taille de ce temple ne peut cepen- 
dant pas être comparée à celle du temple de Kalapodi. Par ailleurs, certains éléments du grand temple, situé plus au $\mathrm{N}$ dans le sanctuaire de Kalapodi, seraient plus proches de ceux du temple de Mitropoli. Ce dernier possède en effet un adyton, des fûts en bois décorés de canaux obliques, des chapiteaux avec des décors variés sur l'échine et des tuiles corinthiennes (voir R. FeLsch et al., "Apollon und Artemis oder Artemis und Apollon? Bericht 1873-1977", AA 95 [1980], p. 73-78; AA 102 [1987], p. 19-21). Ces similitudes et ces variations dans l'architecture confirment la thèse de $D$. Mertens selon qui la construction des temples dans les grands centres durant la $1^{\text {re }}$ moitié du $\mathrm{vI}^{\mathrm{e}} \mathrm{s}$. av. J.-C., sans ignorer celle dans les sanctuaires panhelléniques, évolue de manière dynamique et indépendante (D. MERTENS, "Die Entstehung des Steintempels in Sizilen", Säule und Gebalk. Discussionen zur Archäologischen Bauforschung 6 [1996], p. 25-38).

La statue de culte de Mitropoli appartient à la catégorie des petites statues cultuelles ou votives de la tradition archaïque, au même titre que l'Apollon de Dreros (h. : $0,80 \mathrm{~m}$, daté de la fin du viII ${ }^{\mathrm{e}}$ - milieu viI ${ }^{\mathrm{e}}$ s. av. J.-C., I.B. Romano, "The Dreros Sphyrelata: a reexamination of their date and function", JRA, suppl. 39 [2000], p. 40-50), la statuette d'Apollon en bronze, dédiée par Mantiklos de Thèbes (h.: $0,20 \mathrm{~m}$, datée du $1^{\text {er }}$ quart du $\mathrm{viI}^{\mathrm{e}}$ s. av. J.-C., C. Rolley, La sculpture grecque I, Paris, 1994, p. 129, fig. 109) ou la statuette d'Apollon en bronze (h. :0,106 m) trouvée à l'autel d'offrandes, formé sur les ruines du temple N de Kalapodi, après sa destruction par les Perses en 480 av. J.-C. (R. FLESCH, $A A 95$ [1980], p. 90-99).

Le culte d'Apollon hoplite à Mitropoli pourrait remonter à l'époque Subgéométrique, si on liait cette statue aux deux statuettes cultuelles en bronze de cette époque représentant des guerriers, produites par des ateliers locaux et découvertes anciennement dans la région (H. BIEsantz, Die thessalischen Grabreliefs, Mayence, 1965, p. 33 n $^{\circ} 78-79$, pl. 55 , 142). Le culte de cette divinité devait être encore important au début du $\mathrm{IV}^{\mathrm{e}} \mathrm{s}$. av. J.-C., comme le montre le monnayage contemporain de Mitropoli, qui porte au revers le dieu comme Musagète, mais non comme hoplite (A. MousTaKA, Kulte und Mythen auf thessalischen Münzen, Würzburg, 1983 [Beiträge zur Archäologie, 15], p. 37). Par ailleurs, de nombreux témoignages archéologiques lient Apollon à la Thessalie. Des temples qui lui sont consacrés ont été retrouvés à Larissa (Apollon Kerdoios, Apollon Pythien, F. Salviat, Cl. Vatin, Inscriptions de Grèce centrale, 1971, p. 8-34; P. Franke, "Népov,

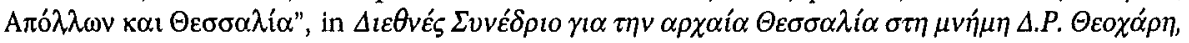
$A D 48$ [1992], p. 372), à Elassona (Apollon Lykeios), à Tebè (Apollon Pythien) et à Kranona (Apollon Proernios, D. TheocharIs, AD 16 [1960], p. 175, 181-182).

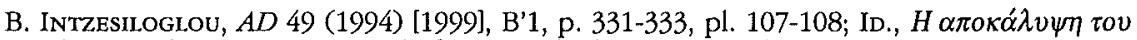

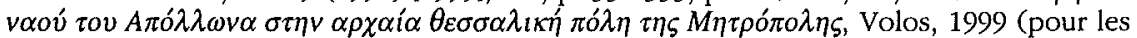

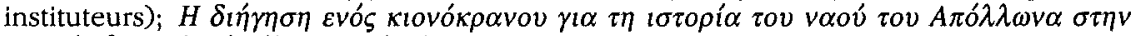

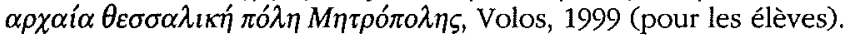

06.03 - Trikala - Asclépieion de l'antique Trikkè - Dans un article, N. Ballas examine la survivance du culte d'Asclépios à travers celui des saints Anargyres, Cosme et Damien, à Trikala. Après un bref survol des témoignages littéraires et des fouilles archéologiques effectuées entre la rive gauche du fleuve Léthaios et la colline de «Kastro », à l'emplacement où l'on situe l'Asclépieion de l'antique Trikkè, l'A. évoque les méthodes thérapeutiques d'incubation pratiquées dans le sanctuaire miraculeux des deux saints. L'église qui leur est consacrée est de plan basilical, bâtie en 1570 (ou 1575), au $N$ d'un îlot qui comportait des restes architecturaux, apparemment liés au culte d'Asclépios pendant la période gréco-romaine. Selon N. Ballas, L. Deubner avait déjà démontré que ces deux saints avaient remplacé, à l'époque byzantine, le culte des Dioscures, Castor et Pollux

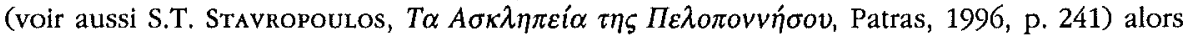
qu'en Thessalie, ils pourraient s'assimiler aux fils d'Asclépios, Podalire et Machaon. Il faut également ajouter que, depuis le $\mathrm{v}^{\mathrm{e}}$ s. ap. J.-C., chaque fois que des ordonnances impé- 
riales interdisent le culte païen, des éléments iconographiques propres à Asclépios peuvent se reconnaître dans les représentations du Christ tandis que l'incubation est liée aux saints Anargyres (voir B. Holtzmann, LIMC II.1 [1984], s.v. Asclépios).

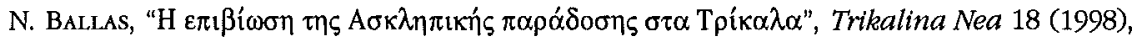
p. $159-168$.

- Sp. Bonoti traite, pour sa part, de la mythologie relative à Asclépios et aux pratiques thérapeutiques appliquées par les médecins de l'Antiquité (les Asclépiades); il mentionne brièvement les fouilles archéologiques qui ont eu lieu à l'Asclépieion de l'antique Trikkè. Les trouvailles des fouilles plus anciennes sont, quant à elles, présentées dans deux articles, de L.K. Makri et K. Galli.

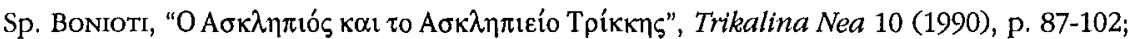

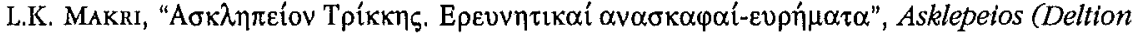

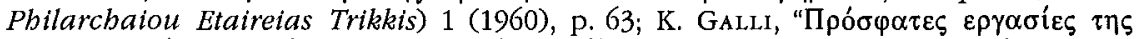

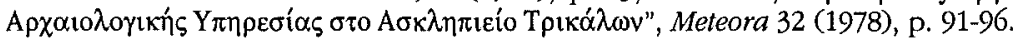

- Ath. Tziaphalias, qui a récemment publié un rapport sur les progrès de la fouille de l'Asclépieion et une vue du site, avait déjà tenté de faire l'historique des travaux archéologiques et de proposer une interprétation des découvertes. Dans un article plus ancien, l'A. attribuait au sanctuaire un ensemble de bâtiments fouillés : des bains du ${ }_{I I I}{ }^{\mathrm{e}} \mathrm{s}$. ap. J.C., avec réfections de la fin du Iv ${ }^{\mathrm{e}} \mathrm{s}$.; une partie de péristyle appartenant à une cour de galets et bordée d'un portique sur son long côté NO; un ensemble de pièces longeant cette cour et datées de la $1^{\text {re }}$ moitié du $\mathrm{I}^{\text {er }} \mathrm{s}$. ap. J.-C. Ces dernières furent restaurées et décorées de mosaïques au $2^{e}$ quart du $\operatorname{sil}^{\mathrm{e}} \mathrm{s}$. ap. J.-C. La présence de Dionysos sur une de ces mosaïques indiquerait, selon le fouilleur, la pratique d'un culte mystique bacchique dans ces pièces. Pour l'A., la cour à péristyle pourrait appartenir au Gymnase de Trikkè, hypothèse plausible, si on localise l'Asclépieion, qui occupe une place centrale dans l'ancienne cité, sur l'agora de la ville. Le fouilleur mentionne, par ailleurs, un parallèle proche : l'« Asclépieion " de l'agora de Messène. L'identification de cet endroit à l'agora de la ville est vraisemblable si l'on considère que, depuis l'époque hellénistique, des purifications, des sacrifices, des rites incubatoires mais aussi des bains, l'emploi de plantes médicinales et de crèmes, la pratique du jeûne et de la marche complétaient des cérémonies, des processions, des courses à pied, des récitations et des représentations théâtrales sans relation directe avec un Asclépieion. D'autre part, le fait que, selon Strabon, l'Asclépieion de Trikkè serait le plus ancien et le plus fameux, pourrait justifier le développement d'un tel sanctuaire au cœur de la ville. Il faut cependant noter que l'identification du complexe architectural de Messène à un Asclépieion est remise en question par F. FELten, "Heiligtumer oder Markte", AK 26 (1983), p. 84-105. Les fouilles récentes semblent également montrer que cet ensemble fut le centre politique de la ville plutôt qu'un Asclépieion (D. Damaskos, Untersuchungen zu bellenistischen Kultbildern, Stuttgart, 1999, p. 49). Par ailleurs, les trois Asclépieia les plus fameux et les mieux fouillés,

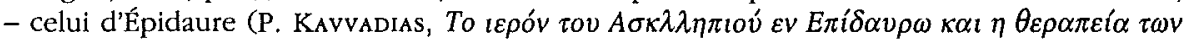

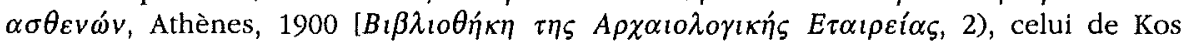
(P. Schatzmann, "Asklepieion: Baubeschreibung und Baugeschichte", in R. Herzog (éd.), Kos: Ergebnisse der deutschen Ausgrabungen und Forschungen I, Berlin, 1932; G. GRUBEN, Die Tempel der Griechen, Munich, 1976, p. 401-410) et celui de Pergame (Altertümer von Pergamon VIII [1968]; XI 1-4, [1969-1984]) -, sont installés et ont fonctionné loin des villes du même nom. Seule la continuation des fouilles pourra donc nous éclairer sur l'évolution architecturale - et, notamment, sur les premières phases (au moins d'époque archaïque) - de l'Asclépieion de Trikkè.

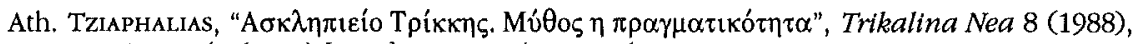
p. 171-218; $A D 48$ (1993) [1998], B'1, p. 249-250, pl. 1. 


\section{Macédoine (Kalliopi ChatziniKolaou et Emmanuel Voutiras)}

\subsection{0 - Gênéralités}

- S. Pingiatoglou étudie le culte de Déméter dans la Macédoine antique. Pausanias fournit seulement l'indication de l'importation du culte de la déesse depuis Thasos. W. Baege a identifié les attributs de la déesse sur des monnaies de Chalcidique, Pella et Thessalonique. La présence du culte de Déméter est attestée par des inscriptions à Dion, Letè, Thasos et Mesembria (Thrace). Différentes trouvailles archéologiques indiquent que la déesse recevait aussi un culte à Béroia, à Pella, dans la région d'Anthémonte, à Kalindoia, à Amphipolis, à Abdère et à Thessalonique, où son culte pourrait avoir été lié à celui de Kabeiros (probablement en tant que Déméter Kabeiraia ou Kabeiria). Un relief votif de Macédoine conservé au Musée National d'Athènes (inv. $n^{\circ} \mathrm{AE}$ 1438) représente Déméter Karpophoros. Des statuettes en marbre représentant Déméter, Korè, des prêtresses ou des dédicants, de même que des figurines en terre cuite représentant des femmes ou des animaux (porcs), et des ustensiles de petite dimension (hydries, kernoi, lampes utilisées dans les cérémonies mystiques et les rituels de purification) étaient dédiés à Déméter. Dans certains sanctuaires de Déméter coexistent les cultes d'autres divinités comme Aphrodite, Ilithyie, Baubô (à Dion), Artémis, Athéna, Pluton (à Pella), les dieux Patrôoi (à Thasos), Cybèle et la Mère des dieux (à Samothrace). Déméter était honorée en tant qu'Eleusinia et Thesmophoros à Pella et à Thasos, et comme déesse des mystères à Mesembria (Thrace). L'influence du culte éleusinien est probable. Les sanctuaires de Déméter sont situés dans des endroits à la charnière entre la campagne et le centre urbain, habituellement sur des flancs montagneux. La déesse était aussi considérée comme protectrice des fortifications. Son culte est attesté entre la fin de la période archaïque et l'antiquité tardive (IV s. ap. J.-C.).

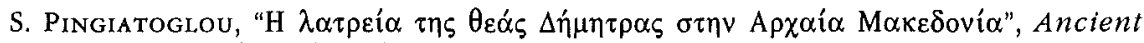
Macedonia VI, vol. 2, Thessalonique, 1999, p. 911-919.

- Discussion des cultes de la haute-Macédoine (Macédoine occidentale), fondés sur le panthéon grec, de même que sur les croyances locales et les pratiques rituelles mystériques. D'après les A., la haute-Macédoine était une région particulière, à la population agricole, avec peu de centres urbains et une structure sociale très conservatrice. Peu de monuments indiquent l'existence du panthéon olympien et des divinités importées depuis l'Orient et l'Égypte. Les A. envisagent trois cas particuliers : a) le culte de Pluton, dont le sanctuaire peut être situé à Aianè (Elimeia), où il s'est substitué à un Asclépieion selon une inscription votive du $\mathrm{II}^{\mathrm{e}} \mathrm{s}$. ap. J.-C. trouvée sur le site; b) la coexistence des cultes d'Héraclès et d'Enodia, qui apparaissent comme les dieux garants des affranchissements (après le $\mathrm{i}^{\mathrm{er}} \mathrm{s}$. av. J.-C.); c) le culte d'Alexandre le Grand, qui apparaît assez tardivement ( $1^{\text {re }}$ moitié du III $^{\mathrm{e}} \mathrm{s}$, ap. J.-C.) et seulement en Lynkestide, la partie $\mathrm{N}$ de la province. Il est en relation avec le culte de Zeus et d'Héra et, dans certains cas, lié à la représentation de deux démons en forme de serpents (Drakon-Drakaina). Des reliefs votifs de Lynkestide montrent Alexandre entre les dieux nommés ci-dessus.

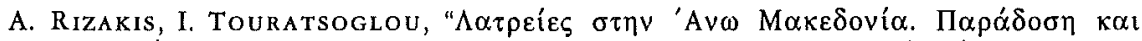

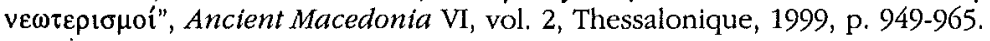

- F. Felten étudie les temples élevés par les rois macédoniens, surtout ceux qui ne sont pas situés en Macédoine.

F. Felten, "Heiligtümer der Makedonen", Ancient Macedonia VI, vol. 1, Thessalonique, 1999, p. 405-417. 
07.01 - Stobi - Discussion du culte impérial et du culte de Némésis à Stobi à l'époque impériale. Mention du sanctuaire de Némésis situé dans cette cité. La déesse était vénérée en tant que protectrice des gladiateurs et des participants à des spectacles de toutes sortes.

J. Wiseman, "Deus Caesar and other gods at Stobi", Ancient Macedonia VI, vol. 2, Thessalonique, 1996 [1999], p. 1359-1370.

07.02 - Kastoria - XVII Éphorie des Antiquités prébistoriques et classiques - Au lieu-dit "Dailaki ", au $S$ de Kastoria, un "bronze macédonien " représentant une chèvre sauvage sur une cage, trouvé en 1997 dans une tombe des débuts de l'Âge du Fer, pourrait, selon l'A., avoir une valeur symbolique ou magique.

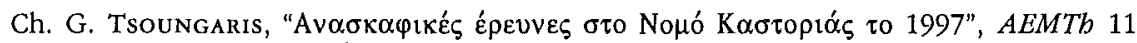
(1997) [1999], p. 25 et n. 36, p. 30 fig. 8.

- Au lieu-dit « Psalida » ou "Megalexandros », des travaux publics ont révélé, en 1997, un sanctuaire de sommet des débuts de la période romaine, à l'O de Kastoria. La fouille qui a suivi a mis au jour quelques fragments de reliefs votifs représentant Zeus en tant qu'Hypsistos, Héra et Hermès.

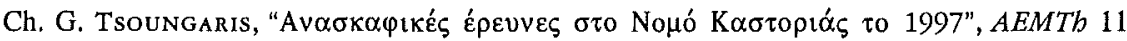
(1997) [1999], p. 27-28, 30 fig. 11-14.

07.03 - Panagia (anciennement «Torniki » ou « Melisko ») - Mention de restes des fondations d'un ancien temple de grande dimension sur le site du Prophète Élie.

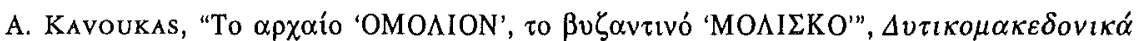
Гра́ $\mu \mu \alpha \tau \alpha 1$ (1999), р. 99.

07.04 - Volon [mont] - G. Karamitrov-Mentessidi a publié les résultats d'un large survey de la région du mont Voion dans l'Orestide méridionale. Voici ce qui relève directement de notre propos :

1) Liknades - La partie inférieure d'une statue féminine ( $2^{\mathrm{e}}$ moitié du $\mathrm{v}^{\mathrm{e}} \mathrm{s}$. av. J.-C.) provient du site de "Gortsia » ou "Diakladose ». Elle a été déposée à la XVII Éphorie des antiquités préhistoriques et classiques (inv, $n^{\circ}$ BEK 1508). Selon l'A., le site indique une zone de sanctuaires. Hécate ou Enodia était honorée dans l'un d'entre eux. Le site est un carrefour encore aujourd'hui (p. 153 et n. 484, p. 202, 345, fig. 69) - Un buste en marbre de Poséidon provient du site de "Kalogeros " et un buste d'Hermès du site d'« Ampeli tou Kampana ». Malheureusement, tous deux sont aujourd'hui perdus (p. 201202) - N. Papadakis avait déjà mentionné parmi les trouvailles d'une tombe creusée dans la roche sur le versant de « Agia Aikaterini " un relief en pierre représentant Déméter tenant une serpe $(\Delta \eta \dot{\eta} \mu \eta \tau \rho \alpha \Delta \rho \varepsilon \pi \alpha v \eta \varphi o ́ p o \varsigma)$, transporté à Constantinople (p. 199) - Une stèle en marbre représentant une triple Hécate provient du site de "Bachtsedia " (inv. $n^{\circ}$ BEK 3225) (p. 201, 346, fig. 71) - Une statue en bronze représentant Héraclès provient du site de «Kopatsia ». L'A. suppose que le site, et surtout la zone entre les terrains de St. Nasiopoulos et A. Bouzopoulos, pourrait avoir été une aire de sanctuaires (p. 200 et n. 605, p. 201).

2) Eratyra (anciennement lieu-dit de "Selitsa »). La hauteur (magoula) d'Eratyra est identifiée comme une zone de fortification, de bâtiments publics et de sanctuaires (p. 288) - Une figurine en terre cuite décrite comme le buste d'une Nikè et portant une inscription en latin provient de la fouille conduite par A. Keramopoulos (p. 192 et n. 585).

3) Loukomi. Les restes d'un bâtiment rectangulaire ont été localisés sur la hauteur de "Agios Nikolaos ». D'après D. Samsaris, ils appartiennent à un sanctuaire (p. 204, n. 618).

4) Xerolimni (anciennement lieu-dit "Sachnilar »). Le torse d'une statuette en marbre, portant un chiton, un himation et une large ceinture sur la poitrine (inv. $n^{\circ}$ BEK 2864) et un relief en marbre fragmentaire représentant un homme habillé de la même manière 
(inv. $\mathrm{n}^{\circ}$ BEK 2865) proviennent du site de «Porta » ou «Portes ». L'A. considère que les fragments représentent Apollon Citharède et fait l'hypothèse d'un sanctuaire situé dans la zone entre les monts Askio et Vourinos. Elle fait également référence à une inscription votive provenant du site (p. 213, 356 fig. 91-92; pour l'inscription : p. 213 et n. 636, p. 355 fig. 90).

5) Platania (anciennement "Boubousti »). L'A. situe un établissement des périodes hellénistique et romaine avec, au moins, un bâtiment public (sanctuaire?) - Elle situe aussi les restes d'un sanctuaire présentant une continuité de culte sur la hauteur de "Agios Theodoros " - Une statuette d'Asclépios provenant du site voisin d'« Anana » pourrait signifier l'existence d'un sanctuaire à cet endroit. Elle a été déposée à la XVII Éphorie des antiquités préhistoriques et classiques par G. Kotaidis (p. 226, 368 fig. 114, p. 370 fig. 117).

6) Mavropigi - Mention de la destruction de sanctuaires dans l'établissement du site de « Kastro » (p. 255).

7) Choregos (anciennement "Chorevos »). Mention d'une statuette votive d'aigle datée de l'époque romaine (inv, $\mathrm{n}^{\circ} 847$ ) et liée au culte de Zeus Hypsistos. L'A. suppose l'existence d'un bâtiment monumental (p. 248-249).

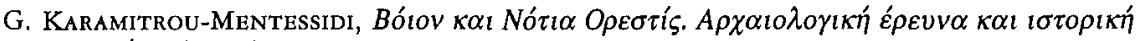

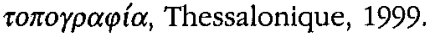

07.05 - Velvendo (Kato Brava) - XVIIe Éphorie des antiquités prébistoriques et classiques - On a trouvé en 1997, près du lac artificiel de Polyphyto, des restes architecturaux, quatre grandes fosses de dépôt contenant des figurines féminines en terre cuite, des encensoirs de culte en terre cuite et une lampe comparable à celles que l'on utilise dans les sanctuaires (p. 62 et n. 10-11), le tout daté de l'époque hellénistique. Selon l'A., cela fait partie du site d'un sanctuaire lié au culte de Zeus Hypsistos et probablement en relation avec les sources sulfureuses naturelles aux vertus curatives localisées dans la zone.

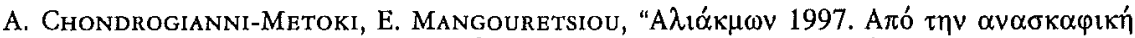

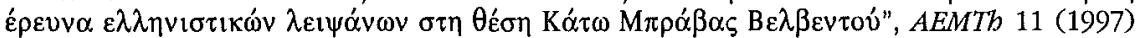
[1999], p. 58-63, 66; fig. 4-9.

07.06 - Rizomata (Paliochora) - XVII Éphorie des antiquités prébistoriques et classiques - Les A. prétendent avoir localisé en 1997 un ensemble de sanctuaires sur le site de "Paliochora » près du village de Rizomata, où des reliefs fragmentaires de l'époque hellénistique avaient été découverts auparavant. Un relief votif mis au jour juste à l'E, représentant un bœuf et portant l'inscription [I]EPO $\mathrm{A \Pi O \Lambda \Lambda [ \Omega NO \Sigma ]} \mathrm{indique} \mathrm{l'existence}$ d'un autre sanctuaire.

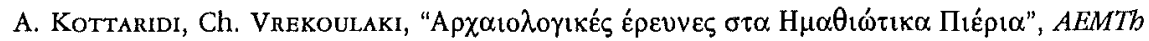
11 (1997) [1999], p. 109-110.

07.07 - Beroia - Réexamen du bouclier monumental, interprété comme une représentation d'un trophée de champ de bataille ou comme un monument guerrier. Selon l'A., son érection relève de l'action de grâce et de la dédicace nécessaires à Zeus Tropaios.

M.M. Markle, "A shield monument from Veria and the chronology of Macedonian shield types", Hesperia 68 (1999), p. 219-254, spéc. p. 241.

07.08 - Vergina - Université Aristote de Thessalonique - La fouille du sanctuaire de la Mère des dieux de l'ancienne Aigai, en 1997, s'est poursuivie du côté O de la zone, au N de la double chambre, où une cour avait été mise au jour, ainsi qu'une structure ressemblant à un fourneau, qui n'a pas livré de trouvailles significatives. Des fragments de figurines en terre cuite ont été trouvées dans la zone, dont des représentations d'Aphrodite tenant Éros et de la Mère des dieux. Les petites pièces du côté $S$ du sanctuaire, à l'E 
de la grande chambre double, ont livré d'intéressants groupes de figurines en terre cuite, dont des représentations d'Aphrodite, Cybèle, Déméter et des bustes ou des masques figurant Dionysos-Bacchus ou Pan. Selon l'A., ce dernier est étroitement associé au culte de la Mère des dieux. Elle fait également le lien entre les canthares de tous types trouvés dans le sanctuaire et la présence de Dionysos qui est en rapport avec le culte principal du Metrôon.

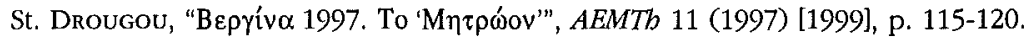

- A. Kottaridi pense que les pyrai funéraires trouvées sur les tombes royales du Grand Tumulus de Vergina indiquent l'existence d'un culte des morts.

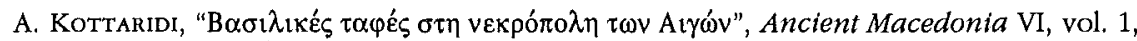
Thessalonique, 1996 [1999], p. 631-642.

07.09 - Pella - XVII Éphorie des antiquités prébistoriques et classiques - Un groupe de bâtiments publics entourant le sanctuaire du héros guérisseur local Darron peut être mis en rapport avec lui.

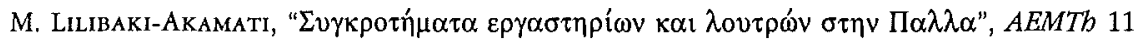
(1997) [1999], p. 201.

- Discussion du sanctuaire de la Mère des dieux et d'Aphrodite localisé à Pella. Le complexe des bâtiments du sanctuaire, situé au centre de la cité, a connu deux phases de construction, l'une à la fin du Iv ${ }^{e}$ av. J.-C., l'autre à la fin du II $^{c}$ s. av. J.-C. Un temple de dimension assez modeste, reconstruit au moins deux fois, était le centre du culte au cours des deux phases. Un grand nombre de figurines en terre cuite représentent surtout Aphrodite à demi nue ou portant des sandales, la Mère des dieux, selon un type rappelant la statue du Metrôon de l'Agora d'Athènes, Athéna portant un casque avec cornes (peut-être en tant que patronne des bœufs), des Érotes et Éros avec Psychè. Il y a aussi un nombre de figurines féminines en terre cuite, des représentations de silènes et de satyres, de petits autels en terre cuite ou en pierre, des stèles votives en pierre représentant la Mère des dieux et la base d'une statue votive d'Aphrodite portant une inscription. Selon l'A., l'existence d'ateliers dans la zone du sanctuaire, pour la fabrication et la vente d'objets votifs, est très probable. Le sanctuaire doit avoir eu une grande importance à l'échelle locale. Aphrodite était honorée comme Pandemos et son culte était probablement en relation avec celui de la Mère des dieux. L'A. suggère que les deux cultes ont existé côte à côte, comme peut l'indiquer le partage d'un sanctuaire commun.

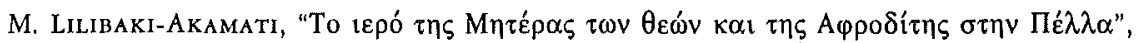
Ancient Macedonia VI, vol. 1, Thessalonique, 1996 [1999], p. 691-704.

- Dans le terrain de B. Savidis, on a repéré, lors de la fouille de sauvetage d'une basilique paléochrétienne, des fragments de reliefs votifs emmurés (ni reproduits, ni décrits) et une colonne aniconique qui, selon l'A., pourrait appartenir aux monuments votifs des périodes hellénistique et romaine, ou au temple du culte impérial.

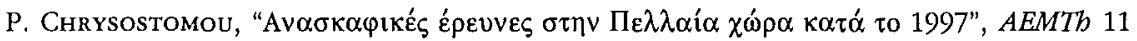
(1997) [1999], p. 219, 229, 230; fig. 3.

07.10 - Pella, agora - Université Aristote de Thessalonique - Le puits de la zone 10, dans la stoa E de l'agora de Pella, fouillée en partie, a livré en 1997 quelques figurines fragmentaires en terre cuite et des moules en terre cuite pour des figurines représentant des divinités, surtout la Mère des dieux et Éros, tous datés de la fin du $\mathrm{II}^{\mathrm{e}} \mathrm{s}$. av. J.-C.

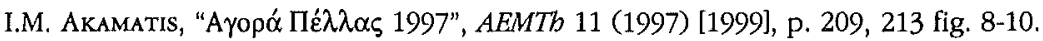

07.11 - Dion - Université Aristote de Thessalonique - La fouille dans le sanctuaire de Déméter en 1997 a contribué à l'interprétation de son architecture et mis au jour des fragments de figurines en terre cuite, des statuettes en marbre et un fragment d'inscrip- 
tion votive à Apollon et Artémis. Dans le sanctuaire d'Isis, des restes de constructions antérieures ont été trouvés sous le sol de la cella et du pronaos.

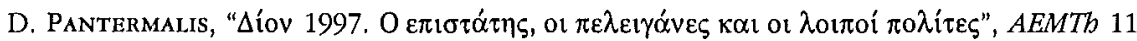
(1997) [1999], p. 233-240.

07.12 - Anchialos - Université Aristote de Thessalonique - La fouille du plateau inférieur en 1997 a achevé l'investigation des bâtiments de la période géométrique. Des zones « de dévotion » (selon les termes des A.) provient un ustensile " de cérémonie », avec des manches terminés par des disques, et une double hache "de cérémonie ».

M. Tiverios, A. Panti, F. Seroglou, A. Avramidou, K. lachanidou, M. Oetthi,

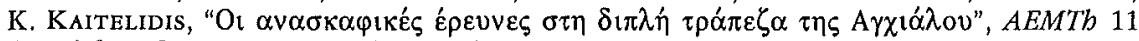
(1997) [1999], p. 300, 302, 304; fig. 3-4.

07.13 - Thessalonique (intra muros) - XVTe Éphorie des antiquités prébistoriques et classiques - La partie supérieure droite d'un pilier figurant la tête d'une Nikè et une aile fragmentaire ont été mises au jour dans la rue Rogoti (près du carrefour avec la rue Tsimiski) durant des travaux d'installation d'une conduite de gaz en 1997. Selon les fouilleurs, le fragment pourrait appartenir à la colonnade du monument des «Incantadas » conservé au Musée du Louvre.

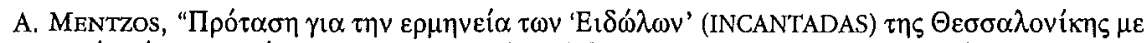

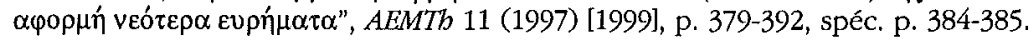

- Un examen de la documentation, surtout épigraphique et statuaire, touchant au culte d'Aphrodite à Thessalonique montre que la déesse, honorée comme divinité de l'Amour, mais aussi en tant qu'Homonoia et Epiteuxidia (probablement proche de l'Euploia), était relativement populaire à l'époque romaine. Nombre d'indices invitent à affirmer qu'Aphrodite était une déesse locale importante dans la région du golfe thermaïque depuis des temps très anciens, avant la fondation de Thessalonique. Selon une tradition déjà connue d'Hellanikos de Lesbos, la ville d'Aineia, située sur un promontoire au $\mathrm{S}$ de la cité, avait été fondée par Énée fuyant Troie après sa destruction par les Achéens. C'était une tradition locale ancienne, si l'on en croit un type monétaire frappé à Aineia dans le $1^{\text {er }}$ quart du $v^{e} s$. av. J.-C. et montrant Énée quittant Troie en portant son père Anchise sur les épaules, accompagné de sa femme et d'un enfant. Denys d'Halicarnasse mentionne l'existence d'un temple d'Aphrodite qu'Énée lui-même aurait fondé sur le promontoire d'Aineia. Aineia fut intégrée au territoire de Thessalonique quand Cassandre fonda sa cité par synœcisme. On peut dès lors affirmer que le culte d'Aphrodite à Thessalonique remonte à cette tradition. Il est possible que les parties en marbre d'un temple archaïque tardif trouvé à Thessalonique, qui porte des marques de pose du Haut-Empire, appartiennent en fait au temple d'Aphrodite d'Aineia. Les « temples itinérants " (selon l'expression d'H.A. Thompson) démontés puis remontés dans le centre civique d'une ville sont surtout connus pour l'Attique. Le temple d'Aineia pourrait avoir été "déménagé " à Thessalonique sous Auguste, en relation avec la construction d'un temple dédié au divin César, connue par une inscription. C'eût été particulièrement approprié, puisque Jules César se considérait comme un descendant d'Énée et d'Aphrodite.

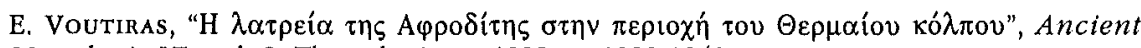
Macedonia VI, vol. 2, Thessalonique, 1999, p. 1329-1343.

07.14 - Stagire - Mention de l'existence de deux sanctuaires archaïques. Un autel, des figurines en terre cuite de grande dimension, des fragments de reliefs et d'inscriptions datées du $\mathrm{vI}^{\mathrm{e}} \mathrm{s}$. av. J.-C. ont été mis au jour dans la zone du premier. Le second a été identifié comme Thesmophorion.

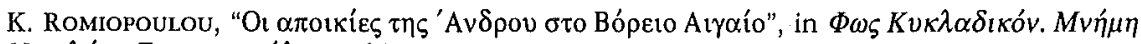

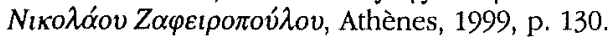


07.15 - Ouranopolts - Discussion du culte d'Hélios dans la péninsule du mont Athos, au NO du village de Nea Roda, près des anciennes cités de Sanè (archaïque et classique) et Ouranopolis (hellénistique), où fut mis au jour un sanctuaire constitué de deux bâtiments datés de la fin de la période archaïque et du début de la période hellénistique. Le premier bâtiment est un oikos archaïque tardif. Des statues en terre cuite représentant des Nikès et appartenant à la décoration du toit font partie des trouvailles les plus appréciables. Le deuxième bâtiment est un temple hellénistique comprenant un pronaos et une cella à trois entrées, une banquette construite et un foyer cérémoniel à l'intérieur. Deux têtes en marbre trouvées dans la cella du temple ont été identifiées comme des représentations d'Hélios et d'une jeune femme. Aucun élément de la documentation mise au jour ne permet d'identifier le propriétaire du sanctuaire archaïque. Par contre, selon l'A., la tête d'Hélios provenant du second bâtiment suggère que le temple lui était dédié et qu'il était probablement associé à un couple de divinités en relation avec lui, soit Létô et Artémis, soit Sélènè et Éos, bien que cette interprétation reste assez problématique. Une telle "association " permettrait d'interpréter les trois entrées de la cella du temple. Des ustensiles de facture locale, rappelant des symboles astraux et provenant du sanctuaire, sont uniques. L'A. suggère de considérer le culte d'Hélios comme un culte nouvellement établi après la campagne d'Alexandre le Grand, qui trouva sur place un ancien temple, probablement dédié à Apollon, importa le nouveau culte et fonda un nouveau temple, alors que l'ancien était toujours en fonction.

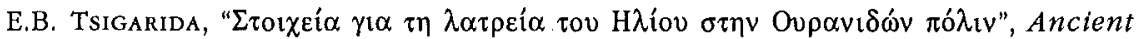
Macedonia VI, vol. 2, Thessalonique, 1999, p. 1235-1245.

\section{Thrace (partim) (Kalliopi CHATZINIKOLAOU et Emmanuel VoutiRAs)}

\subsection{Généralités}

- Discussion des échanges de pratiques cultuelles entre les Grecs des colonies thraces et leurs voisins locaux attestés par des monuments votifs, le changement des types monétaires et l'adoption de nouveaux types iconographiques hybrides pour la représentation de leurs dieux.

M. TAtcheva, "Le mode d'établissement de la coexistence paisible entre le Barbaricum balkanique et les colonies helléniques", Ancient Macedonia VI, vol. 2, Thessalonique, 1999, p. 1127-1134, spéc. 1130-1131.

08.01 - Eleftheroupoli - Mention d'un relief fragmentaire (inv. $n^{\circ}$ L924) représentant le Cavalier thrace, emmuré dans l'une des maisons d'Eleftheroupoli, et d'une statuette votive (aujourd'hui perdue) à Héron-Apollon par M. Publicius Jucundus, qui était l'un de ses prêtres. Cette dernière est datée du début de la période romaine. L'A. signale que Héron ou Héro était une divinité locale thrace honorée entre le $\mathrm{II}^{\mathrm{e}} \mathrm{s}$. ap. J.-C. et la fin de l'Antiquité. Il est souvent lié à Apollon, Dionysos ou Asclépios, sous la forme du cavalierchasseur connu comme le type du Cavalier thrace, et porte beaucoup de noms différents. Un sanctuaire important de Héron-Auloneites a été fouillé sur le flanc $S$ du mont Pangée au cours des deux dernières années. Son culte est bien connu dans la zone entre le Nestos et le Strymon (territoire des anciens établissements de Topeiros, Abdère et Siris).

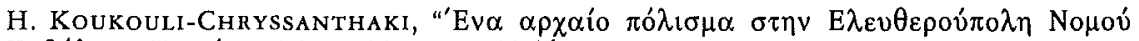

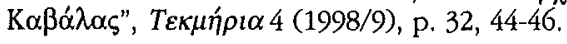

08.02 - Haemus [mont] - L'A. fait l'hypothèse que l'oracle de Dionysos dans l'ancienne Thrace pourrait être situé près de la passe Etropole-Zlatitsa.

D. Boteva, "Following in Alexander's footsteps: The case of Caracalla", Ancient Macedonia VI, vol. 1, Thessalonique, 1996 [1999], p. 187. 
08.03 - Pistiros - Mention de l'existence de restes architecturaux, fosses et biens meubles cultuels, mis au jour dans le port de Pistiros et datés de l'époque classique. Selon les A., la cité était étroitement liée à l'oracle de Dionysos, situé à titre d'hypothèse dans la partie NO du massif montagneux du Rhodope.

L. Domaradzka et M. Domaradzki, "Population structure of Pistiros $\left(^{\text {th }}-4^{\text {th }}\right.$ cent. B.C.)", Ancient Macedonia VI, vol. 1, Thessalonique, 1996 [1999], p. 387-389.

- Mention de l'existence de deux sanctuaires de sommet dans le massif montagneux du Rhodope, sur la route principale provenant du $\mathrm{S}$ de Pistiros.

J. BouzeK, "Pistiros and the south: land and river connections", Ancient Macedonia

VI, vol. 1, Thessalonique, 1996 [1999], p. 190, fig. 2.

08.04 - Debelt - Deux sites avec une concentration de «fosses cultuelles » (selon les termes de l'A.) datés des périodes archaïque et classique ont été mis au jour dans la région du fleuve Sredetzka, près du village de Debelt, dans la région de Bourgas, entre 1981 et 1985. L'A. suggère qu'ils pourraient être liés à l'existence de sanctuaires dans la région.

P. BАвAKov, "Trakijski rituali jami kraj c. Debelt, Burgaska oblac̆t", Arcbeologija (Sofia) 40, 3-4 (1999), p. 62-76.

\section{9. îles de l'Égée (partim) (Patrick Constancio, Alexis D'Hau'tcour'T} et Natacha MASSAR)

09.01 - Chlos (Kato Phana) - École britannique d'Atbènes, XXé Éphorie des antiquités prébistoriques et classiques - En marge d'un nouveau programme de prospection de l'ancienne Phanai, une campagne de nettoyage et de relevés a été menée dans le sanctuaire d'Apollon Phanaios, afin de préciser les données des fouilles qui y furent effectuées en 1934. Celles-ci avaient mis au jour l'angle NE du temple et reconnu deux périboles correspondant à des phases différentes du développement du sanctuaire archaïque. Les recherches effectuées en 1997 et 1998 ont permis de dégager une nouvelle portion du second temenos et d'en préciser le tracé au moyen de procédés de détection géophysique. De même, l'examen minutieux des restes du temple lui-même laisse voir deux phases de construction distinctes qui pourraient éventuellement correspondre aux deux états du péribole. Enfin, un fragment inscrit d'ustensile en calcaire tendre perirrbanterion? - daté paléographiquement du début du $\mathrm{v}^{\mathrm{e}} \mathrm{s}$. av. J.-C. a été découvert. Le texte fragmentaire $(A \Pi O \Lambda \Lambda)$ pourrait être compris comme une dédicace à Apollon dont le nom aurait été élidé.

L. Beaumont, A. Archontidou-Argyri, "New Work at Kato Phana, Chios", ABSA 94 (1999), p. 265-287.

09.02 - Samos (Héraion) - Institut arcbéologique allemand - Sous la direction de H.J. Kienast, des sondages ont été menés le long de la voie sacrée reliant le sanctuaire à la cité afin d'établir l'emplacement et l'aspect du propylon archaïque. Les travaux entrepris en 1998 visaient la partie méridionale de la route afin de compléter les informations obtenues en 1996 pour sa partie N. La limite archaïque a été fortement altérée par les occupations tardives de la zone. Une restitution de l'entrée monumentale du sanctuaire est cependant possible: elle était articulée autour de deux pylônes importants. Ceux-ci encadraient sur leur plus grande longueur, un espace d'env. $6,80 \mathrm{~m}$ de large, peut-être divisé par un pilier central. Le mur méridional du temenos, situé dans le prolongement d'un des petits côtés du pylône $S$, semble se diriger en ligne droite vers la mer, ce qui laisse supposer un temenos archaïque plus important qu'on ne le pensait jusqu'à présent. 
Les premières analyses du matériel céramique révèlent une datation remontant à la $1^{\text {re }}$ moitié du $\mathrm{vI}^{\mathrm{e}}$ s. av, J.-C.

"Jahresbericht 1998 des Deutschen archäologischen Instituts, Abteilung Athen", $A A$ (1999), p. 584-592.

- C.M. Stibbe publie la céramique archaïque laconienne $\left(\mathrm{vII}^{\mathrm{e}}-\mathrm{vI}^{\mathrm{e}}\right.$ s.) découverte lors des fouilles du sanctuaire. Celle-ci atteste les relations suivies entre Sparte et Samos.

C.M. Stıвв, "Lakonische Keramik aus dem Heraion von Samos", MDAI(A) 112 (1997), p. 25-142.

09.03 - Kalymnos (Damos) - XXIre Éphorie des antiquités prébistoriques et classiques Découverte d'un bâtiment public hellénistique à proximité du sanctuaire d'Apollon.

G. Touchais, BCH 122 (1998), Chron., p. 935; D. Blackman, AR 1998-1999 (1999), p. 105.

09.04 - Kos - Université d'Athènes - En 1996 et 1997, à Halasarna, à proximité du sanctuaire d'Apollon, des travaux effectués autour du bâtiment $\Gamma$ ont notamment permis de mettre au jour le seuil de l'édifice et d'en préciser le plan (distyle in antis). Les fondations de quatre bases d'offrandes ont été retrouvées, ainsi que de nombreux fragments architecturaux.

G. Touchais, BCH 122 (1998), Chron., p. 938.

09.05 - Kos - XXII Éphorie des antiquités prébistoriques et classiques - Au lieu-dit "Iraklis sto Psalidi", découverte, lors d'une fouille d'urgence, de vestiges architecturaux d'un bâtiment de culte utilisé jusqu'au $v^{e} s$. av. J.-C. et qui comprenait des phases antérieures; de nombreuses offrandes de l'époque archaïque ont été retrouvées (épées, figurines, aryballes corinthiens, faïences, etc.).

G. Touchais, BCH 122 (1998), Chron., p. 938; D. Blackman, AR 1998-1999 (1999), p. 107.

- Au lieu-dit "Marmaroto », on note la découverte d'une base inscrite, en remploi comme couvercle d'une tombe; mention d'un $\dot{\alpha} \varphi \hat{i} \delta \rho v \mu \alpha$ d'Hestia; l'A. offre un commentaire archéologique et épigraphique de ce mot prenant en compte les restes de la pierre.

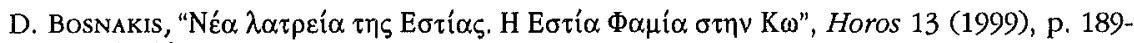
200, pl. 45-46.

09.06 - Rhodes, ville - XXII Éphorie des antiquités prébistoriques et classiques - Lors de fouilles d'urgence menées en 1997 dans le secteur de l'Asclépieion, à l'O de la fortification médiévale, les découvertes archéologiques, dont des bases de statues inscrites, ont confirmé les témoignages littéraires et épigraphiques antérieurs relatifs à l'étendue du sanctuaire.

D. BLACKMAN, $A R$ 1998-1999 (1999), p. 109.

- Comme les années précédentes, la campagne de 1994 a apporté de nombreuses découvertes liées à des rites funéraires variés.

B. Patsiada (nécropole centrale) et E. Kaninia, N. Christodoulidis (nécropole orientale), $A D 49$ (1994) [1999], B'2, p. 771-773; D. BLACKMAN, $A R$ 1998-1999 (1999), p. 105-112 et ID., $A R$ 1999-2000 (2000), p. 125-126.

- Poursuite des fouilles du «vieux temple » ou «temple des dieux» dans le secteur O de la ville (rue Agiou Ioannou - terrain de la Geniki Techniki). La partie E du bâtiment a été reconnue, où l'on a identifié trois hypogées en usage depuis l'époque archaïque et comblés à l'époque paléochrétienne (pour l'hypogée A : voir $A D 48$ [1993], B'2, p. 511). L'hypogée $B$ est creusé dans le rocher et de forme rectangulaire $(6 \times 4,50 \mathrm{~m}$; profondeur intérieure : $2,50-2,80 \mathrm{~m}$ ); on y a retrouvé des traces d'aménagement du rocher pour 
recevoir un escalier en bois de vastes dimensions $(3,20 \mathrm{~m} \times 2,20 \mathrm{~m})$. Le matériel archéologique retrouvé est abondant: morceaux de bases d'ex-voto inscrites, céramique (à partir du $\mathrm{II}^{\mathrm{e}}$ s. av. J.-C., mais en majorité du $\mathrm{III}^{\mathrm{e}}$ au $\mathrm{v}^{\mathrm{e}}$ s. ap. J.-C.); fragments architecturaux, monnaies, aiguilles et objets de verre, fragments sculptés (pied de statue; conduite hydraulique en marbre à tête de lion). L'hypogée $\Gamma$, rectangulaire $(7,10 \times 4,70 \mathrm{~m}$; profondeur : $2,25 \mathrm{~m}$ ), a lui aussi été taillé dans le rocher. Le revêtement intérieur, en grande partie conservé, est constitué de blocs en poros dont les contours sont soulignés par un enduit rouge. Les blocs ont une épaisseur moyenne de $0,50 \mathrm{~m}$ (pl. $244 \alpha$ ). Près de l'angle $\mathrm{NE}$, on a retrouvé les restes d'un escalier étroit dont on a conservé trois marches. Ici aussi, le matériel est abondant. Dans des couches successives, on a retrouvé de la céramique du Iv s. av. J,-C. et des fragments de sigillée figurée, puis des fragments de bases d'offrandes, d'architecture (beaucoup sont inscrits) et de statues, des monnaies de bronze, etc. La couche qui reposait sur le niveau de sol était constituée de terre brûlée, mêlée de charbon et de cendres; on y a retrouvé quelques tessons de la fin de l'époque hellénistique et surtout beaucoup de lampes ( $\mathrm{pl} .244 \delta$ ) et de céramique paléochrétiennes. À l'O du bâtiment, on a découvert, jetés sur le sol, des fragments architecturaux et de sculpture de tailles variables en marbre blanc, tous du $\mathrm{II}^{\mathrm{e}}$ s. av. J.-C.: une statue d'Hermaphrodite, une statue d'Apollon Citharède, une statue acéphale d'une Muse ou de Tychè, une petite statue de Muse ou de Moire, une statue de Thémis (?), une statue de Déméter ou de Cybèle, une tête de pilier hermaïque. Entre les hypogées A et B, on a retrouvé un puits qui contenait beaucoup de matériel archéologique, de la céramique principalement romaine et paléochrétienne, mais également de la fin de l'époque hellénistique, ainsi que des bases de statues de bronze et de marbre blanc, parfois inscrites.

E. Karantzali, $A D 49$ (1994) [1999], B'2, p. 768-769; D. Blackman, $A R$ 1999-2000 (2000), p. 124-125.

- Dans le même secteur (rue Agiou Ioannou), des foulles ont mis au jour, en 1998, des tuyaux hydrauliques en argile qui appartiennent peut-être à la même phase (Iv ${ }^{\mathrm{e}}$-III ${ }^{\mathrm{e}} \mathrm{s}$. av. J.-C.) qu'un autel découvert précédemment.

D. Blackman, AR 1998-1999 (1999), p. 108.

- On notera également que P. Guldager Bilde offre une description détaillée des reliefs qui, dans la nécropole de Karakonero à Rhodes, ornent les parois d'une cour taillée dans le rocher. Ces reliefs représenteraient le retour d'Héphaistos sur l'Olympe. La fonction de la cour est difficile à préciser, faute de fouilles. Il pourrait s'agir soit d'un monument funéraire, soit du lieu de réunion d'un koinon dionysiaque.

P. Guldager Brlde, "Dionysos among the Tombs: Aspects of Rhodian Tomb Culture in the Hellenistic Period", in V. Gabrielsen (éd.), Hellenistic Rbodes; Politics, Culture, and Society, Aarhus, 1999, p. 227-246.

09.07 - Rhodes, Ialysos (terrain Ioannidi) - XXIIe Épborie des antiquités prébistoriques et classiques - Fouilles au $\mathrm{S}$ de l'abside de la basilique paléochrétienne. Des olpès et coupes ioniennes, posées à l'envers, à l'intérieur et autour d'une fosse circulaire, $\mathrm{y}$ attestent l'existence d'un culte chthonien local ( $2^{\mathrm{e}}$ moitié du vi ${ }^{\mathrm{e}}$ s. av. J.-C.).

G. TouchaIs, BCH 122 (1998), Chron., p. 944.

09.08 - Rhodes (Theologos) - XXII Éphorie des antiquités prébistoriques et classiques, Université de Ioannina - Depuis 1991, des travaux sont en cours au sanctuaire d'Apollon Erethimios; deux tombes antérieures (archaïques ou géométriques) avaient été retrouvées à l'intérieur du temple. On a également dégagé un bâtiment carré en poros qui contenait des restes de sacrifice. Une basilique paléochrétienne a pu également être construite sur le site de ce temple, si l'on en juge par la découverte de pavements de mosaïque et d'une cuve baptismale. En 1994, une prospection géophysique (électromagnétique) a tenté de 
retrouver l'emplacement d'éventuels bâtiments et nécropoles, et des travaux de l'OTE ont entraîné des fouilles de sauvetage. En 1997, un vaste édifice public (portique ?) a été mis au jour.

G. Touchars, $B C H 122$ (1998), Chron., p. 944-945; D. BlaCKMAN, AR 1998-1999 (1999), p. 112; ID., $A R$ 1999-2000 (2000), p. 127; L. Marangou, I.C. Papachristodoulou, $A D 49$

(1994) [1999], B'2, p. 781; P. Triandaphyllidis, $A D 49$ (1994) [1999], B'2, p. 781.

\section{Crète (Didier Viviers)}

\subsection{0 - Généralités}

- A l'occasion de la fouille de la nécropole d'Orthi Petra à Eleftherna (et plus particulièrement du monument funéraire $\mathrm{A} 1 / \mathrm{K} 1$ ), N. Stampolidis a repris l'examen d'une catégorie d'objets particulière. Il s'agit d'objets en bronze, de forme ronde, qui ressemblent à des boucliers et furent considérés comme tels, notamment pour le matériel de la Grotte de l'Ida. Or, certains de ces «boucliers » présentent un diamètre qui rend impossible leur utilisation en contexte guerrier (ex. 0,38 m); en s'appuyant sur le contexte archéologique intact d'une tombe d'Eleftherna, l'A. propose d'y reconnaître des couvercles de vases, parfois en utilisation secondaire, auxquels il attribue une fonction rituelle, toutefois non précisée.

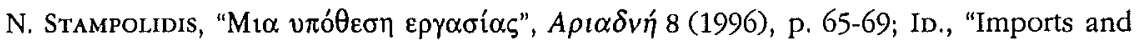
Agalmata: the Eleutherna Experience", in V. Karageorghis, N. Stampolidis (éds), Proceedings of the International Symposium Eastern Mediterranean: CyprusDodecanese-Crete $16^{\text {th }}-\sigma^{\text {th }}$ cent. B.C., Athènes, 1998, p. 175-185.

- K. Psaroudakis convoque les sources archéologiques, philologiques et ethnographiques afin de mettre en évidence le lien entre Dionysos et l'art du métal. Il évoque à cette occasion la présence d'ateliers liés au travail des métaux à proximité ou au sein des sanctuaires dédiés au culte du dieu ainsi qu'à d'autres divinités (pour la Crète : Grotte de l'Ida, Grotte du Diktè, Palaikastro, Kato Sỷmi, Kommos...). L'A. recourt également à l'iconographie des vases pour étayer son propos.

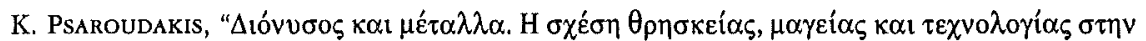

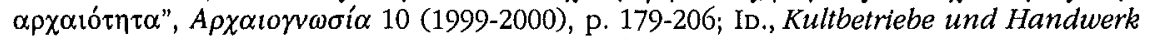
in frïbgriechischer Zeit, Diss. Salzbourg, 1999 (non vidi).

10.01 - Kalyviani (Tyliphos) - XXV Ëphorie des antiquités prébistoriques et classiques - Au pied du promontoire de Grambousa, près d'un Monastère de la Vierge désaffecté, une inscription a été découverte fortuitement et déposée au musée de Chania. Elle conserve 22 lignes d'un traité de paix entre les cités de Phalasarna et de Polyrrhenia, couronné d'un fronton sculpté représentant des thèmes marins. Il s'agit en fait d'une copie d'une inscription trouvée au Diktynnaion (IC II, $\mathbf{x I}, 1)$, de la $1^{\text {re }}$ moitié du $\operatorname{III}^{\mathrm{e}} \mathrm{s}$, av. J.-C. St. Markoulaki, qui publiera l'inscription dans les actes du $8^{\text {e }}$ Congrès international d'études crétoises d'Héraklion, suggère d'y voir un indice de l'existence d'un sanctuaire antique à cet endroit. En attendant les détails de la découverte dans l'article qui publiera le texte de l'inscription, on rappellera néanmoins combien les pierres "voyagent " et combien il convient d'être prudent en l'absence d'autres indices archéologiques.

St. Markoulaki, $A D 49$ (1994) [1999], B’2, p. 739.

10.02 - Phalassarna - XXVe Éphorie des antiquités prébistoriques et classiques - En 1993, les travaux menés à Phalassarna ont permis la découverte d'une aire sacrée jouxtant le mur qui sépare le port militaire du bassin intérieur. Cette aire sacrée est caractérisée par une table d'offrandes au pied de laquelle on a retrouvé une plaque en argent avec deux serpents affrontés, recouverte d'un bol mégarien également en argent, décoré au 
médaillon d'une rosette à neuf pétales et daté de la fin $\mathrm{du} \mathrm{II}^{\mathrm{e}} \mathrm{s}$. ou du début du $\mathrm{I}^{\mathrm{er}} \mathrm{s}$. av. J.C. On connaît à Phalassarna un culte à Akakallis au $\mathrm{I}^{\mathrm{er}}$ s., attesté par une inscription découverte en 1992 sur le mur de courtine du port, mais le lien avec l'autel n'est pas assuré.

D. Blackman, AR 1998-1999 (1999), p. 124.

10.03 - Ltsos - XXV Épborie des antiquités prébistoriques et classiques - En 1994, on a procédé à un nettoyage du site, envahi par une végétation abondante. Ces travaux ont confirmé que le sanctuaire d'Asclépios, fouillé par N. Platon entre 1957 et 1960 ( $c f$. I. Sanders, Roman Crete, Warminster, 1982, p. 84; pl. 40; fig. 20), constituait le centre de ce petit établissement dont le développement est daté du début de l'époque hellénistique. Un abaton a été repéré à l'occasion de ce nettoyage et la topographie générale semble se préciser, sous la direction de Chr. Phrangonikolaki.

St. Markoulaki, $A D 49$ (1994) [1999], B'2, p. 727-728.

10.04 - Chania - XXV Éphorie des antiquités prébistoriques et classiques - Des fouilles, en 1996, ont mis au jour cinq tambours, remployés, appartenant à une unique colonne d'ordre dorique, qui pourrait provenir de l'un des temples archaïques de la cité antique de Kydonia.

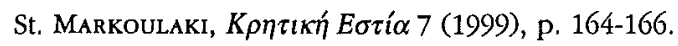

10.05 - Aptère - XXV Éphorie des antiquités prébistoriques et classiques - En 1986 et 1987, le site de l'antique Aptère avait fait l'objet d'un programme de fouille, plus particulièrement au $\mathrm{S}$ du Monastère de Saint-Jean le Théologien ( $c f$. sur les fouilles anciennes : H. Drerup, "Paläokastro-Aptara", in F. MAtz, Forscbungen auf Kreta 1942, Berlin, 1951). Cinq secteurs (I-V) avaient été explorés à cette époque; une $3^{\mathrm{e}}$ campagne eut lieu en 1993 dans les secteurs I et VI, dont la fouille s'est poursuivie en 1994. C'est principalement le secteur I qui nous intéresse ici, en raison de sa localisation au SE du temple à double cella. Un mur de péribole y enceint une aire au sein de laquelle furent édifiés, à l'époque classique, des bâtiments publics. Un dépôt d'époque géométrique suggère cependant une occupation du secteur, sans doute liée à la pratique des cultes, depuis le vin ${ }^{\mathrm{e}}$ s. av. J.-C. En 1994, entre le péribole et la krepis du bâtiment classique, les traces d'un foyer comprenant des os d'animaux, une lampe hellénistique, une monnaie en bronze ainsi qu'une tête de taureau appartenant à une petite figurine en terre cuite ont confirmé l'hypothèse d'une célébration rituelle en plein air. On a également retrouvé des blocs qui appartenaient à l'élévation du temple.

V. Niniou-Kindeli , AD 49 (1994) [1999], B'2, p. 721.

10.06 - Eleutberna (Pyrgi) - Université de Crète - En 1999, les fouilles menées sur l'acropole de l'antique Eleutherna, sous la direction de Th. Kalpaxis, ont mis au jour un bâtiment relativement vaste dont la construction semble remonter au $\mathrm{vII}^{\mathrm{e}} / \mathrm{vI}^{\mathrm{e}} \mathrm{s}$, av. J.-C. Son utilisation se prolongea jusqu'à la fin du $\mathrm{II}^{\mathrm{e}}$ s. ap. J.-C. Certaines des lampes, de type crétois, découvertes dans un dépôt à l'intérieur, semblent, par leur taille considérable, avoir constitué des offrandes, ce qui, en plus de l'emplacement, de l'orientation et de l'appareil des murs de l'édifice, pousse le fouilleur à y reconnaître un bâtiment à usage cultuel.

Th. KalPaxis, Congresso internazionale su Creta Romana e Protobizantina (Iraklion, 23-30 settembre 2000). Preatti, p. 72.

10.07 - Patsos - XXVe Éphorie des antiquités prébistoriques et classiques - Dans une cavité rocheuse de la gorge de Patsos, une fouille de sauvetage menée par V. NiniouKindeli en 1989 avait permis la découverte d'un matériel important (publié par

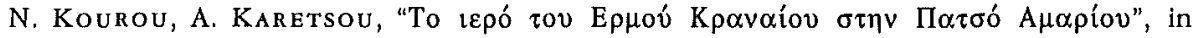


L. RoccheTT', Sybrita. La valle di Amari fra Bronzo e ferro I, Rome, 1994, p. 81-164) qui, en plus des objets dispersés entre les musées d'Héraklion, de Rethymnon et l'Ashmolean Museum d'Oxford, à la suite du pillage de la fin du xix ${ }^{\mathrm{e}} \mathrm{s}$, précise l'occupation du site du MR I à l'époque romaine. Il s'agit d'un sanctuaire dédié, au $\mathrm{I}^{\mathrm{er}} \mathrm{s}$. ap. J.-C. à tout le moins, à Hermès, comme l'atteste une inscription connue depuis longtemps (IC II, Ix, 1). Le matériel le plus ancien provient toutefois vraisemblablement de l'intérieur de la grotte. Quant aux offrandes de l'époque post-palatiale, leur grande qualité et la rareté des types représentés plaident en faveur de l'importance locale du sanctuaire. Une source à proximité explique l'épiclèse Kranaios du dieu Hermès, lequel pourrait être le lointain héritier d'une divinité minoenne de la végétation. En 1994, une fouille a tenté d'établir jusqu'à quelle profondeur les pillages avaient détruit les niveaux archéologiques. De nouvelles figurines, de la céramique d'excellente qualité, des ossements d'animaux et des cornes de taureaux sont venus préciser la chronologie du site : la fréquentation est ininterrompue entre le MR III B et le vire s. av. J.-C., mais l'époque classique n'est pas attestée pour l'instant (avant le $\mathrm{IV}^{\mathrm{e}} \mathrm{s}$.), contrairement aux périodes hellénistique et romaine. La fouille a également confirmé, par la découverte d'une couche de cendres liées à un bûcher, la pratique d'un culte en plein air sur la terrasse qui précède l'abri sous roche.

V. Niniou-Kindeli, $A D 49$ (1994) [1999], B'2, p. 737-738.

10.08 - Ida [grotte de l'] - La presse grecque fait écho à l'étude par I. Sakellarakis du matériel découvert lors des fouilles de la Grotte de l'Ida. Ce haut lieu du culte de Zeus renfermait notamment de multiples petits fragments en ivoire qui, selon l'archéologue, pourraient être attribués à un trône chryséléphantin de la divinité. D'autre part, A. Moustaka a présenté lors du Colloque international Creta romana e protobizantina (Héraklion, 23-30 septembre 2000) une série de bagues découvertes dans la grotte, dont les gemmes permettent une datation au $\mathrm{I}^{\mathrm{er}} \mathrm{s}$. av. J.-C./1 ${ }^{\mathrm{er}}$ s. ap. J.-C. et représentent diverses divinités ou leurs attributs, ainsi que des thèmes en relation avec l'environnement naturel. Voir également $\mathbf{1 0 . 0 0 .}$

To 'E $\theta$ vos (12 juin 2000); A. Moustaka, Congresso internazionale su Creta Romana e Protobizantina (Iraklion, 23-30 settembre 2000). Preatti, p. 91-92.

10.09-Kommos - École américaine d'Athènes - La $19^{\mathrm{e}}$ campagne de fouille a eu lieu en 1994, dans le secteur du sanctuaire grec mais dans des niveaux stratigraphiques minoens. On mentionnera donc brièvement ici l'exploration de deux bâtiments publics, situés au $S$ de la rue minoenne $E-O$ : l'édifice $T$ [MR I] et l'édifice $P$ [MR III A 2], probablement destiné à accueillir les bateaux durant l'hiver. On repère également quelques traces d'une réutilisation de l'édifice $T$ à des fins artisanales (bronziers et céramistes) au MR I et au MR III. C'est en partie sur ces ruines que le sanctuaire de l'époque historique s'est établi. Voir également $\mathbf{1 0 . 0 0}$.

$$
\text { J.W. SHAw, } A D 49 \text { (1994) [1999], B'2, p. 712-715. }
$$

10.10 - Agia Triada - École italienne d'Athènes - A.L. d'Agata publie, de manière remarquable, le matériel exhumé par les fouilles du début du $\mathrm{xIx}^{\mathrm{e}}$ dans le secteur situé à l'E de l'église Saint-Georges, à Agia Triada, dénommé " Piazzale dei sacelli ». Elle en livre tout d'abord une étude précise et exemplaire dans la première partie de l'ouvrage. Ce matériel s'étale du MM III à l'époque hellénistique. On mentionnera ici plus particulièrement celui des périodes PGB et orientalisante (chap. IV, p. 106-196), du milieu du $\mathrm{Ix}^{e}$ s. au $\mathrm{viI}^{\mathrm{e}}$ s. av. J.-C.; il s'agit de terres cuites et d'objets en bronze, dont l'A. fournit une étude à la fois stylistique, technique, chronologique et sociologique, tentant de définir la valeur symbolique de l'iconographie. Seules 13 pièces concernent l'époque hellénistique (chap. V, p. 197-201), entre le $\mathrm{IV}^{\mathrm{e}}$ et le $\mathrm{II}^{\mathrm{e}} \mathrm{s}$. av. J.-C. L'ouvrage dépasse toutefois la simple publication du matériel pour offrir une synthèse archéologique sur la «Piazzale dei sacelli », dans une deuxième partie fort riche. Ces fouilles sont en effet 
demeurées pratiquement inédites et l'A. s'emploie à dresser une synthèse topographique à partir des carnets de fouille et des quelques comptes rendus publiés. Une reconstruction diachronique de la topographie du secteur est ainsi proposée, dont on retiendra plusieurs éléments pour les périodes qui concernent cette chronique :

- le matériel compris entre le milieu du $\mathrm{Ix}^{\mathrm{e}} \mathrm{s}$. et le $\mathrm{viI}^{\mathrm{e}} \mathrm{s}$. (Groupes $\mathrm{D}$ et $\mathrm{E}$ ) a été récolté sur une aire assez vaste; la structure à gradins, dont la construction est antérieure à l'époque hellénistique, est vraisemblablement une aire de sacrifices; la concentration de ce matériel au $\mathrm{N}$ du mur $\mathrm{N}$ de la stoa $\mathrm{FG}$ et près de son mur $\mathrm{E}$ tendrait à prouver que ces structures ont joué un rôle important à cette époque dans l'organisation du culte. Si les kernoi sont à dater du vil ${ }^{\mathrm{e}} \mathrm{s}$., la fosse fouillée près de la stoa FG (constituée essentiellement de restes d'animaux) doit être attribuée à cette phase du sanctuaire.

- le matériel hellénistique (Groupe F) est à la fois moins important et plus localisé (autel, édifice au $\mathrm{N}$ de la stoa $\mathrm{FG}$, édicule de Velchanos ...).

D'autres aspects de la vie des sanctuaires de la "Piazzale » sont ensuite abordés :

- le problème de la continuité à travers le Dark Age (p. 239-241), tout d'abord. On constate en effet que peu de pièces des phases ancienne et moyenne du Géométrique nous sont parvenues, ce qui n'implique pas nécessairement un abandon total du site au $\mathrm{x}^{\mathrm{e}} \mathrm{s}$. et dans la $\mathbf{1}^{\text {re }}$ moitié du $\mathrm{Ix}^{\mathrm{e}} \mathrm{s}$. dans la mesure où les rites ont pu reposer sur l'usage d'offrandes moins durables (libations, petits sacrifices...), comme semble l'indiquer la présence de petits vases à forme ouverte du PG. Au-delà de l'usage auquel ils renvoient, ces derniers attestent à tout le moins d'une reprise de la fréquentation du site au cours du $\mathrm{Ix}^{\mathrm{e}} \mathrm{s}$. Car on ne perdra pas de vue que l'occupation de Phaistos et de sa région au Subminoen et au Géométrique Ancien et Moyen doit encore être démontrée, tant et si bien qu'une interruption de la vie des sanctuaires d'Agia Triada n'est pas du tout impossible.

- peu à peu, l'horizon change profondément et les offrandes deviennent numériquement plus importantes. Si celles-ci reflètent davantage la personnalité de leurs dédicants que celle de la divinité, on y décèlera la présence de groupes familiaux ou sociaux (lien de voisinage ?) marqués par leurs activités de chasse et la guerre. Les types et les conventions stylistiques remontent à la tradition du MR, tandis que deux tendances qui caractérisent la Grèce continentale sont également attestées à Agia Triada, à savoir l'augmentation des dédicaces votives dans la $2^{\mathrm{e}}$ moitié du viII ${ }^{\mathrm{e}} \mathrm{s}$. et l'importance numérique du matériel en bronze.

- peu d'importations sont à relever, en dehors d'une pièce qui fait écho à l'influence phénicienne en Crète entre le $\mathrm{Ix}^{\mathrm{e}}$ et le viI ${ }^{\mathrm{e}} \mathrm{s}$.

- quant à la divinité, l'A. envisage l'hypothèse d'une Artémis, par comparaison avec le matériel du culte d'Artémis Orthia à Sparte; il pourrait ainsi s'agir d'une sorte d'antécédent de la Lato Phytia, déesse de la végétation de Phaistos à l'époque classique ( $c f$. N. Cucuzza, "Leto ed il cosidetto Tempio di Rhea di Festos", Quaderni dell'Istituto di Archeologia della Facoltà di Lettere e Filosofia. Università di Messina, 8 [1993], p. 21-27). En effet, comme à Phaistos, le culte se déroule sur une aire ouverte, à proximité de vestiges minoens encore visibles, que l'on réutilise à des fins cultuelles, comme dans bien d'autres endroits de l'île, attestant ainsi un intérêt pour le passé.

- si l'on veut bien voir que la « reprise » de l'activité des sanctuaires correspond à un développement du site de Phaistos, il n'est pas improbable que les deux phénomènes puissent être directement liés, la cité souhaitant marquer son emprise sur ce lieu de mémoire; l'abandon du $\mathrm{viI}^{\mathrm{e}} \mathrm{s}$. pourrait en conséquence s'interpréter en fonction de la même association à la cité de Phaistos qui semble avoir partiellement perdu son autonomie (à tout le moins sur une partie de son territoire), devant la montée du pouvoir régional de Gortyne. On constate alors une interruption de plus de deux siècles de l'activité des sanctuaires d'Agia Triada. 
- la reprise de l'activité cultuelle au $\mathrm{rv}^{\mathrm{e}} \mathrm{s}$. s'opère essentiellement autour de trois lieux sacrés et serait liée au culte de Déméter; il est en fait malaisé d'établir les éléments de continuité avec la période archaïque au-delà du simple souvenir d'une sacralité du lieu et d'un lien de la divinité avec la fertilité et la végétation. L'A. suggère ainsi, avec une certaine vraisemblance, qu'il puisse s'agir du culte de Déméter, qui connaît à ce moment, en Crète de manière générale et dans la Messara en particulier, un relatif succès (ex. Gortyne, Kamilari...).

À deux moments de leur histoire, les sanctuaires d'Agia Triada auraient ainsi été l'objet d'une réoccupation fondée sur la mémoire de la sacralité du lieu, mais dans un contexte de contrôle politique du territoire environnant par la cité de Phaistos. L'interruption de la fréquentation des sanctuaires au $\mathrm{II}^{\mathrm{e}}$ s. av. J.-C. trouverait dès lors une explication parfaitement cohérente, en relation avec la destruction de Phaistos par Gortyne.

A.L. D'Agata, Haghia Triada II. Statuine minoiche e post-minoiche dai veccbi scavi di Haghia Triada (Creta), Padoue, 1999 (Monografie della Scuola archeologica di Atene e delle missioni italiane in Oriente, 11).

10.11 - Gortyne - École italienne d'Athènes - La presse grecque relate une découverte importante, au cours de la campagne de l'été 2000 au "Prétoire», par les archéologues italiens, sous la direction d'A. Di Vita, à l'arrière du temple connu sous le nom de "Temple du Divin Auguste " ou " des dieux augustéens", d'après une hypothèse fragile d'A. Colini ( $A D 29$ [1973-74], B' 3, p. 909). Il s'agit d'un autel monumental, de $3 \mathrm{~m}$ de long et haut de $3,40 \mathrm{~m}$, fondé selon une orientation différente des autres bâtiments du "Prétoire ", dirigé vers l'O. Des lampes ont été retrouvées à l'intérieur de la construction et tout autour de l'autel, qui semblent dater son utilisation entre le $\mathrm{r}^{\text {er }}$ et le $\mathrm{IV}^{\mathrm{e}} \mathrm{s}$. ap. J.-C. Par ailleurs, M.A. Rizzo a présenté cette découverte au Colloque international Creta romana e protobizantina (Héraklion, 23-30 septembre 2000). Un cippe, trouvé en position de chute sur le premier des trois degrés qui supportent l'autel, portait une dédicace à Theos Hypsistos. On notera toutefois que le lien entre l'autel et la dédicace n'est pas absolument sûr dans la mesure où ce cippe n'est pas nécessairement en position originelle. Après examen sur place, il m'apparaît que l'autel, dans son état actuel, a pu remployer, au moins en partie, des éléments architecturaux antérieurs. L'orientation ellemême, plutôt que de se voir interprétée en fonction du culte du Theos Hypsistos, pourrait devoir être mise en rapport avec l'orientation des édifices les plus anciens de cette partie de la ville (ex. Pythion). On attendra donc avec impatience la publication scientifique de cet important édifice religieux de la zone du "Prétoire».

To 'E $\theta$ vos (20 septembre 2000); M.A. Rizzo, Congresso internazionale su Creta Romana e Protobizantina (Iraklion, 23-30 settembre 2000). Preatti, p. 50-51.

- En 1998, les fouilles italiennes au «Prétoire » s'étaient essentiellement concentrées sur le stade hellénistique $\left(\mathrm{II}^{\mathrm{e}} \mathrm{s}, \mathrm{av}, \mathrm{J} . \mathrm{-C}\right.$.), orienté $\mathrm{N}-\mathrm{S}$, qui se prolonge jusqu'à l'arrière du temple. Le dromos a été reconstruit à l'époque romaine et abandonné après le tremblement de terre de 365 ap. J.-C. Une fouille a également été conduite à l'intérieur et à l'E du temple dont la cella fut réoccupée par un habitat aux $\mathrm{vII}^{\mathrm{e}}$ et $\mathrm{viII}^{\mathrm{e}}$ s. ap. J.-C. Ce temple $(24,25 \mathrm{~m} \times 10,70 \mathrm{~m})$, tétrastyle, édifié sous l'empereur Marc-Aurèle, est élevé sur un haut podium et orienté vers le $\mathrm{N}$; il est précédé d'une place, bordée au $\mathrm{N}$ par l'un des axes viaires (E-O) les plus importants de la cité. On notera la découverte d'une statue féminine en marbre qui pourrait être la statue de culte. En 1997, une gargouille en forme de tête de crocodile $(1,90 \mathrm{~m} \times 0,70 \mathrm{~m} \times 0,52 \mathrm{~m})$ appartenant au temple avait été découverte. Selon le fouilleur, il s'agirait du temple édifié grâce à la générosité de T. Pactumeius et dont les éléments de décoration égyptiens visaient à rappeler l'activité de ce Préfet d'Égypte, à moins qu'il ne faille supposer un culte à des divinités égyptiennes. Le temple fut détruit par le tremblement de terre de 365 ap. J.-C., qui offre à la stratigraphie générale de la ville l'un de ses repères absolus. 


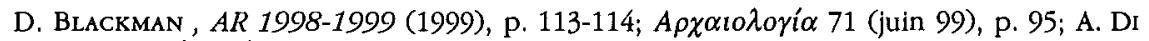

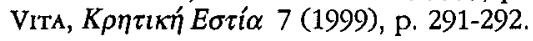

10.12 - Lébéna - XXIII Éphorie des antiquités prébistoriques et classiques - En 1994, le sanctuaire d'Asclépios de l'antique Lébéna a fait l'objet de travaux de nettoyage qui, sans avoir encore redécouvert l'ensemble des vestiges mis au jour par l'École italienne d'Athènes en 1900 et 1910, ont toutefois permis de redégager le portique N, l'escalier $\mathrm{O}$ et une partie du portique occidental. On a également procédé au rangement de colonnes tombées dans le secteur du portique N. M. Melfi a présenté quelques résultats liés à cette campagne de nettoyages lors du Colloque international Creta romana e protobizantina (Héraklion, 23-30 septembre 2000). Cinq phases ont été distinguées, dont la plus visible actuellement semble être celle de la reconstruction romaine à la suite du tremblement de terre de 66 ap. J.-C. mentionné par Philostrate (Vie IV, 34). Cette reconstruction est datée par l'archéologue italienne, sur la base du plan et de la technique de construction, d'entre la fin de l'époque d'Hadrien et la fin de l'époque antonine/début de l'époque sévérienne. Cette datation inclurait le sanctuaire de Lébéna dans le lot des Asclépieia qui firent l'objet d'une phase d'aménagement à l'époque antonine, sous l'impulsion de la famille impériale elle-même et de son entourage. Le T. Flavius Xenion qui dédia une statue du dieu dans le temple (sans doute la statue de culte), proche de Lucius Verus, pourrait, selon $M$. Melfi, être également à l'origine du réaménagement du sanctuaire.

St. Mandalaki, $A D 49$ (1994) [1999], B'2, p. 711; M. MeLFI, Congresso internazionale su Creta Romana e Protobizantina (Iraklion, 23-30 settembre 2000). Preatti, p. 46-47.

10.13 - Prinias - École italienne d'Atbènes, Université de Catane - En 1994, G. Rizza a poursuivi le dégagement de l'habitat établi sur la « Patela ", plus particulièrement devant les temples $\mathrm{A}$ et $\mathrm{B}$. Les abords du temple $\mathrm{C}$ ont également été dégagés. Ces travaux ont ainsi permis de mieux comprendre l'insertion des édifices sacrés dans le tissu urbain.

ASAA 72-73 (1994-1995) [1999], p. 390.

10.14 - Knossos - XXIII Éphorie des antiquités prébistoriques et classiques - Les fouilles de sauvetage menées à l'emplacement de l'hôpital Venizelos, au $\mathrm{N}$ du Palais minoen, ont mis en évidence la limite entre la ville grecque et son cimetière Nord. Si ce dernier fut particullièrement bien étudié ( $c f$. J.N. Coldstream, H.W. Catling (éds), Knossos North Cemetery. Early Greek Tombs I-IV, Athènes, 1996 [ABSA, Suppl. 28]), il en va très différemment du centre civique situé immédiatement au S. De nouvelles fouilles dans ce secteur ont mis au jour, entre autres nombreux vestiges, un puits dans lequel furent retrouvées des figurines en terre cuite représentant la Déméter-Cybèle. Ces découvertes font suggérer à l'A. l'existence d'un sanctuaire à cet endroit, dont la fréquentation s'étalerait de l'époque géométrique au début du $\mathrm{II}^{\mathrm{e}} \mathrm{s}$. av. J.-C. On demeurera cependant très prudent lorsqu'il s'agit d'identifier un culte à l'aide de la seule iconographie des offrandes.

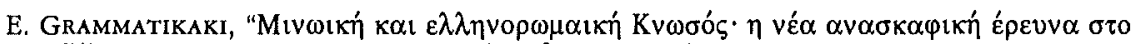

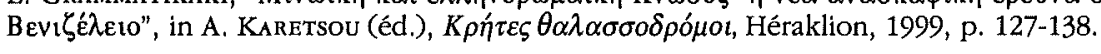

- Dans un article de synthèse sur l'hiatus qui caractérise l'archéologie knossienne entre la fin du vir ${ }^{\mathrm{e}}$ s. et le début du v $\mathrm{v}^{\mathrm{e}}$, J.N. Coldstream et G.L. Huxley sont amenés à dresser un inventaire des indices archéologiques qui attesteraient un arrêt de l'activité à la fin du viI ${ }^{\mathrm{e}}$ s., une phase de quasi-abandon au $\mathrm{vi}^{\mathrm{e}} \mathrm{s}$. et une certaine reprise autour de 500 et peu après. Pour chacune de ces phases, une attention spécifique est portée aux sanctuaires de la cité (sanctuaire de Déméter, "Temple de Rhéa », autel du héros Glaukos ainsi que d'autres sanctuaires connus uniquement par des membres architecturaux épars). La reprise de la fréquentation des sanctuaires semble particulièrement importante à partir des environs de 500 av. J.-C. Quant à l'hiatus archéologique, il faudrait l'interpréter, entre autres explications possibles, comme la conséquence d'une défaite sévère infligée, sans 
doute dans le dernier quart du viI ${ }^{\mathrm{e}}$ s., par Lyttos et ses alliés spartiates à la cité de Knossos, alliée d'Argos. On notera toutefois que cette situation semble toucher, à des rythmes et selon des ampleurs différents, bien d'autres cités crétoises. A phénomène général, ne conviendrait-il pas d'offrir une explication elle aussi plus globale?

J.N. Coldstream, G.L. Huxley, "Knossos: the archaic gap", ABSA 94 (1999), p. $289-307$.

10.15-Amnissos - Dans un article qui aborde l'archéologie de Knossos et d'une partie de son territoire entre la fin du vir ${ }^{\mathrm{e}}$ s. et le début du ve $(c f$. 10.14), J.N. Coldstream et G.L. Huxley réexaminent certains aspects archéologiques du sanctuaire de Zeus Thenatas. Celui-ci présente en effet une "lacune " dans le matériel céramique entre la fin de la période orientalisante et le début $d u v^{e} s$, av. J.-C. (et non pas jusqu'à la fin du $v^{e} s$. comme le suggérait J. Schüfer, Amnisos, Berlin, 1992, p. 181, 183), compte tenu de l'attribution au $\mathrm{vII}^{\mathrm{e}} \mathrm{s}$. av. J.-C. par V. Webb (p. 304-307) des faïences égyptiennes et égyptianisantes que l'on situait généralement au siècle suivant. Webb conclut par ailleurs son réexamen du matériel en attribuant au sanctuaire d'Amnissos davantage de contacts avec Chypre et le Levant qu'avec Rhodes et la Grèce de l'Est.

J.N. Coldstream, G.L. Huxley, "Knossos: the archaic gap", ABSA 94 (1999), p. 299-301; 304-307.

10.16 - Kounavi - XXIII Éphorie des antiquités prébistoriques et classiques - En 1998, on a poursuivi la fouille de la nécropole de l'antique cité d'Eltynia (sur les fouilles de 1993, $c f . A D 48$ (1993) [1998], B'2, p. 463-466). Des dix tombes protogéométriques mises au jour, on retiendra tout particulièrement l'une d'elles pour son dispositif lié aux libations sur un bothros. Les fragments de broches en fer et le crochet à viande que la fouille a révélés au sein du matériel des tombes renvoient, comme dans les fouilles antérieures, à l'accomplissement de banquets funéraires avant la fermeture des tombes.

ЕYППО 2 (1998), p. 144.

10.16 - Tsoutsouros - Des fouilles de sauvetage sur la côte ont permis la mise au jour en 1997 d'un ensemble de bijoux en or et d'objets votifs en bronze (liés à un jeune athlète?).

D. BlaCKMAN , AR 1998-1999 (1999), p. 118 d'après EYППO 1 (1997), p. 124.

10.17 - Kato Symi - Société archéologique d'Athènes, Institute for Aegean Prebistory (New York) - En 1996, il fut essentiellement question de travaux de restauration sur le site; à l'occasion de ces travaux toutefois, quelques vérifications liées à la chronologie des bâtiments du sanctuaire d'Hermès et d'Aphrodite ont pu être effectuées (surtout pour les édifices du $2^{\mathrm{e}}$ mill.), et on notera, pour notre propos, la découverte d'offrandes dans la zone du bâtiment C-D (hellénistico-romain), retrouvées contre ses fondations (e.a. fragments de figurines en terre cuite du haut-archaïsme jusqu'à l'époque hellénistique, fragments de statuettes de taureaux en bronze - ce qui porte à 580 le nombre d'exemplaires connus sur ce site -, autres objets de bronze du viI ${ }^{\mathbf{e}}$ s, av. J.-C., dont un fragment de sceptre à figure de lion). Voir également 10.00.

A. LEMBesi, $P A A H$ (1996) [1999], p. 303-317; pl. 144-150.

10.18 - Viannos (Kastri) - XXIII Éphorie des antiquités prébistoriques et classiques En 1996, des travaux liés à la construction d'un hôtel sur la côte de Keratokambos, à la limite des communes de Chondros et d'Ano Viannos, ont mis au jour un dépôt dont le matériel s'étalant du MM III B/MR I A jusqu'à l'époque archaïque a été récupéré sans possibilité de fouille. La présence de figurines animales peut faire penser à un dépôt votif, sans plus de certitude.

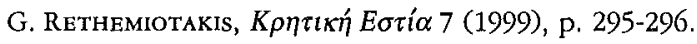


10.19 - Vrokastro [région de] - École américaine d'Athènes - B.J. Hayden a présenté au Colloque international Creta romana e protobizantina (Héraklion, 23-30 septembre 2000) certains résultats de la prospection intensive de la région de Vrokastro. La continuité de l'occupation entre l'époque hellénistique et la période romaine est clairement attestée, notamment sur les sites de deux sanctuaires: celui d'Athéna Oleria, dans la vallée de Meseleri, et celui probablement consacré à Arès et Aphrodite, dans la vallée d'Istron (Kalo Chorio). Ce dernier comprend un petit temple construit ou réaménagé après l'intégration du territoire d'Istron dans la cité de Latô à la fin du $\mathrm{rr}^{\mathrm{e}} \mathrm{s}$. av. J.-C.

B.J. Hayden, Congresso internazionale su Creta Romana e Protobizantina (Iraklion, 23-30 settembre 2000). Preatti, p. 28.

10.20 - Kavousi - École américaine d'Athènes - En 1998, G.S. Gesell a dirigé une campagne d'étude, consacrée notamment à la céramique du bâtiment $G$ de Vronda (autel) et des secteurs environnants. Les deux statues de la déesse aux bras levés et l'équipement rituel ont été restaurés en vue de leur présentation au musée d'Hierapetra. À cette occasion, les fragments de 9 autres statues, 4 autres serpents ainsi que 4 autres kalathoi ont pu être rapprochés et étudiés.

D. BLACKman, $A R$ 1998-1999 (1999), p. 120.

10.21-Pratsos - École britannique d'Athènes - En août et septembre 1998, la prospection archéologique du territoire de Praisos a été poursuivie, sous la direction de $\mathrm{J}$. Whitley. Il s'agissait plus particulièrement de définir les limites du centre urbain. Au S, ces limites sont marquées symboliquement non seulement par la "colline aux tombes" et le sanctuaire de la troisième acropole, mais également par un petit dépôt votif découvert au cours de cette campagne sur son flanc SE. Ce dépôt semble comprendre du matériel s'étalant de l'époque archaiqque à l'époque hellénistique. D'autre part, la prospection a permis de repréciser la localisation d'un dépôt associé à un sanctuaire situé

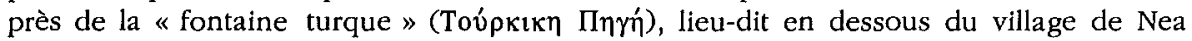
Praisos. Ce dépôt avait été fouillé par Bosanquet, Halbherr et d'autres. La découverte de nouvelles terres cuites confirme la datation (époque archaïque - époque hellénistique); il s'agit de types connus, contrairement aux fragments de lampes qui révèlent des formes jusqu'ici inconnues.

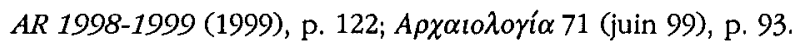

- Les résultats des prospections de 1993 et 1994 font également l'objet d'un important rapport préliminaire. Celui-ci insiste sur les trouvailles qui s'échelonnent du MR III B à la fin de l'époque archaïque. L'aire couverte équivaut à env. $9 \mathrm{~km}^{2}$, au $\mathrm{S}$ de Praisos. L'abandon du site-refuge de Kypia remonte sans doute à la fin du MR III C et l'occupation dess acropoles de Praisos devrait être datée à partir de l'époque géométrique voire protogéométrique. On compte désormais cinq sanctuaires du début de l'Âge du Fer dans la zone urbaine et péri-urbaine de Praisos. Ceux de la troisième acropole (« Altar Hill »), de Vavelli et de Mesamvrysi avaient déjà été identifiés et partiellement fouillés; les prospections de 1993 et de 1994 n'ont pas apporté de nouveauté en ce qui les concerne, sauf pour constater que les deux derniers avaient été largement oblitérés par des travaux récents. Le survey a en revanche précisé l'identification d'un sanctuaire sur le sommet du Prophitis Ilias (= site $n^{\circ} 14$ ) à env. $2,5 \mathrm{~km}$ au SE de Praisos. L'église moderne qui s'y trouve a incorporé en ses murs des blocs et des fragments de colonnes d'un ancien temple dont T.A.B. Spratt (1865, p. 166-167) avait décrit les fondations. Ce voyageur et, plus tard Bosanquet (ABSA 40 [1939-40], p. 64) considéraient les vestiges insuffisants pour autoriser l'identification avec l'un des temples dédiés au Zeus Dictéen (contra P. FAURE, $B C H 84$ [1960], p. 195). Le matériel abondant découvert sur place (essentiellement des coupes à boire en céramique fine, mais également deux fragments de plaques votives en 
terre cuite du vII $^{\text {e }}$ s. av. J.-C. ou encore une épingle en métal) semblerait néanmoins plaider en faveur d'un établissement religieux, en activité depuis l'époque géométrique jusqu'à l'époque hellénistique. Les A. notent toutefois que les découvertes du sanctuaire du Prophitis Ilias diffèrent sensiblement de celles de la troisième acropole (e.a. restes de sacrifices, chaudrons en bronze et armement tant de taille naturelle que miniature...) et pourraient indiquer un culte d'une nature différente. Les $\mathrm{A}$. rappellent que la configuration religieuse de Praisos semble établie au cours du Géométrique Récent, au plus tard, et ne plus changer jusqu'au milieu du $\mathrm{rr}^{\mathrm{e}} \mathrm{s}$. av. J.-C. En effet, rien n'indique que les sanctuaires ruraux soient encore en activité à l'époque romaine. Il en va ainsi du site $n^{\circ} 3$, sur le versant NNE de Papoures où la céramique et une figurine invitent à évoquer une fonction religieuse, mais dont l'activité semble limitée aux époques classique et hellénistique.

J. Whitley, M. Prent, St. Thorne, "Praisos IV: a preliminary report on the 1993 and 1994 survey seasons", ABSA 94 (1999), p. 215-264.

10.22 - Karoumlès (Metriko) - Depuis 1984, un programme d'étude des routes de la Crète proto-historique, sous la direction de I. Tzedakis, a essentiellement concerné la partie SE de l'île, autour du palais de Kato Zakro. À cette occasion, les archéologues ont pu constater la réoccupation de postes de garde de la période paléo-palatiale aux époques postérieures. Ainsi, celui de Metriko semble avoir accueilli un autel archaïque.

D. Blackman, AR 1998-1999 (1999), p. 123.

10.23 - Itanos - École française d'Atbènes, Institut d'études méditerranéennes (FoRTH), XXIV Éphorie des antiquités prébistoriques et classiques - En 1998, les fouilles à l'intérieur de la ville antique ("Quartier d'habitation " secteur v/vir) ont permis de dégager un espace libre, bordé à l'E par une rue à l'époque impériale $\left(\mathrm{r}^{\mathrm{er}}-\mathrm{III}^{\mathrm{e}} \mathrm{s}\right.$. ap. J.-C.). Sous le niveau de la «place " d'époque romaine, on relève la présence d'une banquette de pierre, constituée d'une série de blocs grossièrement taillés auprès desquels fut trouvé un fragment de jambe de statue en marbre présentant un tenon de bronze inséré à la verticale - trace d'une restauration antique -, un fragment de coupe mégarienne à pâte rouge, avec, à l'intérieur, un relief érotique, ainsi que de nombreux fragments de vases en verre peints. Immédiatement à l'E, on a retrouvé une poche de terre brûlée, délimitée par de petites pierres disposées en cercle, qui repose sur un sol de couleur blanchâtre. Il est vraisemblable qu'il puisse s'agir d'une zone cultuelle, au cœeur même de la cité, que l'on est tenté de mettre en relation avec une stèle dont les deux fragments jointifs ont été retrouvés à 48 ans d'intervalle légèrement au $\mathrm{S}$ et qui mentionne un temenos de Leukothea. Cette aire n'était cependant pas vierge de toute construction à l'époque hellénistique (et sans doute auparavant); une fondation imposante, qui s'appuie sur un mur de terrasse, nous en offre la preuve, sans que l'on ait pu procédér au dégagement complet de cette structure, notamment en raison de l'affleurement de la nappe phréatique.

E. Greco, Th. Kalpaxis, Al. Schnapp, D. Viviers, BCH 123 (1999), p. 515-530.

- En 1994, lors d'une campagne préliminaire, la mission archéologique d'Itanos avait découvert, à l'O de la ville, sur une légère éminence, une plate-forme quadrangulaire de $5,20 \mathrm{~m}$ sur $8,60 \mathrm{~m}$ dont la fonction cultuelle fut déduite du matériel, relativement abondant, qui pouvait être aperçu en surface (figurines, lampes etc...). En 1996, une prospection intensive était menée dans ce secteur et on précédait au nettoyage de la "fondation». Cette prospection venait confirmer la destination cultuelle de l'aire et préciser la chronologie de l'occupation, depuis l'époque archaïque jusqu'au II $^{\mathrm{e}} \mathrm{s}$. av. J.-C. Compte tenu des catégories de matériel votif repérées en surface et de la topographie du secteur, on serait tenté de l'associer à Déméter.

Th. Kalpaxis, Al. Schnapp, D. Viviers, BCH 119 (1995), p. 734 et fig. 16; E. Greco, Th. Kalpaxis, Al. Schnapp, D. Viviers, $B C H 121$ (1997), p. 820-822 et fig. 8; A. Kalpaxis, D. Viviers, $A D 49$ (1994) [1999], B'2, p. 753-754. 


\section{[11. Chypre]}

\section{Asie Mineure (Patrick Constancio et Isabelle Tassignon)}

\section{Cilicie}

12.01 - Elaiussa-Sebastè - On notera la présence d'un podium de temple, à proximité duquel a été trouvé un pilier orné d'une représentation très mal conservée d'une divinité masculine, debout, tenant un long sceptre. L'identification à Hermès proposée par l'A. paraît peu fondée.

M.H. SAYAR, "Kilikiya'da epigrafi-tarihi coğrafya araștırmaları 1997", in XVI. Arastırma Sonuçlart Toplantısı, Tarsus, 25-29 Mayts 1998 I, Ankara, 1999, p. 409-421, spéc. p. 413, fig. 7-9.

\section{Pamphylie}

12.02 - Sillyon - Université de Marburg - Mise au jour par M. Küpper d'un temple dorique, au NO de la basilique de Sillyon. La technique de construction et la topographie laissent penser qu'il s'agit d'un édifice d'époque hellénistique. Une inscription dédicatoire fragmentaire, plus tardive que le bâtiment, permet d'attribuer ce temple à Zeus Sôter.

M. KÜPPER, "Sillyon, Bericht über die Arbeiten 1996", in XVI. Araşttrma Sonuçlan Toplantısı, Tarsus, 25-29 Mayıs 1998 II, Ankara, 1999, p. 475-496, spéc. p. 482-483.

\section{Lycie}

12.03 - Tlos - Université d'Antalya - H. Işkan et N. Çevik ont relevé une tombe rupestre à façade de temple avec colonnes in antis. Le fond de la salle témoigne d'un motif d'imagerie funéraire intéressant puisqu'il est orné d'une représentation de Bellérophon. Bellérophon jouissait en Lycie d'une aura spécifique puisqu'il était représenté sur les monnaies de Patara (voir P. FREI, "Die Götterkulte Lykiens in der Kaiserzeit", ANRW II, 18.3 [1990], p. 1859). À Tlos, l'association du héros à un monument funéraire est particulièrement intéressante, car on sait que dans cette localité existait un groupe gentilice appelé B $\varepsilon \lambda \lambda \varepsilon \rho \circ \varphi o ́ v \tau \varepsilon t o l$ (comme dans d'autres cités lyciennes existaient d'autres groupes tirant leurs noms d'autres héros; voir à ce propos l'article de M. WÖRrLE, "Epigraphische Forschungen zur Geschichte Lykiens VII", Chiron 29 [1999], p. 359).

H. IşKAN, N. ÇEVIK, "Tlos 1997", in XVI. Arastırma Sonuçlar Toplantıst (supra 12.02), p. 423-442, spéc. p. 425.

\section{Pisidie}

12.04 - Sagalassos - Université de Leuven - L'équipe de M. Waelkens a, lors de la campagne de 1997, prélevé une série d'échantillons pédologiques, notamment dans le secteur de l'berôon augustéen (où ont été trouvées plusieurs statues publiées dans M. Waelkens, J. Poblome (éds), Sagalassos IV, Leuven, 1997, p. 367-383) et du temple dorique visant à reconstituer la paléovégétation et les vestiges de paléofaune formant l'environnement antique en ces lieux. Les résultats sont attendus.

M. WAELKens, "The 1997 archaeometrical Research and Survey at Sagalassos", in XIV. Arkeometri Sonuçlan Toplantıst, Tarsus, 25-29 Mayts 1998, Ankara, 1999, p. 1-25, spéc. p. 13. 
12.05 - Antioche [de Piside] - La première synthèse relative au sanctuaire de Mên Askaênos est parue dans un ouvrage général consacré à Antioche. Reprenant le dossier des fouilles menées au début du $x^{e}{ }^{e}$ s. par W. Ramsay et J.G.C. Anderson, M. Waelkens et St. Mitchell ont proposé des relevés de l'ensemble du sanctuaire et formulé des hypothèses quant au fonctionnement de ce sanctuaire. Construit vraisemblablement vers le milieu du $\mathrm{II}^{\mathrm{e}} \mathrm{s}$, av. J.-C., il aurait subi quelques aménagements à l'époque romaine. Le temenos qui entourait le sanctuaire était composé en sa partie so de blocs gravés d'édicules votifs, comprenant parfois des inscriptions, toutes d'époque impériale. À l'intérieur de l'enceinte se trouvaient deux temples, un temple principal (dans la cella duquel a été trouvé un bloc octogonal dans lequel les auteurs voient la base de la statue de culte), consacré à Mên et un temple secondaire, plus petit. Plusieurs constructions entouraient ces deux bâtiments : des oikol, un andron ainsi que cinq autres édifices parmi lesquels ce que W. Ramsay avait appelé le "hall d'initiation". L'étude montre que ce local pourrait n'être rien d'autre qu'un lieu de réunion des fidèles comme en témoignent les nombreux ossements d'animaux retrouvés sur le sol et les banquettes, dont un siège offert à Mên par un fidèle du dieu.

On trouvera, dans le même ouvrage, une discussion portant sur le sanctuaire augustéen d'Antioche : traditionnellement considéré comme un sanctuaire dédié à Auguste, avec un temple consacré au culte impérial, il fut récemment réinterprété par $\mathrm{K}$. Tuchelt comme étant voué à une divinité anatolienne (Cybèle, souvent associée à Mên). La chambre souterraine du temple, rapprochée par $\mathrm{K}$. Tuchelt de la pièce enterrée et voûtée se trouvant sous la cella du temple de Zeus à Aezani, en diffère sensiblement : sans escalier, relativement basse (il n'était pas possible de s'y tenir debout, sauf au centre), la chambre souterraine du temple d'Antioche n'aurait pas de fonction cultuelle. Le programme iconographique s'inspirerait aussi peu de la tradition anatolienne, mais renverrait à l'imagerie traditionnelle du triomphe de l'empereur, comme la situation dominante du temple sur le site l'évoque aussi. M. Waelkens démontre, avec des arguments convaincants, qu'il s'agissait bien d'un temple du culte impérial construit du vivant d'Auguste par les habitants, en hommage à celui qu'ils considéraient comme le fondateur de leur colonie.

St. Mrtchell et M. Waelkens, Pisidian Antioch. The Site and its Monuments, Londres, 1998, p. 37-90 et p. 113-173.

\section{Carie}

12.06 - Mandalya [golfe de] - Université de Pise - D. Baldoni et E. La Rocca ont entrepris des sondages dans le temple de la Magna Mater à Çanackk Tepe. Ces travaux montrent que les deux édifices, la cella et la construction annexe, sont contemporains et peuvent être datés des années 180-160 av. J.-C. Un groupe statuaire représentant la déesse assise entre deux cerfs, plus ancien que l'édifice qui l'abritait, constituait vraisemblablement la statue de culte. Situé dans l'axe de l'édifice cultuel, mais à l'extérieur de celui-ci, un noyau de maçonnerie a été identifié comme ayant pu soutenir l'autel. À cet endroit, en effet, un grand nombre de tessons et de statuettes a été mis au jour, évoquant la possibilité d'offrandes. Un bâtiment situé à l'angle SO de la terrasse a vraisemblablement servi de réserves.

- En outre, la même équipe a mis au jour sur le territoire d'Alagün, un relief fragmentaire représentant la déesse assise en anakalypsis, tenant un sceptre. À l'arrière-plan, figure un pilier (?) supportant une statue de culte de cette déesse. Les similarités existant entre cette représentation de statue cultuelle et la déesse de Çanacik Tepe pourraient indiquer que les habitants du territoire d'Alagün adoraient la même déesse, dont le lieu de culte était situé à Çanacik Tepe.

- Sur le territoire de Bargylia, une construction ionique, datée du début du ${ }_{m} I^{\mathrm{e}}$ s. av. J.-C., a été dégagée dont plusieurs eléments architecturaux sont aujourd'hui remployés dans 
l'église. D'après ces éléments, il a pu s'agir d'un petit temple in antis ou de la cella ionique d'un temple périptère de dimensions plus imposantes (en raison du fait que les blocs d'architrave ont une anathyrose, ce qui laisse penser qu'ils ont dû surmonter un mur épais). Aucun élément ne permet cependant d'identifier la divinité qui y était honorée. Au cours des prospections menées sur le territoire de Bargylia, plusieurs dédicaces ont pu être repérées en situation de remploi : ainsi E. La Rocca signale une inscription à Meter Sebastè, la base d'une statue placée dans un sanctuaire d'Isis et Sérapis et des dédicaces à Artémis et à Apollon. Ces dédicaces permettent de conjecturer, selon E. La Rocca, l'existence d'édifices consacrés à ces divinités.

E. LA Rocca, "Archaeological Survey in the Territory of the Gulf of Mandalya: Results of the 1993-1997 Campaigns", in XVI. Arasttrma Sonuclam Toplantssi (supra 12.02), p. 547-567.

12.07 - Alinda - Université d'Aydın - On a procédé au dégagement du temenos et d'une terrasse appartenant à un temple à pronaos in antis situé sur l'acropole d'Alinda. V. Özkaya, O. San et G. Barin évoquent l'hypothèse selon laquelle il aurait pu s'agir d'un temple voué à Artémis, la grande divinité locale, comme tendrait à le suggérer une inscription à Zeus et à Artémis.

V. ÖzKaya, O. SAN, G. BARIN, "Alinda (Karpuzlu)", in XVI. Arastirma Sonuclart Toplantist (supra 12.02), p. 299-323, spéc. p. 303 et p. 314, fig. 7-8.

12.08 - Aphrodistas - Université de New York - Au cours des travaux des années 1997 et 1998, sous la direction de R.R.R. Smith et de Chr. Ratté, ont été mises en lumière les phases principales de la reconversion qui, au début de la période byzantine, transforma le temple d'Aphrodite en église. Du temple périptère qui constituait la construction initiale on fit une église de plan basilical pour lequel l'espace compris entre les colonnades latérales du temple devint la nef de l'église. Cette découverte et l'étude qui en découle montrent à l'œuvre les processus de récupération des lieux de culte païens par le christianisme triomphant.

R.R.R. Smith, Chr. Ratté, "Archaeological Research at Aphrodisias in Caria 1997 and 1998", AJA 104 (2000), p. 221-253, spéc. p. 227 et p. 230, fig. 8.

12.09 - Laodikeia Combusta - Université de Konya - L'équipe dirigée par H. Bahar a découvert un autel votif, sur une face duquel est représenté un buste de Dionysos. L'autel porte une inscription votive, d'époque impériale, dans laquelle le dédicant invoque le dieu " pour les fruits". Un des côtés est orné d'un cep de vigne pourvu de trois grappes de raisins. Il s'agit d'un document éclairant la diffusion du culte dionysiaque, attesté jusqu'ici par l'inscription de Sizma ( $c f$. G. Laminger-Pascher, TAM 11, Suppl., Vienne, $\left.1984, n^{\circ} 149\right)$.

H. BaHAR, "Konya ve çevresi yüzey araştırmaları 1997", in XVI. Araştırma Sonuçlar Toplantist (supra 12.02), p. 23-54, spéc. p. 31, et p. 54, fig. 7-8.

\section{Phrygie}

12.10 - Hierapolis (Pamukkale) - Université polytechnique de Turin - On signalera la découverte, sur l'agora, par l'équipe de D. De Bernardi Ferrero, d'un autel de marbre dédié à Sérapis et d'une statue d'Attis Tristis.

D. De Bernardi Ferrero, "Hierapolis italyan kazı kurulu 1997 dönemi çalısma raporu", in XX. Kazt Sonuçlart Toplantıst, Tarsus, 25-29 Mayts 1998 II, Ankara, 1999, p. 263-281. 


\section{Ionie}

12.11 - Didymes - Institut archéologique allemand - L'analyse des fragments de sculptures du musée de Balat-Milet et du dépôt de pierres de la maison de fouille semble indiquer qu'il existait un type local d'Artémis Péplophore, attesté par un relief et des statuettes d'époque hellénistique et impériale. Ce type devrait éventuellement être mis en rapport avec le sanctuaire de cette déesse mis au jour à Didymes.

"Jahresbericht 1998 des Deutschen archäologischen Instituts, Abteilung Istanbul", $A A$ (1999), p. 611-618.

12.12 - Milet (Kalabaktepe) - Institut archéologique allemand - M. Kerschner publie les résultats de divers sondages qui ont été effectués sur la terrasse orientale du Kalabaktepe, colline qui constituait la partie méridionale de la Milet archaïque. Le matériel et les éléments architectoniques découverts à cet endroit et publiés par A. von Gerkan en 1925 laissaient supposer l'existence d'un temple qui fut reconnu, par la suite, comme celui d'Artémis Chitonè. L'identification ancienne des restes repérés dans la partie NO de cette terrasse n'étant guère assurée, plusieurs sondages - partiellement publiés en 1995 et 1997 - ont été effectués dans cette zone. Lors de la campagne de 1995, trois tranchées ont été implantées à des endroits clefs afin de préciser notamment la chronologie de ce secteur: a) la première (Q.95.6), située à l'E du « temple ", a permis de mettre au jour des fondations quadrangulaires en tuf qui ont été interprétées par leur taille, leur mise en place, leur travail soigné et leur orientation comme les véritables restes du temple, rendant ainsi caduque l'identification topographique d'A. von Gerkan. Ce temple fut détruit et démonté peu après le début du $v^{e}$ s., probablement à la suite de la prise de Milet par les Perses en 494. Le secteur devient alors - et pour un court moment - un quartier d'habitat; b) un deuxième sondage (Q.95.4) effectué dans la partie NE de la terrasse a confirmé cette hypothèse. À cet endroit, au débouché de la rampe qui permettait l'accès à la terrasse du sanctuaire depuis la ville, les restes d'une maison ont êté dégagés. Une anse d'amphore chiote a permis de lui donner comme terminus post quem, le début du $\mathrm{v}^{\mathrm{e}} \mathrm{s}$, , ce qui correspond à la période de réoccupation des autres parties de la colline, et du même coup de proposer une datation pour l'abandon de la rampe orientale. Ce changement d'affectation a, avec raison, étonné le fouilleur. Il en déduit ainsi que « Nur eine fremde, nicht den griechischen Göttern verpflichtete Macht konnte sich darüber hinwegsetzen. Wer sonst als die Perser hätten den Tempel abtragen und das Temenos in ein Wohnvierteil einbezihen können? " (p. 10). Cette hypothèse fort séduisante a le mérite de tenir compte, d'une part, de la très faible durée de la réoccupation, d'autre part, du rassemblement des débris du sanctuaire qui furent enterrés avec soin dans le temenos nettoyé de toute construction. Cette phase se situerait après la victoire de Mycale en 479 av. J.-C. Le temple ne sera toutefois pas reconstruit et la zone restera déserte jusqu'à l'époque byzantine. Peut-être l'espace aura-t-il été considéré comme souillé et le sanctuaire de la déesse installé à un autre endroit, vu que son culte est encore attesté épigraphiquement à la fin du i ${ }^{\mathrm{er}}$ s. av. J.-C. ( $c f$. Fr. Sokolowski, Lois sacrées de l'Asie Mineure, Paris, 1955, $\mathrm{n}^{\circ} 51$ et surtout A. Herda, "Der Kult der Gründerheroen Neileos und die Artemis Chitone in Milet", JÖAI 67 [1998], Hauptblatt, p. 1-48); c) enfin, le troisième sondage (Q.95.5) effectué à la limite septentrionale de la terrasse, a permis essentiellement de définir les différentes phases de son aménagement. On constate ainsi pour le vir ${ }^{\mathrm{e}} s$, deux élargissements successifs vers le $\mathrm{N}$ : le premier est datable du $2^{\mathrm{e}}$ quart du siècle, le second du $3^{e}$ quart. Ces transformations avaient pour but d'accroître la surface utilisable du sanctuaire d'env. $2 \mathrm{~m}$. Une troisième phase, qui ne correspond pas à un élargissement de la terrasse mais à un remblai, est liée à la réoccupation de la zone au début $d_{u} v^{e} s$. On notera que les tessons des deux premières phases ne comprennent que très peu d'importations - ce qui contraste avec les objets exotiques contemporains découverts dans le sanctuaire d'Aphrodite $(c f . \mathbf{1 2 . 1 3})$-, tandis que le remblai compre- 
nait, au sein d'un matériel très mélangé (viır ${ }^{\mathrm{e}}-\mathrm{v}^{\mathrm{e}} \mathrm{s}$.), de nombreuses importations attiques à vernis noir, pour autant qu'on puisse les distinguer des imitations locales.

M. Kerschner, U. Schlotzhauer, "Das Artemisheiligtum auf der Ostterrasse des Kalabaktepe in Milet. Stratigraphie und Keramikfunde der Sondagen des Jahres 1995", $A A$ (1999), p. 7-51.

12.13 - Milet (Zeytintepe) - Institut archéologique allemand - Au début des années 1990, on identifia à Zeytintepe, colline située à env. $1 \mathrm{~km}$ au NO de Kalabaktepe et surplombant l'ancienne ligne de rivage, le sanctuaire archaïque d'Aphrodite Oikousia. Le matériel qui y fut découvert, d'un grand intérêt, est à l'origine de trois articles.

- On considérait bien souvent que les objets égyptiens - ou égyptisants - étaient rares à Milet. La quantité impressionnante d'egyptiaca mis au jour dans le sanctuaire d'Aphrodite a fondamentalement modifié ce point de vue. Ceux-ci sont répartis entre le viII et le $\mathrm{vI}^{\mathrm{e}}$ s., ce temple ayant, lui aussi, été détruit par les Perses en 494. Ils sont très divers, tant par leur forme (amulettes, sceaux, scarabées, statuettes) que par leur matériau (pierre, bronze, faïence). Dans l'ensemble, les objets dont l'origine égyptienne est attestée sont assez rares et pourraient avoir été offerts par des mercenaires rentrés au pays ( $c f$. interprétation de la statuette égyptienne retrouvée à Claros). Ceux-ci pourraient même constituer le groupe d'objets le plus ancien. Cette analyse souligne surtout que la majorité de ces aegyptiaca sont en réalité des imitations, comme le sont aussi bon nombre de scarabées ou d'amulettes magiques ornés de hiéroglyphes. L'origine de ces imitations, et plus spécifiquement des faïences, serait à situer tantôt à Naucratis, tantôt à Rhodes.

G. HöLBL, "Funde aus Milet VIII. Die Aegyptiaca vom Aphroditetempel auf dem Zeytintepe", $A A$ (1999), p. 345-371.

- K. Ketterer publie 7 fragments d'un récipient - d'une forme proche du dinos - de Fikellura, datable du $3^{e}$ quart du $v^{e}$ s. Bien que lacunaires, on peut constater dans un même registre, d'une part la représentation d'un comaste, de l'autre, un animal ailé. Ainsi, pour l'A., « die enge verbindung in der das Symposion und die Flugelwesen auf dem Kessel standen, zeigt, wie stark das Alltagsleben der Ionier mit ihren mythische Vorstellungen verflochten war und welcher Dartellungsreichtum durch dieses Zusammenleben noch zu erwarten ist » (p, 220).

K. Ketterer, "Ein Fikellurakessel aus dem Aphroditeheiligtum", $A A$ (1999), p. 213-221.

- Le sanctuaire d'Aphrodite a aussi livré plusieurs statuettes en terre cuite dont l'arrière, plat, n'est pas travaillé. Au départ de ces exemplaires, datables de la $2^{\mathrm{e}}$ moitié du vi ${ }^{\mathrm{e}} s$., mais aussi de ceux qui ont été découverts à Milet même - à Kalabaktepe notamment -, l'A. se propose d'établir son type stylistique et iconographique. Ces femmes, considérées comme des représentations de «matronale Frau » (p. 261), portent notamment un voile qui leur couvre la tête et le corps à la manière d'un manteau. Elles sont parfois parées d'un collier et d'une fibule : c'est ainsi qu'il conviendrait d'interpréter la protubérance qu'elles présentent sur la partie droite de leur poitrine. Ces représentations surprennent par leur type dans un sanctuaire d'Aphrodite, où l'on s'attendrait à trouver des représentations nues.

V. von Graeve, "Funde aus Milet V. Ein neuer Figurentypus der archaischen milesischen Koroplastik", $A A$ (1999), p. 241-261.

12.14 - Milet (Sanctuaire d'Athéna) - Institut arcbéologique allemand - La fouille d'un puits situé à proximité du sanctuaire d'Athéna a permis de mettre au jour, dans un contexte stratigraphique clos, un fragment de sima appartenant au temple de la déesse. Par sa position archéologique, ce fragment appartient clairement à la phase archaïque de cet édifice, détruit lors de la prise de la ville par les Perses. Ce dernier est comparable à d'autres fragments découverts dans les fouilles anciennes. Ceux-ci font l'objet d'une 
étude détaillée par B.F. Weber. Or, ces éléments avaient été attribués depuis A. von Gerkan à la phase classique du temple qui correspond à l'époque de la reconstruction de la cité. Au départ de cette découverte, un examen minutieux des données de fouilles anciennes - et notamment des dépôts de cendres - est conduit et une nouvelle datation des fondations monumentales du sanctuaire d'Athéna s'en trouve proposée. Bien loin d'appartenir à l'époque classique, ces dernières appartiendraient à un état du temple datable du dernier quart du $\mathrm{vI}^{\mathrm{e}} \mathrm{s}$., hypothèse déjà formulée par Th. Wiegand. Cette monumentalisation du sanctuaire d'Athéna ne serait d'ailleurs pas un cas isolé. En effet, les édifices cultuels de la péninsule milésienne subissent, dans la $2^{\mathrm{e}}$ moitié du $\mathrm{vi}^{\mathrm{e}}$ siècle, d'importantes modifications. Les exemples des sanctuaires d'Artémis à Kalabaktepe et d'Aphrodite à Zeytintepe, la phase IIb du sanctuaire d'Apollon et l'extension de celui d'Artémis à Didymes, la monumentalisation de la voie sacrée ainsi que des lieux de culte voisins et enfin l'autel de Poséidon au cap Monodendri le montrent bien. Rompant avec l'image d'une cité qui entrerait dans une phase de récession économique sous la domination perse, ces découvertes sont à mettre en rapport avec les remarques de P.B. Georges, "Persian Ionia under Darius: The Revolt reconsidered", Historia 49 (2000), p. 1-39.

W.D. Niemeier, A.M. Graeves, W. Selesnow, "Die Zierde Ioniens. Ein archaischer Brunnen, der jüngere Athenatempel und Milet vor der Perserzerstörung", $A A$ (1999), p. 373-413; B.F. WEBER, "Die Bauteile des Athenatempels in Milet", $A A$ (1999), p. 415438.

- En 1957, un couvre-joue en bronze fut exhumé lors des fouilles entreprises dans le secteur du temple d'Athéna. W. Held intègre ce dernier dans une évolution globale des casques à paragnatides mobiles. Cet exemplaire à anneaux, similaire à ceux qui ont été retrouvés à Van, est à dater de la fin du $\mathrm{Ix}^{\mathrm{e}} \mathrm{s}$. et constituerait une pièce de transition entre les modèles orientaux et les casques ioniens archaïques. On retiendra surtout de ceci l'existence d'un élément d'armure parmi le matériel votif le plus ancien du sanctuaire.

W. HeLd, "Vom urartaïsche Raupenhelm zum ionische Helm. Zu einer Wangenklappe aus dem Athenaheiligtum in Milet", MDAI(I) 49 (1999), p. 141-157.

12.15 - Priène - Institut archéologique allemand - À Priène, a débuté en 1998 une nouvelle phase du programme de recherche qui vise à mieux cerner l'évolution urbanistique de cette cité. Lors de cette campagne, on a découvert dans les réaménagements des $v^{e}$ et $\mathrm{vI}^{\mathrm{e}}$ s. ap. J.-C. de la nef $\mathrm{N}$ du portique septentrional de l'agora (dit aussi « portique sacré ») une base de statue. Celle-ci, remployée comme table de magasin, porte l'inscription HPSI.

"Jahresbericht 1998 des Deutschen archäologischen Instituts, Abteilung Istambul", $A A$ (1999), p. 611-618.

12.16 - Épbèse - Institut archéologique autrichien - U. Outschar reprend l'analyse d'un édifice éphésien bien connu, le prétendu temple d'Hadrien, longtemps considéré comme un temple lié à la seconde néocorie de la cité en 132 ap. J.-C. Dissocié de cet événement l'édifice serait antérieur -, il ne peut être considéré comme un véritable temple, dédié au culte impérial : la forme et l'aspect de l'édifice ainsi que sa situation - sur la rue des Courètes, dans l'antique quartier de l'Embolos - en face du cénotaphe d'Androklos et d'édifices similaires, semblent indiquer qu'il s'agit là d'un berôon honorant le « nouveau fondateur » d'Éphèse. La présence et les activités d'Hadrien, accompagné d'Antinous, à Éphèse en 129 ne seraient d'ailleurs pas étrangères à cette assimilation, tout comme les nombreuses chasses auxquelles il participa en Asie Mineure : la geste du héros mythique Androklos et la fondation de la cité elle-même renvoient à une chasse au sanglier ( $c f$. I. THÜR, "Der ephesische Ktistes Androklos und (s)ein Heroon am Embolos", JÖAI 64 [1995], p. 63-103). De même, le culte dont fit l'objet Antinous après sa mort, en octobre 
130, aurait pu trouver une place dans cet édifice, dans la mesure où ce dernier est

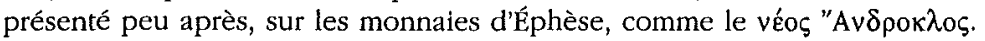

U. Outschar, "Zur Deutung des Hadrianstempels an der Kuretenstraße", in

H. Friesinger, F. Krinzinger (éds), 100 Jahre Österreichische Forscbungen in Ephesos. Akten des Symposions - Wien 1995, Vienne, 1999, p. 443-448.

- En ce qui concerne l'Artémision, G. Forstenpointner, G. Krachler et B. Schildorfer publient une synthèse des résultats obtenus après l'analyse des restes d'animaux retrouvés entre 1976 et 1991 dans le sanctuaire. Les ossements d'animaux découverts aux environs du grand autel ont déjà fait l'objet d'une étude; les autres restes ont été répartis suivant 3 secteurs : (1) la base de culte au $\mathrm{N}$ du grand temple archaique, (2) l'espace entre ce temple et l'bekatompedon, ainsi que (3) la base centrale. Les cuisses, rotules et vertèbres de ruminants calcinées constituent la majorité des ossements retrouvés en (1) et (2) et suggèrent des sacrifices olympiens. De nombreux astragales découverts sur l'ensemble du sanctuaire suggèrent des pratiques divinatoires, tandis qu'on signale une forte proportion de cornes de chèvres (avec une parité gauche/droite) en (2) ainsi qu'aux alentours du temple. La présence d'un sommet de calotte avec deux cornes, permettant un entrelacs, ainsi que la concentration de celles-ci pourraient indiquer l'existence d'un autel à cornes. Le sacrifice de porcs est quant à lui attesté largement en (3) (40,7\% des restes) et est présent en (2) $(15,4 \%)$. Plus de la moitié des ossements appartiennent à des porcelets de moins de 6 mois. Si ce type de sacrifice est attesté dans d'autres sanctuaires d'Artémis, d'Héra ou encore d'Aphrodite, il n'est pas à exclure qu'ils renvoient ici au culte de Déméter Thesmophoros. Parce que l'on a retrouvé, dans les couches submycéniennes à proximité du périptère, de nombreux restes de porcs, en dépit de certaines réserves quant à la représentativité du matériel, les $\mathrm{A}$. supposent "mit einiger Vorsicht als Hinweis auf eine seit früher Zeit bestehende Kultkontinuität verstanden werden » (p. 230). Des restes d'animaux sauvages comme des daims ou des cerfs ont aussi été découverts. Du secteur (3) provient la majorité des quelques restes d'ours et de lions. Si certains d'entre eux doivent être considérés comme des amulettes ( $c f$. dent de lion percée), on peut supposer l'existence de sacrifices sanglants ( $c f$. le cubitus d'ours). Enfin, de l'Artémision proviennent aussi des écailles de tortues terrestres dont une est perforée.

G. ForstenpoIntNer, R. Krachler, B. SChildorfer, "Archäozoologische Untersuchungen zu den Formen des Tieropfers im Artemision von Ephesos", in 100 Jahre Österreichische Forscbungen in Ephesos (supra 12.15), p. 225-232.

- A. Bammer, pour sa part, présente les résultats de fouilles opérées en 1994 à l'E de la cella. Les tessons qui y furent retrouvés trahissent, pour les périodes les plus anciennes, une singulière continuité, puisque les fragments conservés vont du Protogéométrique au Submycénien. Un mur de digue, orienté $\mathrm{N}$-S et composé de moellons irréguliers appareil inhabituel dans le sanctuaire -, a été mis au jour. Dans une seconde phase, à dater du vi ${ }^{e}$ s., il constituera le parement occidental d'une fosse à offrandes. Lors de la construction du grand temple, le mur est en partie détruit et l'ensemble nivelé. De ce nivellement provient une tête en terre cuite mycénienne ou submycénienne, de production locale. Les dégagements entrepris à l'O de ce mur ont révélé une double hache en bronze qui pourrait être minoenne, un fragment de visage mycénien probablement une importation -, une tête en ivoire proche de modèles crétois et un étendard en bronze avec trois animaux évoquant des modèles hittites. Le mur de digue n'est pas datable avec précision, mais il pourrait remonter aux siècles obscurs, voire à l'époque mycénienne durant laquelle ce type de construction est attesté. L'A. reste toutefois prudent sur la fonction de ce dernier : «Ob die Damwand gleichzeitig eine Temenosmauer war, sei dahingestelt. » Les trouvailles, plus particulièrement la double hache et la tête mycénienne, indiqueraient qu'il y avait là, à l'Âge du Bronze, un lieu de culte. Se pose dès lors le problème de la continuité cultuelle avec le sanctuaire géomé- 
trique. Pausanias indique que le culte d'Artémis pré-existe à l'arrivée des Ioniens à Éphèse. La tête en terre cuite serait l'indice le plus ancien d'un culte féminin à l'Artémision, de même que la double hache qui, en Crète, est largement associée à la "Grande Déesse »- même si, en Asie, elle est plutôt un attribut masculin. Leur présence attesterait une grande ancienneté du culte. A. Bammer demeure, avec raison, très prudent, dans la mesure où la continuité d'occupation du lieu, attestée par la céramique, n'implique pas forcément une continuité cultuelle. Il n'exclut donc pas la possibilité de "redécouvertes » dans l'élaboration de la figure de l'Artémis d'Éphèse.

A. Bамmer, "Zur Bronzezeit im Artemision", in 100 Jahre Österreichische Forscbungen in Ephesos (supra 12.16), p. 399-404.

- Un kouros archaïque, inachevé et conservé au musée d'Éphèse à Selçuk, est publié par U. Muss et $M$. Büyükkolanci. Ce kouros, de taille hérö̈que, serait à dater du milieu du vi s. Il se brisa au-dessus des genoux, probablement au moment de son transport. Pour les A., cette sculpture aurait pu être destinée l'Artémision.

U. Muss, M. BüyuckKolancI, "Neue archaische Skulpturen aus der Umgebung von Ephesos", JÖAI 68 (1999), Hauptblatt, p. 33-40.

- À propos de la statue de culte d'Artémis, reprenant l'ensemble des statuettes féminines archaïques découvertes dans l'enceinte du sanctuaire d'Artémis à Éphèse, U. Muss souligne les éléments suivants :

1) il en existe de plusieurs types, allant des rares statuettes nues du $\mathrm{vil}^{\mathrm{e}} \mathrm{s}$, aux figurations semblables aux korès archaïques de la $1^{\text {re }}$ moitié du $v^{e} \mathrm{~s}$. ou encore, des figures féminines vêtues à l'orientale et datées de la même époque;

2) ces représentations n'ont pas été retrouvées dans le périptère géométrique, mais à proximité des bases cultuelles découvertes aux alentours, reflétant ainsi la diversité cultuelle de l'Artémision avant la reconstruction du grand temple à l'époque de Crésus;

3) la présence d'une base sous certaines d'entre elles suggère qu'il s'agit de représentations de statues de culte pouvant correspondre à la diversité des divinités honorées dans le sanctuaire. La présence éventuelle d'une Artémis Chitonè est peu convaincante, dans la mesure où les témoignages concernant cette divinité renvoient à Milet, où son culte est attesté épigraphiquement. Dans la perspective qui est présentée, ces statuettes ne peuvent donc servir de point de départ pour définir l'aspect du xoanon primitif de la déesse, abrité dans le périptère géométrique. On ne peut donc pas rejeter la présence, dès les époques les plus anciennes, des scrota - hypothèse préférée à l'idée des pendeloques votives de formes globulaires - attestés uniquement pour des périodes largement ultérieures. Quant aux ceintures de bronze, retrouvées à proximité de la base cultuelle principale, elles doivent être considérées comme des offrandes.

On a souvent souligné le caractère hétéroclite des éléments constituant la parure et l'habillement des représentations conservées de l'Artémis d'Éphèse - essentiellement d'époque romaine - considérées comme une version syncrétique d'une ou de plusieurs statues plus anciennes. R. Fleischer reconnaît plutôt dans cette particularité l'aboutissement de l'évolution de la garde-robe de la déesse et tente de dresser, dans la mesure des représentations disponibles, les variations d'aspect de la statue de culte. Les monnaies du II $^{\mathrm{e}} \mathrm{s}$. av. J.-C. permettent de l'insérer dans des séries de représentations similaires (en dehors des scrota de taureaux qui lui couvrent le buste) de l'Héra de Samos ou de l'Artémis d'Astyra. Le monnaies qui figurent cette dernière remontant à 400-395 av. J.-C., on pourrait inférer l'existence de ce type à Éphèse à une date antérieure. Ainsi, certains détails de son habillement pourraient même remonter à l'époque archaïque, comme son ependytes ( $c f$. Delphes) ou encore sa ceinture à fibule phrygienne, similaire à des exemplaires en bronze retrouvés dans l'Artémision. 
L'aspect symbolique des représentations qui ornent les vêtements de l'Artémis d'Éphèse (ou du moins celles figurées sur la réplique dite "schöne Artemis 》) est analysé par L. Portefaix afin de déterminer le sens profond des mystères qui accompagnaient la célébration annuelle de la déesse. Les symboles astraux et astrologiques doivent être compris dans une acception néoplatonicienne, celle d'une déesse maitresse de l'univers qui peut soustraire l'initié à l'influence des planètes. Par sa geste mythique, c'est surtout la notion de renaissance qui est soulignée, notamment par la présence de symboles évoquant la vie ( $c f$. les fleurs) et la mort ( $c f$. les démons). C'est avec une attention toute particulière que l'A. souligne l'association abeilles-taureau (évoquée aussi par les scrota) qui rappelle cette renaissance.

Enfin, s'intéressant plus particulièrement aux fils de laine noués que tenait dans chaque main la statue de culte, G. Seiterle souligne d'une part le lien qui existait entre cette matière et la religion grecque, d'autre part le rapport entre cet attribut iconographique et les taureaux amenés pour le sacrifice. Le même A. avait déjà interprété auparavant les protubérances visibles sur la poitrine de la statue de culte comme des scrota de taureaux, accentuant ainsi le lien entre l'animal et la divinité garante de fécondité. Cette interprétation renforcerait l'idée de sacrifices de taureaux destinés à l'Artémis éphésienne.

U. Muss, "Zur Dialektik von Kultstatue und Statuetten im Artemision von Ephesos", in 100 Jabre Österreichische Forschungen in Ephesos (supra 12.16), p. 597-603;

R. Fleischer, "Neues zum Kultbilb der Artemis von Ephesos", ibid., p. 605-609; L. Portefaix, "The Image of Artemis Ephesia - A Symbolic configuration related to her Mysteries", ibid., p. 611-617; G. Seiterle, "Ephesische Wollbinden. Attribut der Göttin - Zeichen des Stieropfer", ibid., p. 251-254.

- La présence d'orifices dans les frontons des temples d'Artémis d'Éphèse et de Magnésie du Méandre - tous deux orientés vers l'O - a depuis longtemps été associée à une épiphanie divine, présentée essentiellement comme l'apparition de la statue de culte par ces ouvertures. Les problèmes, notamment techniques, que pose une telle hypothèse font préférer une autre interprétation. Les restes conservés du temple de Magnésie ainsi que son orientation semblent indiquer qu'au moment de la pleine lune, présidant à la fête de la déesse, la "porte " centrale du fronton permettait l'éclairage direct de la statue de culte. Pour un spectateur situé logiquement à l'extérieur du temple, la représentation divine devait, à ce moment, être particulièrement frappante. Ce système était complété par les «fenêtres » latérales du fronton qui sont, quant à elles, liées aux phases du lever et du coucher de la lune. La lumière de cette dernière, réfléchie sur les colonnes, laissées lisses, qui bordent la statue de culte en accentuait l'effet dramatique. Un système similaire pourrait être avancé pour le sanctuaire d'Éphèse.

O. BINGöL, "Epiphanie an den Artemistempeln von Ephesos und Magnesia am Mäander", in 100 Jabre Osterreichische Forscbungen in Ephesos (supra 12.16), p. $233-240$.

12.17 - Claros - Mission archéologique française - Lors du colloque célébrant le centenaire des fouilles autrichiennes à Éphèse, $\mathrm{J}$. de La Genière a présenté le résultat des recherches menées dans le sanctuaire d'Apollon à Claros. Les quatre années nécessaires à la publication des actes (parus en 1999) imposent de compléter ce compte rendu par celui que le même A. publia en 1998. Ce programme de recherche s'articule autour de trois secteurs principaux :

- L'espace situé entre l'autel et le temple hellénistique d'Apollon:

a) à l'E du temple, une structure circulaire d'env. $6 \mathrm{~m}$ a été mise au jour et identifiée comme un autel. Celui-ci succède à un espace de sacrifice antérieur dont l'utilisation, datée par les restes d'offrandes en terre cuite (e.a. bovidés, mais on notera aussi une statuette égyptienne), remonte à l'époque géométrique. Cet espace est remplacé au milieu 
du $v_{1}{ }^{e} s$. par l'autel circulaire auquel aucune offrande ne peut être associée. Celui-ci présente un remplissage qui le distingue du « Rundbau » de Didymes qui lui est légèrement postérieur (Fin du viI ${ }^{\mathrm{e}}$ s; $c f$. K. Tuchelt, "Drei Heiligtümer von Didyma und ihre Grundzüge", $R A$ [1991], p. 85-98). Il sera remplacé, peu après le milieu du $v^{\mathrm{e}}{ }^{\mathrm{s}} \mathrm{s}$, par un autel rectangulaire auquel sont associées des statuettes en terre cuite d'un personnage tenant une lyre, attestées pour une période s'étendant jusqu'au $\mathrm{IV}^{\mathrm{e}} \mathrm{s}$.

b) les fouilles opérées dans l'adyton du temple hellénistique ont permis de retrouver le mur $O$ et l'angle SO de la cella du temple archaïque d'Apollon, contemporain de cet autel. Ce dernier sera remplacé à une époque qu'il est difficile de déterminer avec précision - fin $\mathrm{rv}^{\mathrm{e}} \mathrm{s}$. ou dans le courant du $\mathrm{mI}^{\mathrm{e}} \mathrm{s}$.

c) au $\mathrm{II}^{\mathrm{e}}$ s. av. J.-C., entre le nouveau temple et son autel monumental, on a disposé lors d'un réaménagement global du sanctuaire, env. cent blocs suivant quatre rangées. La présence d'un anneau, fixé sur ces blocs et leur nombre invitent à reconnaître là un dispositif destiné aux hécatombes.

- Le secteur $\mathrm{N}$, consacré à Artémis :

a) sous les remaniements opérés lors de l'installation de ce dispositif destiné aux hécatombes, on a retrouvé les vestiges de l'autel archaïque, classique et hellénistique d'Artémis. Ce dernier, fortement arasé, laisse percevoir plusieurs phases d'aménagement. À proximité de cet autel, la base de la korè de Timonax a été mise au jour. Celle-ci présente plusieurs états et rehaussements destinés à faire en sorte que la sculpture soit toujours visible au fil des siècles. Déplacé vers l'E lors du remodelage du sanctuaire au II $^{\mathbf{e}}$ s., l'autel ne sera toutefois pas disposé de manière orthogonale par rapport à celui d'Apollon, dans la mesure où un édifice archaïque toujours visible, limitait l'espace disponible vers l'E.

b) à l'o de ces autels arasés se trouvait un édifice archaïque composé d'une salle rectangulaire à orthostates - sur lesquelles reposaient probablement des murs en briques crues - supportée par quatre colonnes et donnant, à l'O, sur une autre pièce rectangulaire.

- Le secteur $\mathrm{S}$ : à l'instar de ce qui a été constaté dans le secteur $\mathrm{N}$, le dispositif mis en place pour les hécatombes a arasé une série de structures plus anciennes :

a) ainsi, la présence de fondations archaïques situées dans un axe N-S et dans l'alignement de l'autel rectangulaire d'Apollon " pose la question de l'existence d'un passage $\mathrm{N} / \mathrm{S}$ dont elles constitueraient la bordure Est " (p. 705). La recherche d'une éventuelle bordure occidentale de ce passage a permis la découverte de fragments de deux kouroi dans un niveau du $\boldsymbol{~ I}^{\mathrm{e}} \mathrm{s}$. L'un d'eux tenait à l'origine un petit animal, l'autre, dont seul le bassin et les cuisses sont conservés, porte une dédicace de Timonax fils de Théodoros, connu comme le dédicant de la korè évoquée plus haut. La formule tò $\pi \rho \hat{\imath} \tau o v ~ i \varepsilon \rho \varepsilon v ́ \sigma \alpha \varsigma$, pratiquement identique sur les deux sculptures, semble exclure qu'il s'agisse là de la mention de la première prêtrise du sanctuaire puisque de nombreux ex-voto du $\mathrm{vII}^{\mathrm{e}} \mathrm{s}$. ont été découverts.

b) un épais mur archaïque, orienté $\mathrm{E}-\mathrm{O}$ et probablement contemporain des autels d'Apollon et d'Artémis pourrait constituer le péribole du sanctuaire, marquant là sa limite méridionale.

J. DE LA Genière, "Claros 1995", in 100 Jahre Österreichische Forscbungen in Epbesos (supra 12.16), p. 703-706; EAD., "Claros. Bilan provisoire de dix campagnes de fouille", REA 100 (1998), p. 235-268.

\section{Lydie}

12.18 - Sardes - Université de Berkeley - Les travaux menés dans le temple d'Artémis par C.H. Greer.ewalt Jr, visaient à éclaircir le plan du temple et notamment l'existence 
d'une colonnade prostyle en face du pronaos. Un puits datant de la fin de l'époque romaine y fut ultérieurement construit. C'est là que furent trouvés plusieurs fragments statuaires dont une tête colossale de Commode et celles d'autres membres de la famille impériale antonine. R.R.R. Smith a également réexaminé une tête colossale provenant du temple d'Artémis, identifiée depuis G.M.A. Hanfmann comme une représentation de Zeus aux traits du prétendant séleucide Achaios : il s'agirait d'une tête de Marc-Aurèle. Si le temple ne présente pas de lieu très clairement destiné à la mise en scène de telles images, cette découverte apporte des éléments susceptibles d'éclairer d'un jour nouveau la problématique de l'association de l'empereur et de sa famille aux cultes locaux.

C.H. Greenewalt Jr, "Sardis: Archaeological Research 1997", in XX. Kazı Sonuçları Toplantist (supra 12.02), p. 1-14; voir aussi C.H. Greenewalt Jr, M.L. Rautman, "The Sardis campaigns of 1996, 1997 and 1998", AJA 104 (2000), p. 643-681, spéc. p. 673-676, fig. 32 .

\section{Mysie}

12.19 - Pergame - Institut archéologique allemand - G. de Luca et W. Radt publient le matériel issu des sondages systématiques effectués principalement en 1994 au niveau des fondations du Grand Autel et des multiples chambres qui en constituent la trame. Le remplissage des différentes chambres présente un matériel très hétérogène (tuiles et vases de formes variées) remontant jusqu'à l'époque archaïque, avec toutefois une forte proportion de céramiques datables du $\mathrm{III}^{\mathrm{e}} \mathrm{s}$, av. J.-C. Les artefacts les plus récents, quant à

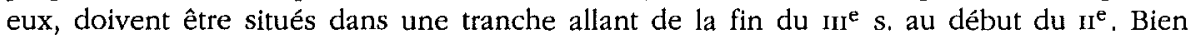
qu'on ne puisse proposer une chronologie très fine, ces résultats impliquent qu'on ne peut dater les débuts des travaux des environs de 190-180 av. J.-C. sans pour autant accréditer les hypothèses historiques qui les associent à la victoire d'Eumène II sur les Galates en 165 av. J.-C. Ainsi, les A. pencheraient pour la fin des années 170, ce qui renverrait à l'attentat manqué contre le souverain de Pergame à Delphes - commandité par les Macédoniens ( $c f$. l'étoile figurant sur le bouclier du guerrier tombé) - et correspondrait à une émission monétaire spécifique : le tétradrachme d'argent au portrait d'Eumène qui, par conséquent, ne doit plus être attribué à son successeur, Attale II. Le monument érigé par le souverain était destiné à remercier tous les dieux d'avoir non seulement sauvé son existence, mais encore, au-delà, la dynastie attalide. On notera en outre un bref excursus consacré au problème de la datation des phases 9, 10 et 11 de l'Asclépieion de Pergame. Leur datation basse (vers 170-160 av. J.-C. pour la première d'entre elles au lieu de 200-191 av. J,-C.) ne serait guère défendable dans la mesure où elle se fonde essentiellement sur une acception trop stricte de parallèles typologiques et qu'elle s'intègre mal dans le cadre chronologique global de Pergame.

G. DE LuCA, W. RADT, Sondagen im Fundament des grossen Altars, Berlin, 1999.

- Par ailleurs, les données épigraphiques mettent en lumière une évolution dans la vénération des souverains de Pergame qui ne font l'objet d'un culte qu'à partir d'Attale Ier (241-197 av. J.-C.), pratique largement renforcée par Eumène II (197-159 av. J.-C.). Å l'exception du premier, qui semble avoir été honoré ainsi de son vivant, ce culte est généralement institué par les successeurs dans une optique dynastique. Dans cet article, sont essentiellement passés en revue les lieux censés abriter ce culte : a) ainsi, l'A. réfute-til l'hypothèse qui fait du bâtiment à niches, situé près du théâtre, l'Attaleion connu par des inscriptions de Téos. Cette attribution repose essentiellement sur une identification stricte des " Attalistes " aux Technites de Dionysos, association dont le bâtiment à niches de Pergame serait le siège. Dans cette perspective, l'Attaleion serait à situer à Téos; b) c'est la chronologie du "temenos dédié au culte des souverains», situé directement au S des portes de la cité, qui est ensuite révisée. La présence de marques de carriers identiques, 
d'une part sur les blocs constituant la première phase de cet édifice, d'autre part sur les blocs du sanctuaire de Déméter serait un indice de leur contemporanéité. En conséquence, la construction du temenos serait à dater non plus du règne d'Attale $\mathrm{I}^{\text {er }}$, mais de celui d'Eumène II. Cet édifice serait le siège d'une association similaire aux « Attalistes 》 de Téos, chargée du culte des souverains; Attale $I^{\text {er }}$ y aurait été honoré selon des dispositions établies par Eumène II; c) le bâtiment à abside, dont le plan orienté E-O est rendu plus lisible par les sondages effectués dans les fondations du Grand Autel, est attribué à Attale Ier. Il s'agirait là de l'instauration d'un culte royal par le souverain luimême; il est le premier à adopter le titre de roi. Le caractère archaïque de l'édifice serait lié à la volonté de donner une "ancienneté " à cette dynastie; d) cette interprétation est indissociable de celle de l'édifice qui lui succède sous le règne d'Eumène II : le Grand Autel de Pergame. L'A. rejette les interprétations de l'édifice qui ont déjà été proposées (autel du temple d'Athéna, culte divin, monument de victoire) dans la mesure où elles négligent largement la signification de la frise intérieure, de style classique, consacrée au récit du héros mythique Télèphe, considéré comme un ancêtre des Attalides. Il serait le siège du culte du souverain divinisé, assurant ainsi la continuité avec l'édifice qu'il remplace; e) enfin, dans le sanctuaire d'Héra, Attale II, honoré comme sunnaos, y était représenté divinisé.

H. SCHWARzer, "Untersuchungen zum hellenistischen Herrscherkult in Pergamon", MDAI(I) 49 (1999), p. 249-300.

- Enfin, W. Raeck présente brièvement le Trajaneum qui fait l'objet, pour l'instant, de nouvelles recherches afin de préciser le plan des structures hellénistiques qu'il a recouvertes ( $c f$. W. RAECK, "Untersuchungen zur Vorgängerbebauung des Trajaneums von Pergamon I: Überblick. Obere Hangstufe", MDAI(I) 49 [1999], p. 333-361), On connaissait déjà les fragments de deux sculptures monumentales identifiées comme les statues de culte de Trajan et d'Hadrien. Les travaux de restauration effectués dans ce secteur depuis une trentaine d'années ont permis la découverte de nombreux autres éléments sculptés, dont la partie supérieure d'un visage ainsi que le bassin d'une statue assise. Ceux-ci devaient appartenir à la monumentale statue de culte de Zeus Philios, dont la présence est attestée dans ce temple, d'une part de manière épigraphique, d'autre part par des monnaies qui figurent une cella avec les représentations de 'Trajan en armure et d'une divinité assise tenant un sceptre. On ne peut toutefois pas déterminer avec certitude si la statue d'Hadrien, absente des données iconographiques et épigraphiques, est contemporaine des deux autres.

W. RAECK, "Ein Gott für den Kaisertempel. Archäologisches vom Trajaneum in Pergamon", Antike Welt 30 (1999), p. 105-111.

\section{Troade}

12.20 - Parion - Université Atatürk d'Erzurum - L'équipe de C. Başaran a découvert les fondations, d'une facture très soignée, d'un temple situé à proximité du théâtre. Aucun élément ne permet jusqu'à présent d'identifier la divinité qui y était honorée.

C. Başaran, "Parion 1997 araştırmaları", in XVI. Araștırma Sonuçlar Toplantısı (supra 12.01), p. 349-364, spéc. p. 352 . 


\section{Grande Grèce (Massimo Osanna)}

13.01 - Cumes - Dans un ouvrage de synthèse concernant les fondations coloniales et l'organisation des établissements de Pithécuses et de Cumes, L. Jannelli trace le bilan de la dernière décennie de recherche, prenant notamment en considération les données sur les cultes de Cumes. L'A. s'interroge avant tout sur la chronologie de l'implantation des temene : le sanctuaire du fonds Valentino, au SO de la cité, près des fortifications, semble avoir été fréquenté dès le viI ${ }^{\mathbf{e}} \mathrm{s}$, av. J.-C. comme l'atteste la découverte d'un bâtiment de culte et d'un matériel votif (céramique ionienne et corinthienne), dont des vases à parfum à décor figuré et des statuettes féminines, qui tiennent parfois une colombe. L'attribution à Héra (dont le culte à Cumes est attesté par Phlégon de Tralles) semble assurée par la découverte de coupes de la fin de l'époque archaïque présentant des dédicaces, incisées, à la déesse; la présence de la déesse, qui dans la mère-patrie assume souvent des fonctions maritimes (Samos, Perachora), se révèle significative du fait de la localisation du sanctuaire près de la zone portuaire. L'acropole, vraisemblablement fréquentée par les colons dès la fondation, a livré des traces éparses de la phase du hautarchaïsme : sont prises en considération les données inédites de la fouille de Gabrici en 1910 dans la zone du sanctuaire d'Apollon, qui avait récupéré une centaine de fragments céramiques compris entre le dernier quart du virr ${ }^{\mathrm{e}}$ et le début du $\mathrm{vi}^{\mathrm{e}} \mathrm{s}$. L'étude traite essentiellement de vases à boire, kotyles et skyphoi, et des types à verser, comme les onochoés et les cruches, associées à quelques cratères et à quelques exemplaires destinés à la cuisson, au transport et au stockage des produits alimentaires. Une telle découverte (qui fait surgir de façon significative le thème du banquet rituel) vient combler le vide documentaire entre le début de l'expérience coloniale et le $\mathrm{vI}^{\mathrm{e}} \mathrm{s}$., époque pour laquelle la documentation archéologique concernant le culte apollinien devient significative (réalisation de l'important terrassement sur lequel sera construit le grand temple d'Apollon).

L. Jannelli, "Ischia e Cuma", in E. Greco (éd.), La città greca antica. Istituzioni, società e forma urbana, Rome, 1999, p. 303-328.

13.02 - Paestum - Istituto Orientale di Napoli et École française de Rome - Dans le volume Poseidonia-Paestum IV, sont présentés les résultats des fouilles récentes effectuées le long des côtés $\mathrm{O}, \mathrm{S}$ et d'un sondage à la limite $\mathbf{E}$ du forum de Paestum. Ils permettent d'effectuer une lecture diachronique des structures depuis la fin de la période archaïque jusqu'à l'époque impériale. De nouvelles données sont présentées, concernant l'édifice thermal du côté SO, dont sont fournies une lecture d'ensemble et une proposition de reconstitution. Le long du côté méridional, dans la zone dudit "Giardino romano », de nouvelles données sont apparues concernant les phases de construction de la chapelle quadrangulaire avec autel, dont l'attribution à Héraclès est confirmée par la découverte d'une statuette en plomb. Présentation d'une synthèse des nouvelles enquêtes conduites dans la zone du Macellum destinée à comprendre les structures déjà apparentes et à définir des problèmes stratigraphiques issus de l'occupation de la zone à partir de la fin du vi ${ }^{\mathrm{e}}$ s. av. J.-C. jusqu'à la période du Moyen- et du Bas-Empire. Des résultats de l'enquête de la zone SE, il ressort une nouvelle lecture de l'articulation des phases monumentales du flanc $\mathrm{E}$ du forum. De la zone SE du sanctuaire sont apparues des données permettant une nouvelle lecture des structures apparentes, avec l'hypothèse de la présence de cultes thérapeutiques pour lesquels on propose le couple Apollon Maleatas - Asclépios. Présentation d'une analyse du matériel sculpté des périodes hellénistique et romaine du forum, avec une proposition de reconstitution de séries statuaires, orientées vers une définition de la réorganisation urbanistique en fonction du culte impérial (M. Denti). Voir également $\mathbf{1 4 . 0 3}$.

E. Greco (éd.), Poseidonia-Paestum IV, Forum Ovest-sud-est, Rome, 1999. 
13.03 - Elée - Soprintendenza archeologica per le province di Salerno, Avellino, Benevento, Institut archéologique autrichien - Dans un volume collectif consacré aux plus récentes enquêtes menées dans la zone urbaine d'Élée, sont présentés les résultats provenant de la reprise des fouilles dans le secteur du sanctuaire d'Athéna, situé sur la colline de l'acropole ( $c f$. dans le même volume, F. Krinzinger, "Zu den Monumentalisierungsphasen der Akropolis von Velia", p. 23-33). L'analyse des données récentes, mises en relation avec les résultats des fouilles antérieures, met en place un nouveau cadre pour l'articulation monumentale de l'acropole, en particulier le secteur occidental de la terrasse supérieure du sanctuaire. Quelques structures archaïques tardives, dont émerge un beau mur en appareil polygonal, représentent peut-être les traces du sanctuaire à mettre en rapport avec la première implantation de la polis (la sacralité de la zone semble attestée par un petit dépôt votif dans une cavité du banc rocheux). Des structures postérieures en appareil quadrangulaire, ainsi que des entailles dans la roche, pourraient renvoyer à d'imposants travaux de terrassement d'époque classique qui auraient complètement "resystématisé " cette zone fortement escarpée de l'acropole. Un édifice rectangulaire avec un portique s'élève dans ce secteur à l'époque hellénistique, quand un imposant comblement vient niveler et agrandir considérablement la partie occidentale de la colline, recouvrant les restes des implantations plus anciennes. Le nouvel édifice ferme l'extrémité occidentale de la terrasse en créant une coulisse scénographique pour le temple à l'avant-plan. La construction de l'édifice ne constitue pas une intervention isolée, mais s'insère plutôt dans un programme de systématisation générale de l'acropole : c'est à ce moment que remonte le prolongement du mur monumental de temenos, non moins qu'une série d'interventions tant dans le sanctuaire que dans l'espace sacré situé le long de la ligne de faîte de la colline. Parmi ceux-ci, il faut signaler en particulier les travaux de monumentalisation de la zone d'entrée du sanctuaire d'Athéna, situé dans la partie centrale du péribole septentrional, et l'érection d'un portique sur le côté $S$. Parmi le matériel mis au jour, on peut signaler les pièces votives provenant du «comblement » et de la couche de nivellement, appartenant sans doute à deux dépôts perturbés, le premier refermé dans la $1^{\text {re }}$ moitié du $\mathrm{v}^{\mathrm{e}} \mathrm{s}$. av. J.-C., le second au cours du $\mathrm{IV}^{\mathrm{e}} \mathrm{s}$. : terres cuites figurées féminines, branches de corail, vaisselle de bronze, armes, céramique à figures noires portant des graffiti (dont des dédicaces à Athéna). La céramique attique trouvée au cours des nouvelles fouilles est publiée de façon exemplaire dans le même volume par R. Maffetrone, "Ceramiche figurate di età classica da Velia", p. 85-108.

L. Cicala, C.A. Fiammenghi, R. Maffettone, L. Vecchio, "Problemi di topografia storica dell'Acropoli di Velia: l'edificio ellenistico ad ovest del tempio", in Neue Forschungen in Velia, Akten das Kongresses "La ricerca archeologica a Velia" (Roma 1-2 July 1993), Vienne, 1999, p. 39-59.

- Par l'analyse des enquêtes antérieures effectuées dans la zone située sur le versant $S$ de la colline de Velia, entre l'acropole et le promontoire de Castelluccio, G. Tocco reprend en considération les diverses interprétations avancées pour le grand complexe de portiques, traditionnellement interprété comme une agora, localisé au début des années 1950. Il se dispose sur la dernière des trois terrasses qui définissent et structurent architecturalement un profond vallon naturel où coule l'eau d'une source. Les résultats des découvertes récentes (campagnes 1991-1992) sont brièvement présentés. Ils ont livré de nouveaux éléments concernant les structures et la chronologie de la zone pavée et des portiques $\mathrm{O}$ et $\mathrm{E}$ : pour l'établissement du complexe, il est possible de localiser un grand travail de nivellement servant à la création de la terrasse sur laquelle se trouvent la place pavée et les portiques, datés, sur la base du matériel découvert, d'une période postérieure au début du ${ }^{e}{ }^{e}$ s. av. J.-C. ( $c f$. dans le même volume L. Cicala, L. VeCCHio, "Le indagini stratigrafiche nell'area della c.d. Agorà di Velia", p. 67-72). Le complexe est établi dans une zone précédemment inoccupée et se caractérise par la présence d'eau et de travaux 
hydrauliques notables. Prenant en considération les trois terrasses du vallon, qui pourraient se rapporter à un contexte unique (source, canal, fontaine, place avec portiques et thermes), son caractère particulier apparait, qui trouve un répondant dans les complexes consacrés au culte d'Asclépios, comme celui de Kos.

G. Tocco Sciareldi, "Spazi pubblici a Velia: l'agorà o un santuario?", in Neue Forscbungen in Velia, Akten das Kongresses "La ricerca archeologica a Velia" (Roma 1-2 July 1993), Vienne, 1999, p. 61-65.

13.04 - Métaponte - Dans une étude qui traite de l'archéologie de Métaponte et de sa chôra, A. De Siena propose une nouvelle identification des temples A et B du sanctuaire urbain de la colonie achéenne: bien que les édifices aient été par le passé attribués, le premier à Apollon Lykaios, le second à Héra, l'A. pense maintenant pouvoir identifier le temple A (le principal de la zone sacrée) à un Héraion, le $B$ à un Apollonion, considérant que les inscriptions mentionnant Apollon proviennent toutes de la zone orientale et de l'intérieur du temple B, bien que l'autel du temple A ait livré des statuettes féminines en terre cuite. Le temple ionique $D$ voisin est attribué, à titre d'hypothèse, à Artémis ( $c f$, aussi A. De Srens, Archeologia dell'acqua in Basilicata, Potenza, 1999, p. 6163). La nouvelle attribution, qui verrait Héra comme propriétaire du plus grand temple du sanctuaire urbain, mériterait une discussion plus approfondie et une présentation exhaustive des données.

A. De Siena, "La colonizzazione achea del Metapontino", in D. Adamesteanu (éd.), Storia della Basilicata. 1. L'Antichità, Rome/Bari, 1999, p. 211-245.

13.05 - Herakleta - Dans une étude de synthèse sur Herakleia et son territoire, L. Giardino analyse de manière circonstanciée les fonctions et solutions urbanistiques des trois secteurs qui articulent l'espace urbain (la Collina del Castello, la vallée médiane et la terrasse méridionale). Pour notre propos, c'est surtout l'analyse de la petite vallée médiane qui est intéressante, car elle est riche en eau de source et d'écoulement, laquelle présente un caractère sacré qu'atteste la concentration de lieux cultuels sur presque toute sa surface $(150 \times 1700 \mathrm{~m})$, allant jusqu'à présenter l'aspect d'une « unica, grande area santuariale ». Presque au centre de la vallée se trouve un temple périptère avec péribole, qui s'élève sur une zone déjà fréquentée à l'époque archaïque, comme l'attestent des terres cuites architecturales et des objets votifs; au SE se trouve le lieu consacré à Dionysos (auquel sont associés Aphrodite et Asclépios, d'après des inscriptions) caractérisé par un autel et de petits locaux destinés, entre autre, à la tenue de repas rituels; plus à l'E, le sanctuaire de Déméter, constitué de multiples structures en terrasses dans la zone d'une source, à l'o du temple et du musée moderne, près du lit d'un petit ruisseau, se trouve enfin un édifice composé de plusieurs pièces disposées autour d'une cour et dont le matériel rappelle une destination cultuelle plus qu'un habitat (il pourrait s'agir d'un lieu consacré à une divinité guérisseuse comme Apollon ou Asclépios). Toute la zone privée d'édifices, comprise entre le sanctuaire de Dionysos et les pentes méridionales de la collina del Castello, identifiée récemment comme agora (M. Torelli, "Ricerche a Heraclea", in Atti Taranto XXVI, 1986, Naples, 1987, p. 693-695), est interprétée par Giardino comme une agora "dalle marcate connotazioni religiose», différente de l'agora commerciale qui devait se situer sur la terrasse méridionale, plus large et mieux desservie par les voies d'accès.

L. Giardino, "Herakleia: città e territorio", in D. Adamesteanu (éd.), Storia della Basilicata. 1. L'Antichità, Rome/Bari, 1999, p. 294-337.

13.06 - Thourioi - Dans une contribution de synthèse sur l'établissement urbain de Thourioi, où sont également intégrées les données de découvertes plus récentes, E. Greco, partant d'une lecture des sources, reconsidère le problème des voies de communication urbaines de la colonie, attirant l'attention sur les noms de routes fournis par Diodore de 
Sicile (XII, 10, 6-7) et sur la possibilité de leur identification archéologique. Allant d'E en $\mathrm{O}$, on rencontre immédiatement l'Héracléenne (un nom de voie côtière répandu, qui pourrait coïncider avec le tracé urbain de la voie qui s'étend le long de la côte ionienne); ensuite l'Apbrodisia, l'Olympias (correspondant à la grande place de 100 pieds du «Parco del Cavallo ") et la Dionysias, vers la campagne. Parmi les routes perpendiculaires à celles-ci, on comptait l'Heroa, nom en rapport avec des cultes hérö̈ques (œciste ?), normalement localisés près de l'agora. Sur la base de la comparaison avec d'autres cités grecques (comme Thasos), on peut supposer que le nom des quatre places en relation avec des divinités trouve son origine dans la présence, le long de ces axes routiers, de sanctuaires importants, à attribuer dès lors à Aphrodite, Zeus Olympios, Dionysos. On en déduit que l'implantation de Thourioi prévoyait une dispersion des sanctuaires, un modèle-différent, donc, de celui en usage dans les cités coloniales archaïques, où les espaces sacrés étaient concentrés en un seul lieu ou disposés en cercle à la limite de l'espace urbain ( $c f$. aussi E. Greco, "Nomi di strade nelle città greche", in M. CAstoldi (éd.), Koinà. Miscellanea di studi archeologici in onore di Pietro Orlandini, Milan, 1999, p. 223-229).

E. Greco, "Turi", in ID., La città greca antica. Istituzioni, società e forma urbana, Rome, 1999, p. 413-430.

\section{Sicile (Nicola CucuzzA)}

14.01 - Catania - Centro di Studi sull'Archeologia Greca (C.N.R.) di Catania - Parution d'une étude sur les kotyles et les coupes corinthiennes mises au jour par la fouille conduite en 1959 sous la place San Francesco. Il s'agit du premier travail d'ensemble sur l'une des catégories de l'abondant matériel découvert (plus de 13000 vases et terres cuites inventoriés) et interprété comme une partie du dépôt d'un sanctuaire de Déméter (G. RizzA, $B d A$ [1960], p. 247-262). La céramique corinthienne est majoritaire dans le matériel mis au jour sous la place. L'étude n'analyse pas les probèmes liés au culte et se concentre sur les 796 kotyles et les 110 coupes corinthiennes produites entre la fin du Corinthien Ancien et le Corinthien Récent II.

L. Grasso, Stipe votiva del santuario di Demetra a Catania 1.1. Kotylai e coppe corinzie figurate, Palerme, 1998 [2000].

14.02 - Camarina - Soprintendenza ai Beni Culturali e Ambientali di Ragusa - G. Di Stefano illustre dans diverses contributions la disposition des soubassements interprétés comme des fondations d'autels et de petites chapelles découvertes du côté oriental de l'agora; on note également la présence de petits autels dans les nécropoles fouillées.

G. Di STI.FAr ): "L'Agorà di Camarina in Sicilia", in Proceedings of the $X V^{\text {tb }}$ International Congress of Classical Archaeology (Amsterdam, July, 12-17, 1998), Amsterdam, 1999, p. 150-153; ID., "I recenti scavi di Camarina", in Un ponte fra l'Italia e la Grecia. Atti del Simposio in onore di Antonino Di Vita (Ragusa, 13-15 febbraio 1998), Padoue, 2000, p. 194-212; ID., "Sacelli e altari nell'agorà di Camarina", in I. Berlingò, H. Blank, F. Cordano, P.G. Guzzo, M.C. Lentini (éds), Damarato. Studi di antichità classica offerti a Paola Pelagatti, Milan, 2000, p. 276-287.

- $\AA$ « Castiglione di Ragusa », au cours de travaux agricoles, près du petit centre à l'intérieur des terres de Camarina, fut mis au jour un petit monument constitué d'une sculpture archaïque dans un bloc de calcaire avec des protomés de bovin et de cheval, et une inscription ( $c f$. MANGANARo, ZPE 128 [1999], p. 115-132). Il s'agirait d'un tropaion ou d'un herôon élevé durant les événements advenus dans la région au vi ${ }^{\mathrm{e}} \mathrm{s}$. av. J.-C.

Archeologia viva 77, settembre/ottobre 1999. 
14.03 - Géla - A.M. Ardovino consacre une étude aux systèmes cultuels de Déméter dans les deux colonies de Poseidonia et Géla par l'examen parallèle des données archéologiques dans deux sanctuaires démétriaques; pour ce dernier centre, il passe en revue la documentation relative aux sanctuaires mis au jour, en particulier celui de Bitalemi. Les offrandes sont réparties, depuis celles en métal en passant par les statues en terre cuite de grande dimension (édifice XII sur l'acropole), par celles de petite dimension, toujours en terre cuite, jusqu'aux vases miniatures. Il faut en outre remarquer la présence plus que probable d'hommes parmi les fidèles, d'ailleurs implicite dans l'épisode de Télinès (Hérodote, VII, 153); les hommes n'étaient peut-être pas admis aux rites particuliers, comme c'est le cas en d'autres endroits du monde grec. Il souligne l'importance du sanctuaire de la "via Fiume", dans lequel le soubassement en grès est interprété comme un thesauros.

A.M. Ardovino, "Sistemi demetriaci nell'Occidente greco. I casi di Gela e Paestum", in M. Castoldi (éd.), Koinà. Miscellanea di studi archeologici in onore di Pietro Orlandini, Milan, 1999, p. 169-187.

14.04 - Vassallaggi - Soprintendenza ai Beni Culturali e Ambientali di Caltanissetta, Università di Milano - Publication des 78 tombes de la nécropole méridionale fouillée au cours de l'année 1956. Les sépultures, presque exclusivement des inhumations, datent des trois derniers quarts du $\mathrm{v}^{\mathrm{e}} \mathrm{s}$. av. J.-C. Elles sont présentées une par une, avec les données de fouille et l'analyse du matériel. Cette étude soignée examine également le matériel des fouilles de 1961 (pour un total de 262 tombes). On fait l'hypothèse de l'existence de semata (probablement en bois) qui marquaient la présence des tombes. Sur la base des nombreux fragments céramiques récupérés près de chacune des sépultures, on pense que le rituel funéraire comprenait des libations, suivies de la destruction intentionnelle des vases utilisés (cratères, petites coupes, œnochoés). Les observations sur la composition du matériel sont intéressantes, les tombes masculines caractérisées par la présence de cratères et couteau ou strigile et vase pour onguents : les couteaux originellement enveloppés ont pu servir à la répartition des viandes lors des repas sacrificiels. Grâce à cette étude d'ensemble et aux informations déjà publiées sur les tombes découvertes en 1961 et sur la nécropole occidentale fouillée en 1983-1986 (P. OrLandinI, NS [1971] et N. Gullì, QuadMessina 6 [1991], p. 23-42), la nécropole de Vassallaggi devient un des sites les mieux connus pour aborder, dans la perspective des rites funéraires, le rapport entre colons grecs et monde indigène au $\mathrm{Iv}^{\mathrm{e}} \mathrm{s}$. av. J.-C.

M. Przzo, "Vassallaggi (S. Cataldo, Caltanissetta). La necropoli meridionale, scavi 1956", Notizie degli Scavi di Antichità, série IX, vol. IX-X (1998-1999) [2000], p. 207-395.

14.05 - Entella - Scuola Normale di Pisa - G. Nenci émet ici l'hypothèse selon laquelle la nécropole de Petraro serait le lieu de découverte de la lamelle d'or inscrite de caractère orphique (SEG XLIV, 750) : la lamelle, du vi ${ }^{e}-v^{e} s$. av. J.-C., avait probablement été déposée dans une tombe du $\operatorname{III}^{\mathrm{e}} \mathrm{s}$. av. J.-C.

G. NENCr, "Varia Elyma: novità epigrafiche, numismatiche, toponomastiche e cultuali dall'area elima", in Terze giornate internazionali di studi sull'area elima (GibellinaErice-Contessa Entellina 23-26 ottobre 1997), Pise/Gibellina, 2000, p. 809-821, spéc. p. $814-815$.

14.06 - Sélinonte - Soprintendenza ai Beni Culturali e Ambientali di Trapani Présentation des stèles découvertes dans le sanctuaire de Zeus Meilichios, tout juste au N de celui de la Malophoros, au cours des fouilles menées entre 1915 et 1920 (GaBrici, MAL 32 [1927]). Le corpus comprend 81 exemplaires découverts au cours des fouilles, en plus de deux probablement issus de la même zone et conservés dans la commune de Castelvetrano. Les stèles, réparties en deux groupes (aniconiques et figurées), sont classées par types; leur utilisation semble déjà attestée entre la fin du vir ${ }^{\mathrm{e}}$ et le début du $\mathrm{vi}^{\mathrm{e}} \mathrm{s}$. av. J.-C. 
et se prolonge encore après la destruction de Carthage en 409 av. J.-C. Au groupe des stèles figurées appartiennent des exemplaires avec une, deux et, dans deux cas, quatre têtes. V. Tusa identifie celle à deux têtes comme la représentation du couple divin Zeus Meilichios et Pasikrateia, attestée par l'inscription du temple G (IG XIV, 268), plutôt qu'Enodia ou Meilichiè. L'étude s'attache surtout à la chronologie et aux aspects formels des stèles et ne prend pas en considération le culte auquel elles se rapportent, en dépit de la référence à la lex sacra (SEG XLIII, 630) connue depuis peu, qui semble provenir précisément de la zone du sanctuaire et qui contient des indications sur le culte rendu à Zeus Meilichios, qui se différencie en un culte «en Mysko » et un autre «en Eutbydamo » (cf. désormais N. Cusumano, Kokalos 43-44 [1997-98], p. 777-783 et G. Camassa, "La lex sacra di Selinunte", in M.I. Gulletta [éd.], Sicilia Epigraphica, Pise, 1999, p. 141-148).

M.L. Sfamà, V. Tusa, Le stele del Meilichios di Selinunte, Padoue, 2000.

- Partant de l'analyse de la lex sacra, E. Curti et R. van Bremen interprètent le dispositif découvert par Gabrici sous le naïskos de Zeus Meilichios - et qu'il date du Iv s, av. J.-C. comme l'berôon de Myskos (avec tombe et conduit pour verser des liquides), où se seraient écoulées les libations mentionnées dans la lex sacra; pour le culte de Meilichios «en Eutbydamo», on propose une localisation sur l'agora.

E. Curti, R. van Bremen, "Notes on the Lex Sacra from Selinous", Ostraka 8 (1999), p. 21-33.

14.07 - Sélinonte - Université de Turin - Dans une étude monographique sur le temple $\mathrm{M}$, L. Pompeo propose une hypothèse de restitution de l'édifice comme distyle in antis, dorique, au sommet d'un escalier qui le relie à l'autel. D'après l'A., le temple, qui fut en usage entre le $2^{\mathrm{e}}$ quart du $\mathrm{vI}^{\mathrm{e}}$ et la fin du $\mathrm{v}^{\mathrm{e}}$ s. av. J.-C., pourrait avoir été dédié à Héraclès, peut-être représenté sur une figurine fragmentaire en terre cuite avec jambières et massue. Les pièces mentionnées - deux plaques de l'autel avec relief du $v^{e} s$. av. J.-C., représentant une amazonomachie et deux coupes avec un graffito $\mathrm{HE}$ relèvent d'une fréquentation cultuelle antérieure à la construction de l'édifice - pourraient faire penser à Héra, comme le reconnaît l'A. elle-même.

L. Pомрео, Il complesso architettonico del tempio $M$ di Selinunte. Analisi tecnica $e$ storia del monumento, Florence, 1999.

14.08 - Lilybaeum - Soprintendenza ai Beni Culturali e Ambientali di Trapani Publication de l'étude complète des tombes trouvées entre 1987 et 1992 (sur la nécropole du site, $c f$. E. Caruso, "La necropoli ed il tofet di Lilibeo", in Terze giomate internazionali di studi sull'area elima, Pise/Gibellina, 2000, p. 217-262). Les quelque 450 sépultures datent pour une large part des trente dernières années du $\mathrm{Iv}^{\mathrm{e}}$ jusqu'au $\mathrm{I}^{\mathrm{er}} \mathrm{s}$. av. J.-C.; nous nous contenterons de signaler ici la présence de la mâchoire, des côtes et d'une partie des pattes antérieures d'un cheval, qui pourraient suggérer l'hypothèse d'un sacrifice.

B. Bechtold, La necropoli di Lilybaeum, Rome, 1999.

14.09 - Monte Iato - Université de Zürich - Dans une étude d'ensemble sur la plus ancienne poterie sigillée du site sont publiées les pièces du portique 15 de la Maison à péristyle 1, parmi lesquelles deux petits autels de pierre de différentes dimensions, une statuette en terre cuite acéphale d'Aphrodite et une tête féminine en terre cuite avec un polos bien plus ancienne que le contexte de destruction de la maison (milieu du $\mathrm{i}^{\mathrm{er}} \mathrm{s}$. ap. J.-C.). Les produits manufacturés démontrent l'existence d'un culte domestique abrité dans un espace de l'étage supérieur.

B. Heidinger, Studia Ietina VIIT. Die frübe Terra sigillata vom Monte Iato, Sizilien (Ausgrabungen 1971-1988) und frübkaiserzeitliche Fundkomplexe aus dem Peristylbaus I, Lausanne, 1999, spéc. p. 255-260, 480-496. 


\section{Index géographique}

Athènes. Acropole 01.01; Agora 01.02; Mets 01.05; Plaka 01.03; Zappeion 01.04

Attique. Agios Georgios 01.12; Anaphlystos 01.10; Anavyssos 01.11; Eleusis 01.06; Gerakas 01.10; Myrrbinonte 01.09; Oè 01.07; Pbylè 01.07; Rhamnonte 01.09; Skala Oropou 01.08; Spilies 01.07; Stavros 01.10; Thorikos 01.12

Péloponnèse. Arcadie : Asea (Agios Elias) 02.16; Kleitor (Agios Athanasios) 02.18; Lafka (Tria Goupata) 02.22; Lepreon 02.17; Lousoi 02.19; 02.20; Ménalie 02.16; Nedas (fl.) 02.17; Pheneos 02.20; Phigalie (Kourdoubouli) 02.17; Stympbale 02.21; Tégée (Agios Sostis) 02.15; Tégée 02.14. Argolide : Argos 02.04; Ëpidaure 02.05; 06.03; 02.06; Trachia 02.05. Corinthie : Corinthe 02.01; 02.21;02.22; 05.03; 05.05; 05.14; 05.17; 13.01; Isthmia 02.02; Némée 02.03. Élide : Élis 02.12; Olympie 02.13; 06.02; Perachora 02.02; 13.01; Solygeia 02.02. Laconie : Amyclées 02.09; Geraki 02.10; Sparte 02.07; 02.08; 09.02; 10.10. Messénie : Messène 02.11; 06.03

Béotie. Potniai 05.10

Étolie. Kalapodi 06.02

Grèce «de 1'Ouest». Acarnanie : Drymonas 05.02; Gionia 05.04; Lepenou 05.03; Oiniadai 05.01; Spathari 05.03. Épire : Achéron (fl.) 05.00; 05.06; Achérousia (lac) 05.06; Ambracie 05.05; 05.10; 05.16; Boutbrôtos 05.12; Cassôpie 05.06; Delvitsi 05.07; Dodone 05.08; Dourouti 05.10; Elea 05.07; Ephyra 05.00; Gitanai 05.11; Glyki 05.00; Goumani 05.11; Kalpakiotikos (f1.) 05.11; Kastritsa 05.09; Liatovouni [colline de] 05.13; Marmara 05.07; Molossie 05.09; Paramythia [région de] 05.07; Passaron 05.10; Phanari [plaine du] 05.06; Philiates 05.11; Tekmon 05.09; Thesprôtie 05.06; 05.07; 05.11; Thyamis (fl.) 05.11. Îles ioniennes : Corfou 05.16; 05.17; Ithaque 05.17; 05.18; Leucade, Phryni (grotte d'Asvotripa) 05.17. Yllyrie méridionale : Apollonia 05.14; 05.16; 05.17; Havaleas 05.15; Kryegjata 05.15; Mallakastra 05.15; Shtyllas 05.14; 05.15

Phthiotide, Thessalie. Elassona 06.02; Kranona 06.02; Larissa 06.02; Lethaios (fl.) 06.03; Melitaia 06.01; Mitropoli 06.02; Tebè 06.02; Thèbes 06.01; Trikala 06.03; Trikkè 06.03

Macédoine. Aianè 07.00; Aigat 07.08; Amphipolis 07.00; Anchialos 07.12; Anthémonte 07.00; Beroia 07.00; 07.07; Choregos 07.04; Dion 07.00; 07.11; Elimeia 07.00; Eratyra 07.04; Kalindoia 07.00; Kastoria 07.02; Letè 07.00; Liknades 07.04; Loukomi 07.04; Mavropigi 07.04; Nea Roda 07.15; Ouranopolts 07.15; Panagia (anciennement "Torniki 》 ou " Melisko ») 07.03; Pella 05.10; 07.00; 07.09; Pella, agora 07.10; Platania 07.04; Rizomata (Paliochora) 07.06; Sanè 07.15; Stagire 07.14; Stobi 07.01; Thessalonique 07.00; 07.13; Velvendo (Kato Brava) 07.05; Vergina 07.08; Voion [mont] 07.04; Xerolimni 07.04

Thrace. Abdère 07.00; Debelt 08.04; Eleftheroupoli 08.01; Haemus [mont] 08.02; Mesembria 07.00; Nestos (fl.) 08.01; Pistiros 08.03; Siris 08.01; Strymon (fl.) 08.01; Topeiros 08.01

Iles de 1'Égée. Chios (Kato Phana) 09.01; Kalymnos (Damos) 09.03; Kos 06.03; 09.04; 09.05; 13.03; Rhodes (Theologos) 09.08; Rhodes, Ialysos 09.07; Rhodes, ville 09.06; 12.13; Samos 09.02; 13.01; Samothrace 07.00; Thasos 07.00

Crète. Agia Triada 10.10; Amnissos 05.18; 10.15; Aptère 10.05; Chania 10.04; Diktè [grotte du] 10.00; Eleutberna 10.06; Gortyne 10.10 10.11; Ida [grotte de 1'] 05.18; 10.08; Istron 10.19; Itanos 10.23; Kalyviani 10.01; Karoumiès 10.22; Kato Symi 10.00; 10.17; Kavousi 10.20; Knossos 10.14; Kamilari 10.10; Kommos 10.00; 10.09; Kounavi 10.16; Kydonia 10.04; Kypia 10.21; Latô 10.19; Lébéna 10.12; Lisos 10.03; Lyttos 10.14; Mesamvrysi 10.21; Messara 10.10; Metriko 10.22; Palaiokastro 10.00; Patsos 10.07; Phaistos 10.10; Pbalassarna 10.01; 10.02; Polyrrhenia 10.01; Praisos 10.21; Prinias 10.13; Pyrgi 10.06; Tsoutsouros 10.16; Tyliphos 10.01; Vavelli 10.21; Viannos (Kastri) 10.18; Vrokastro [région] 10.19 
Asie Mineure. Carie : Alagün 12.06; Alinda 12.07; Aphrodisias 12.08; Bargylia 12.06; Çanacik Tepe 12.06; Laodikeia Combusta 12,09; Mandalya [golfe de] 12.06; Sizma 12.09. Cilicie : Elaiussa-Sebastè 12.01. Ionie : Claros 12.13; 12.17; Didymes 12.11; 12.17; 12.14; Éphèse 12.16; Kalabaktepe 12.12; 12.14; Magnésie du Méandre 12.16; Milet 12.12; 12.13; 12.14; 12.16; Monodendri (cap) 12.14; Priène 12.15; Téos 12.19; Zeytintepe 12.13; 12.14. Lycie : Patara 12.03; Tlos 12.03. Lydie : Sardes 12.18. Mysie : Pergame 06.03; 12.19. Pamphylie : Sillyon 12.02. Phrygie : Hierapolis 12.10. Pisidie : Antioche 12.05; Sagalassos 12.04. Troade : Astyra 12.16; Parion 12.20.

Grande Grèce. Cumes 13.01; Élée 13.03; Herakleia 13.05; Métaponte 13.04; Paestum 13.02; 14.03; Pithécuses 13.01; Thourioi 13.06

Sicile. Camarina 14.02; Catania 14.01; Entella 14.05; Géla 14.03; Lilybaeum 14.08; Monte Iato 14.09; Sélinonte 14.06; 14.07; Vassallaggi 14.04

\section{Index thématique}

activités métallurgiques : $01.08 ; 10.00$

affranchissements 05.11

animaux sacrifiés : bovins 02.02 ; 12.16; caprins 02.01; cerfs 12.16; cheval 14.08; daims 12.16; ossements $02.01 ; 02.02 ; 02.16 ; 02.22 ; 10.05 ; 10.07 ; 12.16$; oursins 02.01 ; ovins $02.01 ; 02.02$; 02.16; poissons 02.01 ; porcins $02.01 ; 05.10 ; 12.16$

animaux votifs 10.18; abeilles 12.16; aigle 07.04; bœuf 07.06; chèvre (cornes de) 12.16; chèvre en bronze 07.02; chien en bronze 06.02; colombes 13.01; lion (dent de) 12.16; ours 12.16; serpents $05.15 ; 10.02 ; 10.20$; taureau (cornes de) 10.07 ; taureau (tête de) 10.05; taureau en bronze 10.17; tortues (écaille de) 12.16

armes votives 02.02 ; 10.21 ; boucliers 10.00 ; boucliers miniatures 02.22 ; carquois 02.13 ; casques 02.13; couvre-joue 12.14; double hache 07.12; 12.16; flèches (pointes de) 02.13

atelier de sanctuaire 05.16

autels : $01.04 ; 01.07 ; 01.09 ; 02.16$ (de cendres); 05.07; 05.08; 07.14; 10.22; 12.05; 12.09; 12.10; $12.16 ; 12.19 ; 13.05 ; 14.01 ; 14.06$; bothros $01.04 ; 10.16$; fosses $08.04 ; 12.16$; table d'offrandes $02.17 ; 10.02$

céramique/《vaisselle »: 02.03; 02.09; 05.01; 05.11;06.02;09.02; 10.00; 10.07; 12.19; amphores 06.02 ; canthares $02.08 ; 02.11 ; 07.08$; coupes $01.10 ; 09.07 ; 10.21 ; 10.22 ; 14.01 ; 14.04$; cratères 01.08 ; $02.01 ; 02.07 ; 13.01 ; 14.04$; cruches 13.01 ; dinos 12.13 ; hydries 07.00 ; kalathoi 01.12 ; 10.20; kernoi 01.12; 05.10; 07.00; 10.10; kotyles 01.08; 13.01; 14.01; lécythes 01.08; 01.10; 02.21; lekanai 02.08; œnochoés 13.01; 14.04; olpès 09.06; phiales 01.12 ; 05.10; skyphoi 01.08 ; $02.11 ; 13.01$; vaisselle en bronze 13.03 ; vases à parfum 13.01 ; vases miniatures $02.01 ; 02.08 ; 02.10 ; 02.14 ; 05.10 ; 07.00$

chœur féminin 05.17

contexte funéraire : banquets funéraires 10.16; cénotaphes $01.08 ; 02.07 ; 12.16$; cultes funéraires $01.08 ; 02.08 ; 05.13 ; 05.14 ; 07.08 ; 09.06 ; 14.04$; fosses 01.08 ; hypogées 09.03 ; incinération 05.14; inhumation 05.14; lamelle " orphique " 14.05; semata 05.13; 14.04; tombes $01.08 ; 05.10 ; 05.13 ; 05.14 ; 05.15 ; 09.06 ; 10.16 ; 12.03 ; 14.04 ; 14.08$

continuité cultuelle $06.03 ; 10.10 ; 10.19 ; 12.16$

cultes de souverains $07.00 ; 07.01 ; 07.09 ; 10.11 ; 12.05 ; 12.16 ; 12.18 ; 12.19$

cultes domestiques 14.09

cultes funéraires ( $c f$. contexte funéraire)

cultes hérö̈ques 13.06

cultes thérapeutiques $13.02 ; 13.03 ; 13.05$

dépôt votif ( $c f$. ex-voto) 
desservants : $01.03 ; 07.00 ; 08.01 ; 12.17$

divinités/héros :

Agamemnon 02.09

Akakallis 10.02

Alexandra $c f$. Kassandra

Androklos 12.16

Aphrodite $02.11 ; 05.05 ; 07.00 ; 07.08 ; 07.09 ; 07.13 ; 10.18 ; 10.19 ; 12.08 ; 12.12 ; 12.14 ; 12.16$; 13.05; 14.09; Epiteuxidia 07.13; Euploia 07.13; Homonoia 07.13; Oikousia 12.13; Pandemos 07.09

Apollon $05.12 ; 06.02 ; 07.06 ; 07.11 ; 07.15 ; 08.01 ; 09.02 ; 09.03 ; 12.06 ; 12.17 ; 13.01 ; 13.05$; Agyieus 05.11; 05.16; Citharède 07.04; 09.06; Erethimios 09.08; hoplite 06.02; Kerdoios 06.02; Lykaios 13.04; Lykeios 06.02; Maleatas 02.06; 13.02; Musagète 06.02; Phanaios 09.01; Proemios 06.02; Pythios 02.20; 06.02; Sôter 05.05

Arès 10.19

Aristoménès 02.11

Artémis 02.19; 05.14; 05.16;07.00; 07.11;07.15;10.10; 12.06; 12.07; 12.14; 12.16; 12.18; 13.03; Agrotera 01.05; Chitonè 12.12; 12.16; Elaphebolia; Hegemonè 05.10; Hemera 02.20; Orthia 02.08; 10.10; Péplophore 12.11; Phôsphoros 05.10; Pyrônia 02.20

Asclépios $02.11 ; 05.12 ; 06.01 ; 07.04 ; 08.01 ; 10.02 ; 10.12 ; 13.02 ; 13.03 ; 13.05$; Esculape 05.12

Athéna $02.05 ; 02.17 ; 05.11 ; 05.12 ; 07.00 ; 07.09 ; 12.13 ; 12.14 ; 13.03$; Alea 02.14; Koria 02.18; Oleria 10.19; Pallènè 01.10; Polias 02.17; 02.21; 05.18; Sôteira 01.09

Attis Tristis 12.10

Baubô 07.00

Bellérophon 12.03

Cavalier thrace 08.01

Cybèle 01.03; 01.09; 07.00; 07.08; 09.06; 10.14; 12.05; 12.06

Darron 07.09

déesse aux bras levés 10.20

Déméter 01.09; 01.12; 02.01; 05.10; 07.00; 07.08; 07.11;09.06;10.10;10.14; 10.23; 13.05; 14.01; Drepanophoros 07.04; Kabeiraia ou Kabeiria 07.00; Karpophoros 07.00; Malophoros 14.06; Melaina 05.18; Thesmia 02.20; Thesmophoros 12.16

Dionè 05.08

Dionysos 01.01; 02.07; 02.17; 05.12; 06.03; 08.01; 08.02; 08.03; 12.09; 13.05; DionysosBacchus 07.08

Dioscures 06.03

divinité féminine $02.04 ; 05.10$

divinités égyptiennes 10.11

Drakon/Drakaina 07.00

Énée 05.05; 07.13

Enodia $07.00 ; 07.04 ; 14.06$

Éos 07.15

Éros 05.11;07.08; 07.09;07.10

Glaukos 10.14

Hécate 02.15; 05.10; 07.04

Hélios 07.15

Héphaistos 09.06

Héra $07.00 ; 07.02 ; 12.16 ; 12.19 ; 13.01 ; 13.03 ; 14.07$; Héra Teleia 05.18

Héraclès $07.00 ; 07.04 ; 13.01 ; 14.07$

Hermaphrodite 09.06 
Hermès 01.09; 02.11; 05.17; 07.02; 07.04; 10.17; 12.01; criophore 05.17; du Cyllène 02.20; Kranaios 10.07

Héron-Apollon 08.01

Héros 12.15

Héros klaikophoros 02.05

Hestia 09.05

Isis 01.03; 01.09; 07.11; 12.06

Kabeiros 07.00

Kassandra 02.09

Korè 01.09; 02.01; 05.10 ( $c f$. Perséphone)

Létô 07.15; Lato Phytia 10.10

Leukothea 10.23

Machaon 06.03

Meilichiè 14.06

Melikertes 02.02

Mên Askaênos 12.05

Ménélas $c f$. Ménélaion

Mère des dieux 01.02; 07.00;07.08; 07.09; 07.10

Meter Sebastè 12.06

Moire 09.06

Muse 09.06

Myskos 14.06

Némésis 07.01

Nikè $07.04 ; 07.13$

Nymphes 01.11; 05.17; 05.18

Opheltès 02.03

Palaimon 02.02

Pan 01.11; 05.11; 05.17; 07.08

Pasikrateia 14.06

Patrôoi 07.00

Perséphone 02.15 ( $c f$. Korè)

Pluton 07.00

Podalire 06.03

Poséidon 02.02; 12.14

Psychè 07.09

Rhéa 10.14

Satyre 02.11;05.11;05.17

Sélènè 07.15

Sérapis $12.06 ; 12.10$

Silènes 05.17

Thémis 09.06

Theos Hypsistos 10.11 (cf. Zeus Hypsistos)

Tychè 09.06

Ulysse $05.17 ; 05.18$

Zeus 02.13; 05.08; 05.10; 07.00; 10.08; 12.05; 12.07; 12.18; Dictéen 10.21; Hypsistos 07.02; 07.04; 07.05; Meilichios 14.06; Messapeus 02.08; Philios 12.19; Sôter 01.09; 02.17; 12.02; Thenatas 10.15; Tropaios 07.07 (cf. Theos Hypsistos)

épiphanie divine 12.16 
ex-voto et mobilier cultuel : 01.08; 01.09; 09.06; 13.01; 13.05; aegyptiaca 10.15; 12.13; 12.17; aphidruma 09.05 ; bagues 10.08 ; barquettes 02.17 ; bijoux en or 10.16 ; brûle-parfums 02.11; ceintures de bronze 12.16; chaudrons 10.21; dépôt votif $02.08 ; 02.09$; 02.10; 05.04; $07.05 ; 10.18 ; 10.21 ; 13.01 ; 14.01$; encensoirs 07.05 ; épingles $02.16 ; 10.21$; flambeau en bronze 01.09; fouets 05.00; gong rituel 05.08; lamelles oraculaires 05.08 ; lampes 07.00 ; $07.05 ; 09.06 ; 10.05 ; 10.06 ; 10.21 ; 10.23$; larnax 06.02 ; masques 05.18 ; 07.08; objets en bronze $01.08 ; 10.00 ; 10.10 ; 10.16$; objets orientaux 02.13 ; perirrbanteria $02.05 ; 09.01$; plaques $01.10 ; 01.12 ; 02.08 ; 02.09 ; 02.11 ; 02.17 ; 02.21 ; 10.02 ; 10.21$; protomés $02.11 ; 02.12$ (lion); 14.01 (bovin et cheval); reliefs : 01.03; 02.15; 05.05; 07.02; 07.06; 07.10; 12.06; 12.11; sceaux 02.13; 05.10; sceptre 10.17; sculptures 01.07; 01.09; siège 12.05; statuettes/figurines 01.06; 01.10 (oiseaux); 02.08; 02.09; 02.11; 02.21; 02.22; 05.01; 05.02; 05.04; 05.05 (avec polos style dédalique); 05.07; 05.10; 05.16; 05.16; 05.17; 05.18; 06.01; 06.02; 07.00; 07.08; 07.09; $07.11 ; 07.14 ; 10.07 ; 10.10 ; 10.14 ; 10.17 ; 10.23 ; 12.06 ; 12.11 ; 12.13 ; 12.16 ; 12.17 ; 13.01 ; 13.01$; 13.03; 13.04; stèles : $06.01 ; 06.02 ; 14.06$; trépieds 02.02 ( $c f$. animaux votifs, armes votives, autels, statues)

fêtes: Hemerasia 02.20; mystères bacchiques 06.03; mystères d'Éleusis 01.04; 07.00; Panathénées 01.02; pleine lune 12.16; Thesmophories 01.04

incubation 06.03

koinon dionysiaque 09.06

libations $06.02 ; 10.10 ; 10.16 ; 14.04$

néocorie 12.16

noms de personnes: Achaios 12.18; Alexandre le Grand 07.00; 07.15; Attale Ir 12.19; Attale II 12.19; Auguste 07.13; 10.11; 12.04; Brasidas 02.07; Cassandre 07.13; Dorimachos 05.08; Euarchidas 02.05; Eumène II 12.19; Évagoras 02.17; Hadrien 12.16; Hadrien 12.19; Jules César 07.13; Junia Rufina 05.12; Lucius Verus 10.12; M. Publius Jucundus 08.01; Mantiklos 06.02; Marc-Aurèle 12.18; Paul-Émile 05.08; Peithôla fille de Pharakidas 06.02; Sargon II 02.13; T. Flavius Xenion 10.12; T. Pactumeius 10.11; Thoukritos fils d'Alkimachos 01.09; Timonax fils de Théodoros 12.17; Trajan 12.19

oracles $08.02 ; 08.03 ; 12.16$

processions 06.03

purifications $06.03 ; 07.00$

repas rituel ( $c f$. contexte funéraire) : $01.08 ; 13.01 ; 14.04$

restes végétaux 02.01

sacrifices $01.08 ; 10.10 ; 10.21 ; 12.16 ; 12.17 ; 14.08$; hécatombes 12.17 ( $c f$. animaux sacrifiés)

sanctuaires : abaton 10.02; adyton 06.02; Amyklaion 02.09; Aphrodision 05.05; Apollonion 13.04; Artémision 12.16; Asclépieion 02.05; 06.01; 06.03; 09.06; 12.19; Attaleion 12.19; bûcher 10.07; cella à trois entrées 07.15; de sommet 07.02; Diktynnaion 10.01; Dionysion 01.01; édifice circulaire 02.07; 05.10; foyer 10.05; grotte $01.11 ; 02.22 ; 05.17$; 05.18 ; 10.00 ; 10.08; Héraion 06.02; 09.02; 13.04; berôon 01.07; 02.11; 05.05; 05.07; 12.04; 12.16; 14.02 ; 14.07; bestiatorion 01.12 ; 02.01; hypètre 01.04; 10.07; maison sacrée 05.08; Ménélaion 02.07; 02.08; 02.09; Metrôon 01.02; 07.08; 07.09; Nekyomanteion 05.00; nymphée 05.12; Parthénon 01.00; prytanée 05.08; Pythion 10.11; sources sulfureuses 07.05; Telesterion 01.06; temple passim; Thesmophorion 02.15; 05.10; 07.14; Trajaneum 12.19

statues : 02.11; 05.02; 05.08; 07.04; 09.06; de culte : 01.02;02.17; 06.02; 10.11; 10.12; 12.05; 12.06; 12.16 ; 12.19 ; korès $02.21 ; 12.16 ; 12.17$; kouroi 02.21 ; $05.16 ; 12.16 ; 12.17$; piliers hermaïques : 01.09; trône 10.08; vêtements 12.16; xoanon 05.05 ( $c f$. divinités/héros; ex-voto)

syncrétisme iconographique 08.00

technites de Dionysos 12.19

trophée $07.07 ; 14.02$ 